
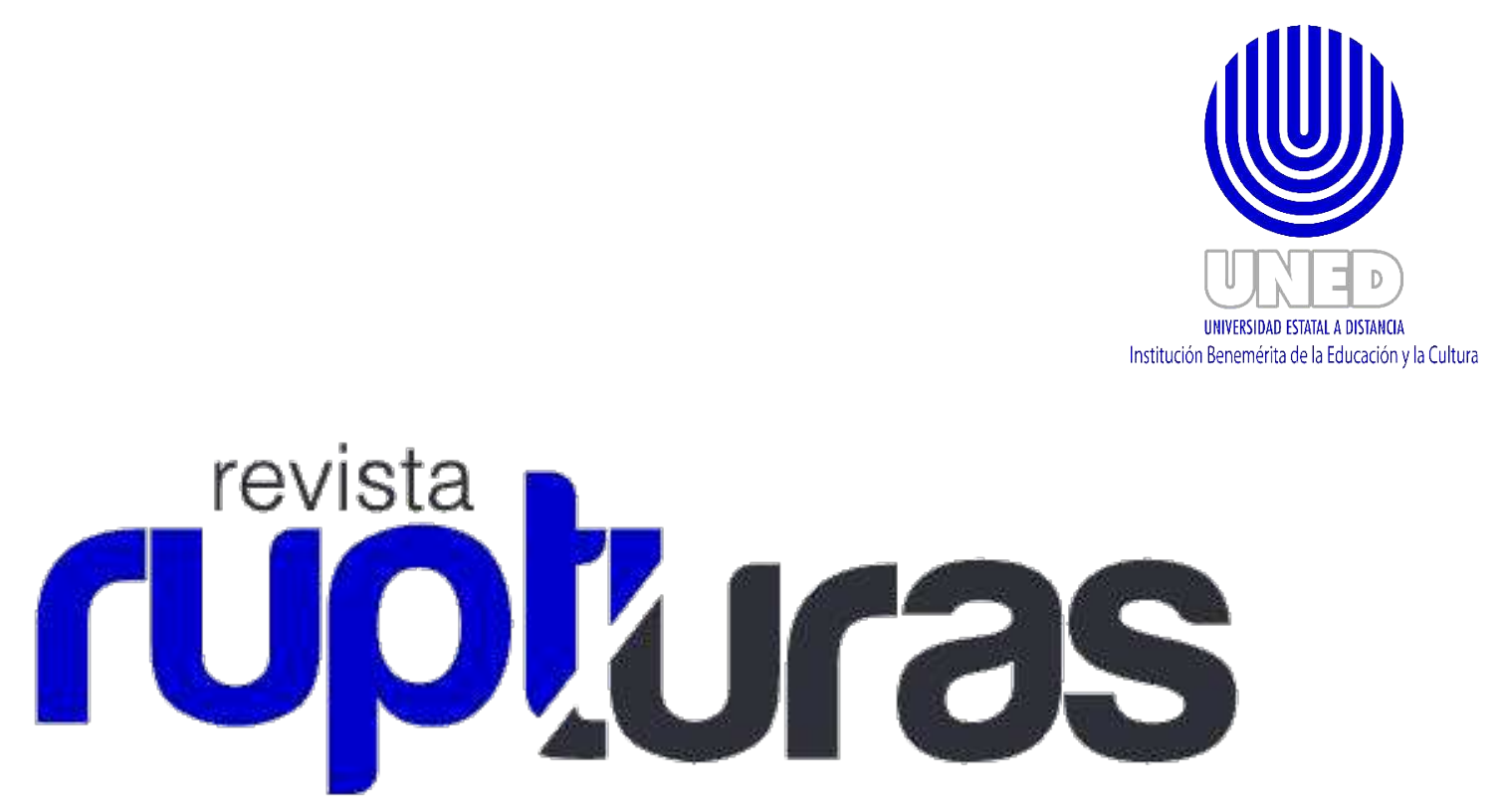

Revista Rupturas 1(2), San José, Enero-Junio del 2012. ISSN 2215-2466

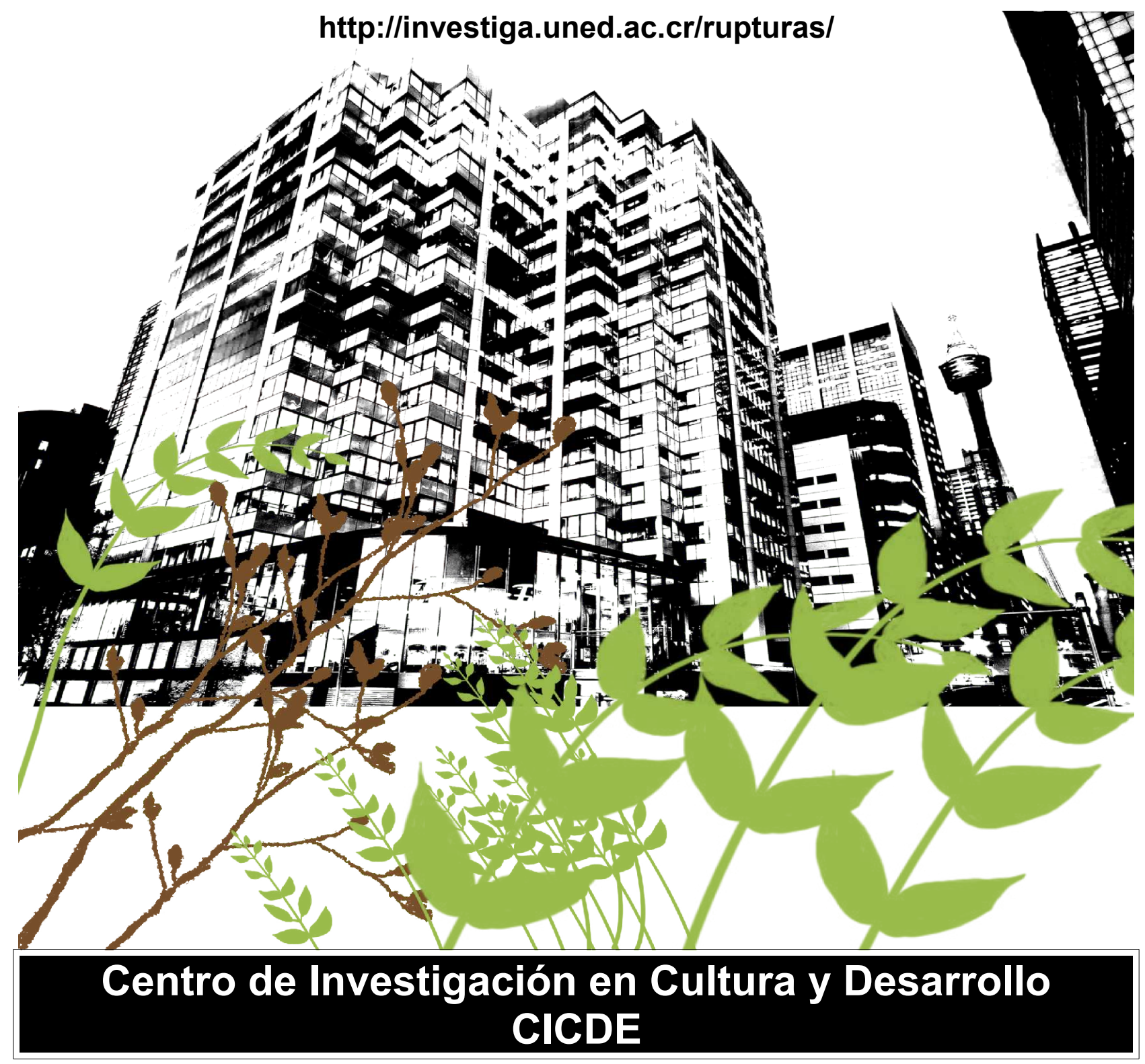


Revista Rupturas, Volúmen 1 Número 2

Centro de Investigación en Cultura y Desarrollo (CICDE)

Universidad Estatal a Distancia (UNED)

San José, Costa Rica

2012 


\section{Contenido}

Presentación

\section{Artículos}

El papel de las Comisiones Plenas en la dinámica legislativa en Costa Rica

Por José Andrés Díaz González

Los dueños de la palabra en Costa Rica en un contexto de reforma neoliberal

Por Francisco Robles Rivera y Koen Voorend

El fenómeno del cambio climático: Un análisis crítico desde la perspectiva de la economía ecológica

Por Roberto Jiménez Gómez

De los movimientos a la acción política: Mujeres organizadas en los comités patrióticos en la lucha contra el Tratado de Libre Comercio

Por Roxana Morales Bonilla

La creación de respuestas con sectores sociales rurales: Retos desde la investigación

Por Jorge Luis Hernández Cascante

\section{Documentos}

Oscar Wilde y Reinaldo Arenas. Enigmas de pasión

Por Rodrigo Quesada Monge iv

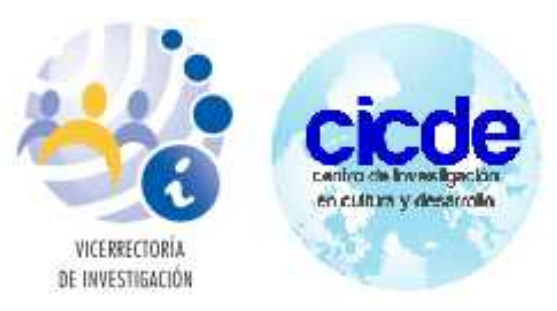

Consejo editorial

Luis Paulino Vargas Solis Cristina D'Alton Kilby

Dagoberto Núñez Picado Laura Guzmán Stein

Rodrigo Quesada Monge Mario Zúñiga Núñez

Coordinación editorial Orlando Amarís Cervantes revista.rupturas@gmail.com

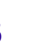




\section{Presentación}

Para el Centro de Investigación en Cultura y Desarrollo (CICDE) de la Vicerrectoría de Investigación de la UNED, es un honor y una satisfacción presentar el segundo número de la Revista Rupturas.

Cuando apareció el número inaugural, en julio pasado, nos fijamos como meta prioritaria lograr poner a disposición de la comunidad académica de Costa Rica y Centroamérica, un segundo número de Rupturas en el mes de diciembre de 2011. Gracias al esmerado trabajo del equipo que participa en la edición de la revista, ese compromiso se ha cumplido. Ello aporta un elemento positivo adicional: avanzamos eficazmente en el proceso de cumplimiento de los requisitos necesarios para lograr la indexación en Latindex, a mediados de 2012. Y esto debe ser agradecido a ese excelente equipo: Orlando Amarís, Editor de Rupturas, y Andrey Badilla y Pablo Díaz, quienes han brindado el indispensable apoyo técnico.

Este segundo número incorpora trabajos que discuten diversas temáticas, todas atinentes a los procesos de cambio sociocultural, económico y político que actualmente agitan nuestras sociedades: género, campesinado, consolidación de grupos económicos de poder, desarrollo económico y procesos de decisión parlamentaria son los temas que se discuten en los artículos que se publican. Un elemento adicional que debe resaltarse es la incorporación de dos artículos y, respectivamente, dos autores, externos no solamente al CICDE, sino a la propia Universidad Estatal a Distancia (UNED).

Además inauguramos una nueva sección que hemos titulado Documentos, en la cual se publicarán trabajos no inéditos pero de mucho mérito, cuya difusión constituye un aporte académico relevante. Esta sección inicia con un trabajo del Dr. Rodrigo Quesada Monge, miembro del Consejo Editorial de Rupturas, titulado "Óscar Wilde y Reinaldo Arenas. Enigmas de pasión", un escrito que profundiza en algunos de los aspectos menos discutidos y analizados en relación con estos dos escritores, excepcionales tanto por el alto vuelo literario de su producción literaria, como por el carácter transgresor tanto de su obra como de sus propias vidas.

Nos queda por delante el reto de incorporar una mayor cantidad de contribuciones provenientes de investigadoras e investigadores ubicados en otras instituciones distintas a nuestro Centro y a la UNED. Igualmente es prioritario para Rupturas elevar cada vez más el nivel de exigencia y calidad académica de los materiales que publica. En ese sentido, seguimos trabajando en afinar los procedimientos y metodologías que se aplican para la revisión y selección de los artículos, como también en la ampliación del equipo de quienes nos apoyan en las evaluaciones correspondientes. 
De forma similar, nos planteamos el reto de profundizar nexos con instituciones hermanas dedicadas a la investigación sobre sociedad y cultura, así como con las publicaciones científicas que estas generan.

Lo logrado nos satisface porque corresponde, con exceso, a lo que nos habíamos propuesto hace tan solo un año atrás. Pero lo que queda por hacer es mucho más. Es un desafío que asumimos con gusto y que esperamos cumplir a plenitud.

\section{Dr. Luis Paulino Vargas Solís}

Director a.i.

Centro de Investigación en Cultura y Desarrollo (CICDE)

Director Revista Rupturas

Vicerrectoría de Investigación

UNED 


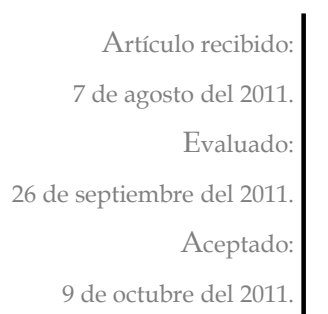

9 de octubre del 2011.

\section{El papel de las Comisiones \\ Plenas en la dinámica legislativa en Costa Rica (1998-2010)}

RESUMEN

El presente texto pretende aportar en la comprensión de la dinámica de la Asamblea Legislativa de Costa Rica, por medio del estudio del rol de las Comisiones Plenas en la aprobación de leyes entre 1998 y 2010. Analizando la distribución y los cambios de las relaciones de poder provocadas por el transfuguismo parlamentario, se busca determinar los diferentes escenarios presentes en las Comisiones Plenas durante el periodo de estudio y su impacto en el proceso de toma de decisiones en la Asamblea Legislativa.

Palabras Clave

Poder Legislativo, Parlamento, Toma de Decisiones, Transfuguismo parlamentario, Costa Rica.

\section{The Role of "Comisiones Plenas" in the legislative dynamics in Costa Rica (1998-2010)}

\section{ABSTRACT}

This text pretends to contribute to the understanding of Legislative dynamics in Costa Rica, by the study of "Comisiones Plenas" role in law approval between 1998 and 2010. By the analysis of power relationships distribution and changes derived of parlamentary faithless, the determination of different scenarios present in "Comisiones Plenas" during the studied period and their impact in the decision making process in the Legislative Assembly is pursued.

KEY WORDS

Legislature, Parliament, Decision Making, Parlamentary Faithless, Costa Rica.

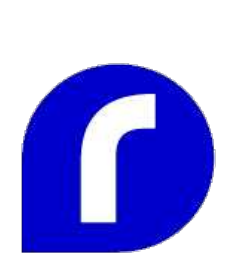

José Andrés Díaz González
Licenciado en Ciencias Políticas. Estudiante de la Maestría Académica en Historia de la Universidad de Costa Rica. Profesor e Investigador de la Escuela de Ciencias Políticas de la Universidad de Costa Rica, e Investigador del Instituto de Estudios Sociales en Población de la Universidad Nacional. Correo electrónico: joseandres.diaz@ucr.ac.cr 


\section{El papel de las Comisiones Plenas en la dinámica legislativa en Costa Rica (1998-2010)*}

Los Estados democráticos modernos han encontrado en el Congreso ${ }^{1}$ el espacio institucional en el cual los diferentes grupos políticos representan y defienden los intereses de la población, a partir de su ideología y visión de mundo. Este es un espacio deliberativo por excelencia, en el cual se pretende realizar un proceso de toma de decisiones que permita consensuar las diferentes posiciones e intereses de los actores políticos.

Por ello es relevante el estudio del Congreso como parte fundamental del sistema político, por ser el lugar donde la voluntad popular converge a partir de la distribución de poder determinada por medio de los procesos electorales. En el caso de Costa Rica, existen múltiples investigaciones centradas en el estudio y análisis del sistema electoral y de partidos políticos, los cuales buscan comprender las causas de sus transformaciones a partir de las preferencias del electorado (Alfaro, 2006; Fernández, 2000; Rojas, 2003), así como por los cambios ocurridos en la gobernanza electoral, entendida esta como las normas y pautas que regulan los procesos electorales (Picado, 2009 y Sobrado, 2007), y aún los estudios que buscan analizar integralmente el sistema político costarricense le dan especial relevancia al comportamiento del sistema electoral; no obstante, la mayoría de las investigaciones realizadas sobre el tema no profundizan en cómo han afectado los cambios en el sistema de partidos políticos en la dinámica parlamentaria costarricense $\mathrm{y}$, en muchos casos, se supone la labor de este como una "caja negra" o, por otro lado, se concluye que la alta fragmentación del sistema electoral incide en la ingobernabilidad y parálisis que afectan el proceso de toma de decisiones en el seno del Congreso. Surge así la necesidad de dirigir esfuerzos en la búsqueda de una mayor comprensión acerca de cómo la
* El presente artículo expone algunas de las conclusiones del proyecto de investigación "Dinámica parlamentaria y proceso de toma de decisiones en la Asamblea Legislativa de Costa Rica (1962-2010)" ( $N^{\circ} 213-\mathrm{B} 0-180$ ), realizada en la Escuela de Ciencias Políticas de la Universidad de Costa Rica durante 2010.

El autor desea agradecer a los evaluadores del presente artículo por sus comentarios y observaciones sobre el mismo. No obstante, cualquier error $u$ omisión que el artículo presente es únicamente

responsabilidad del autor.

1. En el presente documento se utilizarán los términos Congreso, Asamblea Legislativa, Parlamento y Poder Legislativo, como sinónimos, sin profundizar en las diferencias teóricoconceptuales que puedan existir entre ellos. 
dinámica legislativa costarricense ha variado a lo largo del tiempo, así como de identificar los principales motivos que han ocasionado dicho cambio, y esclarecer cómo los elementos políticos, estructurales e institucionales han incidido en los procesos de toma de decisiones en la Asamblea Legislativa.

Para conocer mejor el funcionamiento interno de la Asamblea Legislativa se debe estudiar el comportamiento de los partidos políticos al interior del Congreso y los cambios en la dinámica de los procesos de toma de decisiones y su relación con los cambios en la representatividad y el sistema político costarricense. En este caso particular se analiza el desempeño de las Comisiones Legislativas Plenas de la Asamblea Legislativas, las cuales fueron instituidas con el propósito de servir como mecanismos que faciliten y agilicen el proceso de discusión y aprobación de leyes en el parlamento costarricense.

Se analiza los cambios y funcionamientos en la dinámica de las Comisiones Plenas en la primera década del siglo XXI (1998-2010), debido a que se identifica en este periodo la transición de un sistema de partidos políticos bipartidista a uno multipartidista (Alfaro, 2006); por lo cual se espera observar si dicha transición ha afectado o influido en el funcionamiento de estos órganos legislativos, afectando así el desempeño de la Asamblea Legislativa.

Se debe aclarar que si bien este artículo se concentra en analizar los cambios en las cuotas de poder de los partidos políticos representados en la Comisiones Plenas y, de esta manera, su capacidad de influir en los procesos de votación de estos órganos legislativos; en ningún momento se desea obviar la existencia de factores externos (como por ejemplo: grupos de presión, cambios en la coyuntura política nacional o internacional, intervención de otros Poderes del Estado, etc.) que pueden intervenir, modificar o influir en las tendencias de votación de los grupos políticos representados en la Asamblea Legislativa.

De esta manera, dada la existencia de múltiples elementos que pueden intervenir en los procesos de negociación y toma de decisiones en el Poder Legislativo, lo que se pretende es aportar en la consideración de un factor adicional para la compresión de las dinámicas que acontecen en la Asamblea Legislativa, esta es la capacidad de influir en la aprobación o rechazo de un proyecto de ley, que tiene un partido político a partir del número de votos con los que cuenta o controla.

En el ejercicio moderno de la democracia, se necesita tanto de procesos de agregación de intereses y preferencias como procesos integradores para crear cierta unidad, orden y confianza en las instituciones, procesos, organizaciones y demás partes del sistema como tal (Rivas, 1997). De esta manera, el Poder Legislativo, como espacio de representación y 
confrontación política, tiene el deber de realizar dichos procesos como parte fundamental de los sistemas democráticos. No obstante, la labor del Congreso será reflejo de la representatividad, polarización política y volatilidad del sistema de partidos políticos y de la sociedad en general; esto repercutirá directamente en su labor legislativa, y generará escenarios que dificultarán o facilitarán el proceso de toma de decisiones en su seno.

Por lo tanto, es de suma importancia entrar a estudiar las dinámicas y cambios en los procesos de toma de decisiones en el interior de la Asamblea Legislativa, para así identificar cómo las relaciones de poder, la formación de coaliciones, la polarización ideológica y los problemas de representatividad que acontecen en la sociedad costarricense, afectan los procesos parlamentarios.

Lo anterior es importante de tener en cuenta, ya que a pesar de la existencia de intereses, grupos y coyunturas externas e internas que pueden influir en la dinámica legislativa de toma de decisiones, al final las decisiones a lo interno de la Asamblea Legislativa se resuelven mediante procesos de votación, lo cual implica la necesidad de contemplar el peso que tiene cada partido político representado en el congreso para conformar coaliciones ganadoras (grupos con el número de votos necesarios para aprobar o rechazar una decisión) y cómo esto puede aumentar o disminuir su capacidad de negociación.

\section{Las Comisiones Legislativas Plenas entre 1998 y 2010}

Las Comisiones Legislativas Plenas se crean en 1993 mediante la modificación del artículo 124 de la Constitución Política de Costa Rica: "La Asamblea Legislativa puede delegar, en comisiones permanentes, el conocimiento y la aprobación de proyectos de ley. No obstante, la Asamblea podrá avocar, en cualquier momento, el debate o la votación de los proyectos que hubiesen sido objeto de delegación". De esta manera, las Comisiones Legislativas Plenas son entes con la capacidad de aprobar leyes por sí mismas, sin necesidad de llevarlos al Plenario, siempre y cuando estas leyes no sean de materia exclusiva de conocimiento del Plenario Legislativo.

Así, las Comisiones Legislativas Plenas son producto de la evolución del sistema parlamentario, y son creadas como mecanismos para generar una gestión legislativa más eficiente (Muñoz, 1997), lo anterior lleva a formular la siguiente pregunta: ¿Han podido las Comisiones Legislativas Plenas incidir positivamente en la gestión parlamentaria costarricense? 


\section{Gráfico 1}

Comparación del total de leyes aprobadas con las leyes aprobadas en Comisiones Plenas por legislatura (1998-2010)

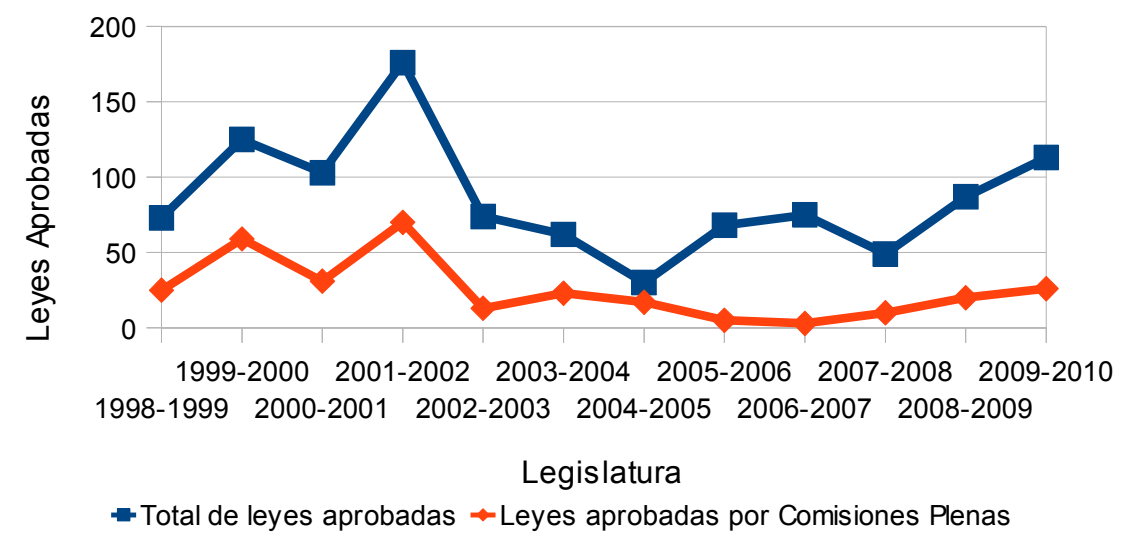

Fuente: Construcción propia, a partir de datos proporcionados por la Unidad de Análisis de la Gestión Parlamentaria del Departamento de Servicios Parlamentarios de la Asamblea Legislativa de Costa Rica. Octubre, 2010.

El gráfico 1 muestra una comparación entre el número de leyes aprobadas por la Asamblea Legislativa, y el número de leyes aprobadas en las Comisiones Legislativas Plenas, entre 1998 y 2010. Como se puede observar, entre la legislatura 1998-1999 y 2002-2003, el Plenario y las Comisiones Plenas mantienen casi el mismo comportamiento. Es decir, el comportamiento de las Comisiones Plenas parece ser un reflejo de lo que ocurre en el Plenario Legislativo.

Pero a partir de la legislatura 2003-2004 esta situación cambia, y las dinámicas de estos órganos legislativos se comportan de forma diferente. Algunos puntos que llaman la atención son la legislatura 2004-2005 donde las Comisiones Legislativas Plenas son las que aportan la mayor parte de leyes aprobadas por el Congreso durante dicho año; y las legislaturas 2005-2006 y 2006-2007, donde las Comisiones Plenas solo aportan el $7,35 \%$ y $4 \%$, respectivamente, de las leyes aprobadas (Cuadro 1).

Así, entre la legislatura 1998-1999 y 2009-2010, el papel que parecen jugar las comisiones legislativas plenas es muy cambiante, ya que si bien en promedio aportan cerca del $28 \%$ de las leyes aprobadas en ese periodo, existen grandes fluctuaciones en su actuación, pasando de años donde aportan incluso el $60 \%$ de toda la legislación aprobada, a años donde solo aportan el $4 \%$. 
Cuadro 1. Leyes aprobadas por legislatura en el Plenario Legislativo y en las Comisiones Legislativas Plenas. Asamblea Legislativa, 1998-2010 (absolutos y relativos)

\begin{tabular}{lccccc}
\hline \multirow{2}{*}{ Legislatura } & \multicolumn{2}{c}{ Plenario Legislativo } & \multicolumn{2}{c}{ Comisiones Plenas } & \multirow{2}{*}{ Total } \\
\cline { 2 - 4 } & Absoluto & Relativo & Absoluto & Relativo & \\
\hline $1998-1999$ & 48 & $65,75 \%$ & 25 & $34,25 \%$ & 73 \\
$1999-2000$ & 66 & $52,80 \%$ & 59 & $47,20 \%$ & 125 \\
$2000-2001$ & 72 & $69,90 \%$ & 31 & $30,10 \%$ & 103 \\
$2001-2002$ & 106 & $60,23 \%$ & 70 & $39,77 \%$ & 176 \\
$2002-2003$ & 61 & $82,43 \%$ & 13 & $17,57 \%$ & 74 \\
$2003-2004$ & 39 & $62,90 \%$ & 23 & $37,10 \%$ & 62 \\
$2004-2005$ & 13 & $43,33 \%$ & 17 & $56,67 \%$ & 30 \\
$2005-2006$ & 63 & $92,65 \%$ & 5 & $7,35 \%$ & 68 \\
$2006-2007$ & 72 & $96,00 \%$ & 3 & $4,00 \%$ & 75 \\
$2007-2008$ & 39 & $79,59 \%$ & 10 & $20,41 \%$ & 49 \\
$2008-2009$ & 67 & $77,01 \%$ & 20 & $22,99 \%$ & 87 \\
$2009-2010$ & 87 & $76,99 \%$ & 26 & $23,01 \%$ & 113 \\
\hline
\end{tabular}

Fuente: Construcción propia,a partir de datos proporcionados por la Unidad de Análisis de la Gestión Parlamentaria del Departamento de Servicios Parlamentarios de la Asamblea Legislativa de Costa Rica. Octubre, 2010

El gráfico 2 muestra que el aporte total de las Comisiones Legislativas Plenas al número de leyes aprobadas tiende a disminuir de manera global en este tiempo, pasando de un $28 \%$ en el periodo de 1998-2002, a un $15 \%$ en el periodo 2006-2010. Entonces ¿Cuál es el impacto real de las Comisiones Legislativas Plenas en la dinámica Parlamentaria costarricense?

\section{Gráfico 2}

Comparación del total de leyes aprobadas con las leyes aprobadas en Comisiones Plenas por periodo de

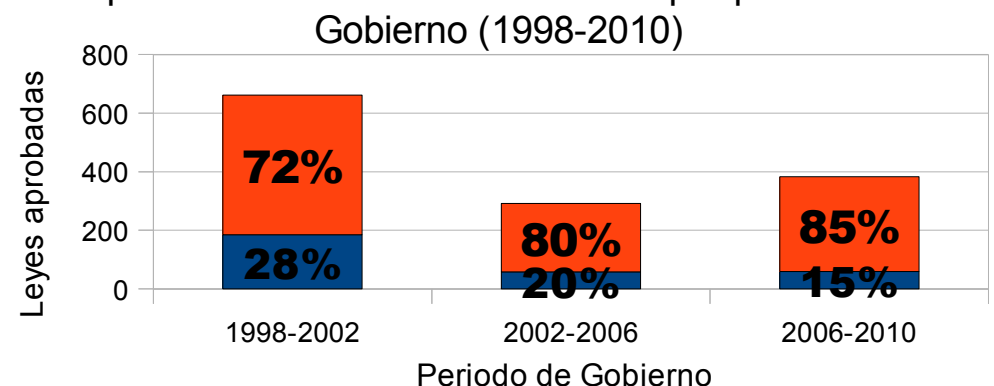

Leyes aprobadas por Comisiones Plenas

$\square$ Total de leyes aprobadas

Fuente: Construcción propia, a partir de datos proporcionados por la Unidad de Análisis de la Gestión Parlamentaria del Departamento de Servicios Parlamentarios de la Asamblea Legislativa de Costa Rica. Octubre, 2010 


\section{Gráfico 3}

Relación de leyes aprobadas por el Plenario Legislativo y las Comisiones Plenas, por legislatura.

Asamblea Legislativa, 1998-2010

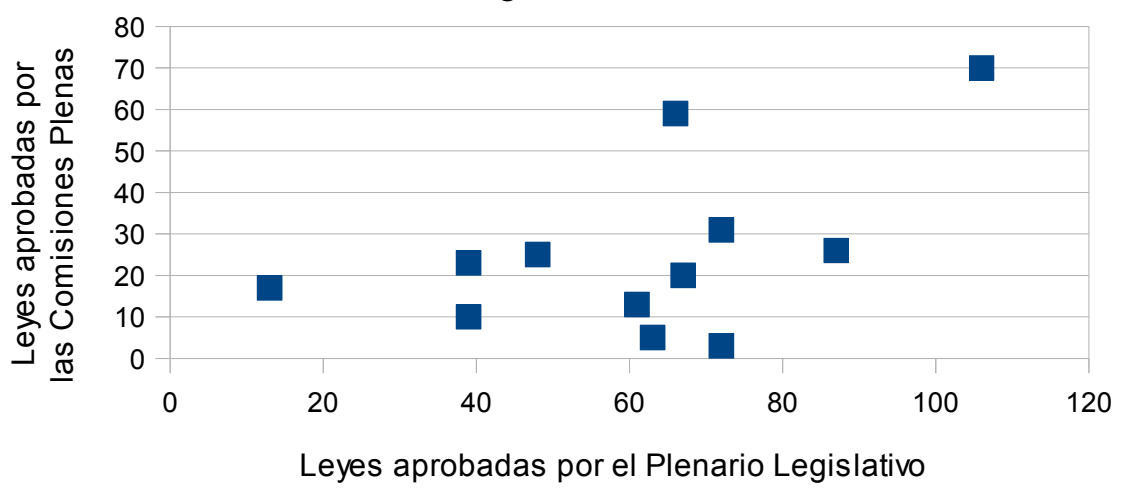

Fuente: Construcción propia, a partir de datos proporcionados por el Departamento de Servicios Parlamentarios de la Asamblea Legislativa de Costa Rica. Octubre, 2010

El gráfico 3 muestra la relación existente entre el número de leyes aprobadas por el Plenario Legislativo y el número de leyes aprobadas por las Comisiones Legislativas Plenas. Se observa que la relación entre ambas variables es algo dispersa. El coeficiente de correlación entre estas variables es de 0,5 lo cual indica que existe una relación medianamente fuerte entre ambas, no obstante, el coeficiente de determinación $\left(R^{2}\right)$ o poder explicativo de dicha correlación solamente es de 0,25 ; en otras palabras, solo la cuarta parte de las legislaturas pueden explicarse mediante la mediana relación que existe entre las leyes aprobadas por el Plenario Legislativo y las aprobadas por las Comisiones Legislativas Plenas.

Con lo anterior se constata que el impacto de las Comisiones Legislativas Plenas en este período del proceso de aprobación de leyes es baja; con lo que se podría inducir que estos espacios no son aprovechados por la Asamblea Legislativa para la discusión y generación de acuerdos políticos que permita mejorar la gestión y actuación del parlamento costarricense.

Una nueva pregunta surge de los datos observados hasta el momento: ¿Por qué las Comisiones Plenas no han tenido un rol más activo en el desempeño legislativo durante este periodo? A continuación se esbozan algunas respuestas tentativas o hipótesis a dicha pregunta, basadas principalmente en la distribución del poder a lo interno de estos órganos legislativos, las cuales deberán ser confirmadas o refutadas en futuras investigaciones que profundicen en el tema, analizando con más detenimiento las diferentes coyunturas políticas de cada período legislativo estudiado. Como se mencionó al principio de este artículo, no 
se parte de la idea de que solo los factores internos pueden afectar la dinámica de los procesos decisorios en la Asamblea Legislativa, sino que existe una multitud de factores externos que también intervienen en dichos procesos; no obstante, el objetivo del documento es tratar de mostrar cómo puede intervenir la distribución del poder en la labor de las Comisiones Plenas. Lo anterior, en procura de aportar conocimiento sobre uno de los múltiples factores que deben ser tomados en cuenta para una mejor comprensión del funcionamiento del Poder Legislativo en Costa Rica.

El artículo 124 de la Constitución política de Costa Rica establece que:

La Asamblea nombrará las comisiones permanentes con potestad legislativa plena, de manera que su composición refleje, proporcionalmente, el número de diputados de los partidos políticos que la componen. La delegación deberá ser aprobada por mayoría de dos tercios de la totalidad de los miembros de la Asamblea, y la avocación, por mayoría absoluta de los diputados presentes.

Esto es importante ya que la forma en que se encuentran conformadas las comisiones puede incidir en elementos como los proyectos que sean delegados a ellas por el Plenario Legislativo, así como en la facilidad de alcanzar acuerdos y tomar decisiones, o en el control de las Comisiones Legislativas por parte del partido de Gobierno, entre otros.

\begin{tabular}{|c|c|c|c|c|c|c|}
\hline $\begin{array}{l}\text { Partido } \\
\text { Político } \\
\end{array}$ & Plena Primera & $\begin{array}{c}\text { Índice de } \\
\text { Banzhaf }\end{array}$ & Plena Segunda & $\begin{array}{l}\text { Índice de } \\
\text { Banzhaf }\end{array}$ & Plena Tercera & $\begin{array}{c}\text { Índice de } \\
\text { Banzhaf }\end{array}$ \\
\hline PLN & 7 & 0.0909 & 8 & 0.1667 & 8 & 0.1667 \\
\hline PUSC & 9 & 0.6364 & 9 & 0.5 & 9 & 0.5 \\
\hline FD & 1 & 0.0909 & 1 & 0.1667 & 1 & 0.1667 \\
\hline PIN & 1 & 0.0909 & - & - & - & - \\
\hline PALA & 1 & 0.0909 & - & - & - & - \\
\hline ML & - & - & - & - & 1 & 0.1667 \\
\hline $\mathrm{RC}$ & - & - & 1 & 0.1667 & - & - \\
\hline
\end{tabular}

Fuente: Construcción propia, Noviembre, 2010

El cuadro 2 muestra la distribución de escaños, así como el índice de poder de Banzharf, para las Comisiones Legislativas Plenas en el periodo 1998-2002. El índice de Banzhaf es un indicador del poder o capacidad de influir en la adopción de una decisión que tiene un agente o jugador, en los casos en que las decisiones se toman por votación. El valor de Banzhaf asigna a un jugador $i$ la media aritmética de las contribuciones que dicho jugador hace a las coaliciones que se puede unir. En un juego simple, o de votación ponderada, un jugador solo aporta algún beneficio a la coalición ganadora en la que es crítico, es decir, en donde él se convierte en el pivote para lograr que la coalición se convierta en ganadora (Dubey y Shapley, 1979). 
La Comisión Legislativa Plena Segunda y la Plena Tercera presentan la misma distribución de poder, donde el Partido Unidad Social Cristiana (PUSC) -que en dicho periodo fungía como partido de Gobierno- domina las Comisiones, y los restantes partidos comparten la misma cuota de poder. En la Comisión Plena Primera la situación es similar, salvo que hay una mayor cantidad de partidos políticos representados. Lo anterior provoca que la cuota de poder del PUSC sea superior.

Cuadro 3. Leyes aprobadas por legislatura por las Comisiones Legislativas Plenas. Asamblea Legislativa, 1998-2002

\begin{tabular}{ccccc}
\hline Legislatura & Total & $\begin{array}{c}\text { Plena } \\
\text { Primera }\end{array}$ & $\begin{array}{c}\text { Plena } \\
\text { Segunda }\end{array}$ & $\begin{array}{c}\text { Plena } \\
\text { Tercera }\end{array}$ \\
\hline $1998-1999$ & 25 & 8 & 7 & 10 \\
$1999-2000$ & 59 & 18 & 25 & 16 \\
$2000-2001$ & 31 & 10 & 10 & 11 \\
$2001-2002$ & 70 & 29 & 23 & 18 \\
\hline Total & $\mathbf{1 8 5}$ & $\mathbf{6 5}$ & $\mathbf{6 5}$ & $\mathbf{5 5}$ \\
\hline
\end{tabular}

Fuente: Construcción propia, a partir de datos proporcionados por la Unidad de Análisis de la Gestión Parlamentaria del Departamento de Servicios Parlamentarios de la Asamblea Legislativa de Costa Rica. Octubre, 2010

No obstante esta situación, durante el periodo 1998-2002, se aprobaron la misma cantidad de leyes en la Plena Primera y Segunda, lo cual parece indicar que el número de partidos políticos representados en estas, así como la distribución del poder en las mismas, no fue un elemento de peso que afectara de manera directa el número de leyes que se aprobó en cada comisión. Como contraste, la Plena Tercera, cuya distribución de poder era idéntica a la Plena Segunda, aprobó diez leyes menos en dicho periodo (Cuadro 3).

Cuadro 4. Distribución de escaños en las Comisiones Legislativas Plenas e índice de Banzhaf. Asamblea Legislativa, 2002-2006

\begin{tabular}{lcccccc}
\hline $\begin{array}{l}\text { Partido } \\
\text { Político }\end{array}$ & Plena Primera & $\begin{array}{c}\text { Índice de } \\
\text { Banzhaf }\end{array}$ & Plena Segunda & $\begin{array}{c}\text { Índice de } \\
\text { Banzhaf }\end{array}$ & Plena Tercera & $\begin{array}{c}\text { Índice de } \\
\text { Banzhaf }\end{array}$ \\
\hline PLN & 6 & 0.33 & 7 & 0.33 & 5 & 0.2308 \\
PUSC & 6 & 0.33 & 6 & 0.33 & 7 & 0.3846 \\
ML & 2 & 0 & 2 & 0 & 2 & 0.0769 \\
PAC & 5 & 0.33 & 4 & 0.33 & 4 & 0.2308 \\
RC & - & - & - & - & 1 & 0.0769 \\
\hline
\end{tabular}

Fuente: Construcción propia. Noviembre, 2010

Para el periodo 2002-2006 se encuentra que las Comisiones Legislativas Plena Primera y Segunda tienen la misma distribución de poder, donde se pueden observar dos hechos llamativos: el primero, que no hay un partido político dominante, ya que tres partidos políticos se reparten el poder por igual; segundo, que a pesar de contar con representantes en dichas 
comisiones, el Partido Movimiento Libertario (ML) no tenía una cuota de poder en estas, lo cual se debe a que la cantidad de votos que controla (dos en cada caso) son insuficientes para aportar en la aprobación de un proyecto, en otras palabras, no era necesario para conformar coaliciones ganadoras (Cuadro 4).

En el caso de la Comisión Legislativa Plena Tercera (Cuadro 4), el PUSC se destaca como el partido dominante o con la mayor cuota de poder, seguido por el Partido Liberación Nacional (PLN) y el Partido Acción Ciudadana (PAC), y luego por el ML y Renovación Costarricense (RC).

\begin{tabular}{lcccc}
\hline \multicolumn{2}{l}{$\begin{array}{l}\text { Cuadro 5. Leyes aprobadas por legislatura } \\
\text { Plenas. Asamblea Legislativa, }\end{array}$} & por las Comisiones & Legislativas \\
\hline Legislatura & Total & $\begin{array}{c}\text { Plena } \\
\text { Primera }\end{array}$ & $\begin{array}{c}\text { Plena } \\
\text { Segunda }\end{array}$ & $\begin{array}{c}\text { Plena } \\
\text { Tercera }\end{array}$ \\
\hline $2002-2003$ & 13 & 6 & 5 & 2 \\
$2003-2004$ & 23 & 9 & 6 & 8 \\
$2004-2005$ & 17 & 3 & 9 & 5 \\
$2005-2006$ & 5 & 3 & 1 & 1 \\
\hline Total & $\mathbf{5 8}$ & $\mathbf{2 1}$ & $\mathbf{2 1}$ & $\mathbf{1 6}$ \\
\hline
\end{tabular}

Fuente: Construcción propia, a partir de datos proporcionados por la Unidad de Análisis de la Gestión Parlamentaria del Departamento de Servicios Parlamentarios de la Asamblea Legislativa de Costa Rica. Octubre, 2010

Como puede observarse en el cuadro 5, la Comisión Plena Tercera aprobó una menor cantidad de leyes que la Plena Primera y Plena Segunda, durante este periodo. Asimismo, en la Comisión Plena Tercera el PUSC era el partido dominante, y no compartía el poder en cuotas iguales con otros partidos presentes, como ocurrió en las otras comisiones (Cuadro 4).

Lo anterior podría hacer pensar que al tener el PUSC una mayor cuota de poder en esta Comisión, se facilitaría el proceso de toma de decisiones; no obstante los datos revelan que todos los partidos políticos representados en la Comisión Plena Tercera tenían una cuota de poder, es decir, tenían la capacidad de formar coaliciones ganadoras; lo que provocaba que, a diferencia de lo que ocurría en la Plena Primera y Segunda donde solo tres partidos políticos tenían capacidad de decisión, en la Plena Tercera eran cinco los partidos políticos que podían intervenir en la toma de decisiones; esto posiblemente podría provocar que los procesos de negociación en esta Comisión fueran más complejos.

Para el periodo de Gobierno 2006-2010 se encuentra una variación muy importante respecto a la distribución del poder en la Comisiones Plenas. Como se observa en el cuadro 6, en las Comisiones Plenas Primera y Tercera, si bien el PLN es el partido con una cuota de poder mayor, cada agrupación política presente en dichas comisiones mantiene una cuota de poder, es decir, tienen capacidad de intervenir en el proceso de toma de decisiones para aprobar o rechazar los proyectos de ley en ellas 
presentados. No obstante, lo que diferencia a este periodo de Gobierno, es que la Comisión Plena Segunda se encontraba en completo control por parte del PLN; en otras palabras, los restantes partidos políticos representados en dicha comisión no reunían los suficientes votos para intervenir en el proceso de tomas de decisiones.

Cuadro 6. Distribución de escaños en las Comisiones Legislativas Plenas e índice de Banzhaf. Asamblea Legislativa, 2006-2010

\begin{tabular}{lcccccc}
\hline $\begin{array}{c}\text { Partido } \\
\text { Político }\end{array}$ & Plena Primera & $\begin{array}{r}\text { Índice de } \\
\text { Banzhaf }\end{array}$ & Plena Segunda & $\begin{array}{c}\text { Índice de } \\
\text { Banzhaf }\end{array}$ & Plena Tercera & $\begin{array}{c}\text { Índice de } \\
\text { Banzhaf }\end{array}$ \\
\hline PLN & 8 & 0.4615 & 10 & 1 & 9 & 0.6364 \\
PUSC & 1 & 0.0769 & 2 & 0 & 2 & 0.0909 \\
FA & 1 & 0.0769 & 4 & 0 & - & - \\
PAC & 6 & 0.1538 & - & - & 5 & 0.0909 \\
PASE & 1 & 0.0769 & - & - & - & - \\
ML & 2 & 0.1538 & 2 & 0 & 2 & 0.0909 \\
RC & - & - & 1 & 0 & 1 & 0.0909 \\
\hline
\end{tabular}

Fuente: Construcción propia. Noviembre, 2010

Podría pensarse que el control absoluto que tenía el PLN en la Comisión Plena Segunda durante dicha administración fuera aprovechado por esta agrupación política, ya que la Plena Segunda fue la comisión más productiva durante esos cuatros años (Cuadro 7). Sin embargo, la diferencia con las otras dos comisiones no es muy significativa; asimismo, llama la atención que en los dos primeros años de dicho gobierno solo se aprobaron cuatro leyes en la Comisión Plena Segunda, a pesar de estar completamente controlada por el partido de gobierno, misma cantidad de leyes aprobadas por la Comisión Plena Tercera -a pesar de la fragmentación de poder a lo interno de esta y que en la primera legislatura no se aprobara ninguna ley en dicha comisión- y una menos que en la Comisión Plena Primera, que logró aprobar cinco leyes en los primeros dos años de Gobierno.

Cuadro 7. Leyes aprobadas por legislatura por las Comisiones Legislativas Plenas. Asamblea Legislativa, 2006-2010

\begin{tabular}{ccccc}
\hline Legislatura & Total & $\begin{array}{c}\text { Plena } \\
\text { Primera }\end{array}$ & $\begin{array}{c}\text { Plena } \\
\text { Segunda }\end{array}$ & $\begin{array}{c}\text { Plena } \\
\text { Tercera }\end{array}$ \\
\hline $2006-2007$ & 3 & 1 & 2 & 0 \\
$2007-2008$ & 10 & 4 & 2 & 4 \\
$2008-2009$ & 20 & 6 & 10 & 4 \\
$2009-2010$ & 26 & 7 & 10 & 9 \\
\hline Total & $\mathbf{5 9}$ & $\mathbf{1 8}$ & $\mathbf{2 4}$ & $\mathbf{1 7}$
\end{tabular}

Fuente: Construcción propia, a partir de datos proporcionados por la Unidad de Análisis de la Gestión Parlamentaria del Departamento de Servicios

Parlamentarios de la Asamblea Legislativa de Costa Rica. Octubre, 2010 
Los datos anteriores parecen indicar una falta de interés de los legisladores y las legisladoras por utilizar las Comisiones Plenas como espacios que permitan agilizar la discusión parlamentaria y el proceso de aprobación de leyes. Parece, por lo tanto, que las Comisiones Plenas se presentan como espacios estratégicos donde son enviados proyectos puntuales que a la mayoría parlamentaria les interesa aprobar con cierta celeridad. Además, parece que existe una tendencia por utilizar de manera más selectiva este instrumento parlamentario ya que, como se aprecia en el gráfico 2, el porcentaje total de leyes aprobadas por la Asamblea Legislativa que se realiza en las Comisiones Plenas tiende a disminuir desde el periodo 1998-2002.

No se puede obviar que uno de los motivos que puede dificultar la toma de decisiones de las Comisiones Plenas es que estas solo se reúnen obligatoriamente un día a la semana y por un espacio generalmente no mayor a dos horas; lo cual podría considerarse como un obstáculo en el trabajo de los legisladores en dichos espacios parlamentarios. No obstante, los proyectos de ley que son analizados en dichas comisiones son delegados por el Plenario Legislativo, por tanto, se podría esperar que estos hayan sido discutidos y consensuados por un grupo importante de legisladores, lo que debería facilitar el trabajo en dichas comisiones, así como el proceso de toma de decisiones en estas.

\section{Efectos del transfuguismo en las Comisiones Legislativas Plenas: 1998-2010}

La legislación costarricense permite a un diputado separarse del partido político por el cual fue electo, sin que esto implique que pierda su escaño. Este transfuguismo parlamentario afecta la dinámica de la Asamblea Legislativa y la relación de poder entre los diferentes grupos políticos. Anteriormente se analizaron los datos con la conformación establecida en ellas a partir de los partidos políticos que participaron en el proceso electoral, ya que dichas conformaciones son las consideradas en primera instancia por el Presidente de la Asamblea Legislativa para conformar las Comisiones el $1^{\circ}$ de mayo de la primera legislatura, y tradicionalmente no varía a pesar de las posibles separaciones de diputados. Así, en este apartado se busca observar si el transfuguismo ha impactado de manera significativa el trabajo de las Comisiones Legislativas Plenas durante la primera década del siglo XXI.

El cuadro 8 muestra cómo varía el número de agrupaciones políticas ${ }^{2}$ presentes en las Comisiones Legislativas Plenas y su comparación con el número de leyes aprobadas por estas cada legislatura. La correlación entre ambas variables es de $-0,48$, esto indica que existe una correlación inversa moderadamente fuerte entre el número de agrupaciones políticas y la cantidad de leyes aprobadas en las Comisiones Plenas, en otras palabras, a más grupos políticos conforman las Comisiones Plenas, menos leyes logran ser aprobadas (Gráfico 4). No obstante, el coeficiente
2. Por agrupación política se entiende los diputados independientes o los bloques de diputados que se conforman a partir de los legisladores que dejan los partidos políticos por los cuales fueron electos. 
de determinación de dicha correlación es apenas de 0,23 , lo cual indica que su poder explicativo es bajo, ya que solo aproximadamente una cuarta parte de los casos pueden explicarse a partir de la relación de dichas variables.

Cuadro 8. Cambio en el número de agrupaciones políticas presentes en las Comisiones Legislativas Plenas y cantidad de leyes aprobadas. Asamblea Legislativa, 1998-2010

\begin{tabular}{lcccccc}
\hline \multirow{2}{*}{ Legislatura } & \multicolumn{2}{c}{ Plena Primera } & \multicolumn{2}{c}{ Plena Segunda } & \multicolumn{2}{c}{ Plena Tercera } \\
\cline { 2 - 7 } & $\begin{array}{c}\text { Agrupaciones } \\
\text { Políticas }\end{array}$ & $\begin{array}{c}\text { Leyes } \\
\text { Aprobadas }\end{array}$ & $\begin{array}{c}\text { Agrupaciones } \\
\text { Políticas }\end{array}$ & $\begin{array}{c}\text { Leyes } \\
\text { Aprobadas }\end{array}$ & $\begin{array}{c}\text { Agrupaciones } \\
\text { Políticas }\end{array}$ & $\begin{array}{c}\text { Leyes } \\
\text { Aprobadas }\end{array}$ \\
\hline $1998-1999$ & 5 & 8 & 4 & 7 & 4 & 10 \\
$1999-2000$ & 5 & 18 & 4 & 25 & 4 & 16 \\
$2000-2001$ & 5 & 10 & 4 & 10 & 4 & 11 \\
$2001-2002$ & 5 & 29 & 4 & 23 & 4 & 18 \\
$2002-2003$ & 7 & 6 & 5 & 5 & 6 & 2 \\
$2003-2004$ & 8 & 9 & 5 & 6 & 6 & 8 \\
$2004-2005$ & 8 & 3 & 5 & 9 & 8 & 5 \\
$2005-2006$ & 8 & 3 & 5 & 1 & 8 & 1 \\
$2006-2007$ & 6 & 1 & 5 & 2 & 5 & 0 \\
$2007-2008$ & 6 & 4 & 5 & 2 & 6 & 4 \\
$2008-2009$ & 7 & 6 & 5 & 10 & 6 & 4 \\
$2009-2010$ & 7 & 7 & 5 & 10 & 6 & 9 \\
\hline
\end{tabular}

*Por agrupación política se entiende los diputados independientes o los bloques de diputados que se conforman apartir de los legisladores que dejan los partidos políticos por los cuales fueron electos.

Fuente: Construcción propia, a partir de datos proporcionados por la Unidad de Análisis de la Gestión Parlamentaria del Departamento de Senvicios Parlamentarios de la Asamblea Legislativa de Costa Rica. Noviembre, 2010.

Sin embargo, otra forma de tratar de determinar el impacto del transfuguismo en las Comisiones Plenas es observar cómo este varía la distribución de las cuotas de poder a lo interno de dichas Comisiones. Así, por ejemplo, en el cuadro 4 se mostraba que el ML no tenía ninguna cuota de poder en las Comisiones Plenas Primera y Segunda tal y como habían sido conformadas originalmente; no obstante, el transfuguismo cambia la relación de poder a lo interno de dichas comisiones permitiendo al ML captar una cuota de poder que le permite intervenir de manera más efectiva en el proceso de toma de decisiones de dichas comisiones.

El gráfico 5 muestra cómo varía la relación entre el número de leyes aprobadas y la cantidad de agrupaciones políticas con una cuota de poder efectiva para intervenir en el proceso de toma de decisiones. La correlación entre ambas variables es de $-0,17$; si bien continúa siendo negativa la relación, esta es muy cercana a 0 , lo cual es un indicio de una débil relación entre ambas. Esto se confirma con el coeficiente de determinación de dicha correlación el cual es 0,03. 


\section{Gráfico 4}

Relacción entre número de agrupaciones políticas y leyes aprobadas en las Comisiones Plenas por legislatura.

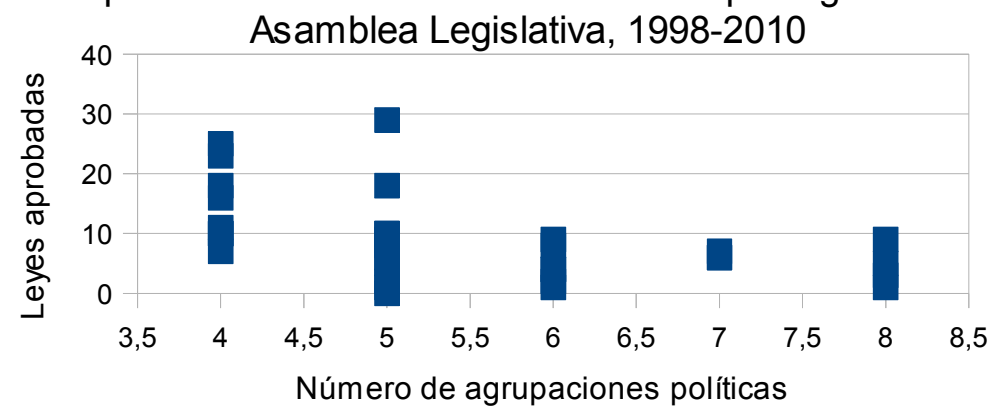

Fuente: Construcción propia, a partir de datos proporcionados por la Unidad de Análisis de la Gestión Parlamentaria del Departamento de Servicios Parlamentarios de la Asamblea Legislativa de Costa Rica.

\section{Gráfico 5}

Correlación entre número de grupos políticos con poder y leyes aprobadas en las Comisiones Plenas por legislatura. Asamblea Legislativa, 1998-2010

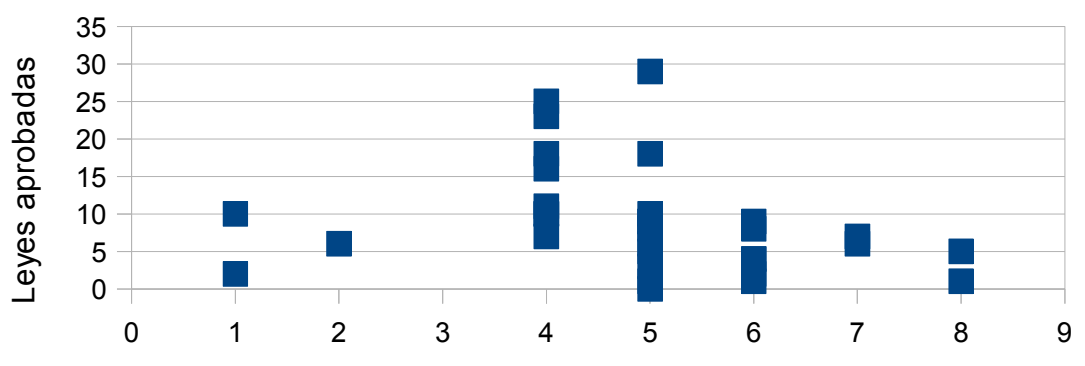

Número de grupos políticos con poder

Fuente: Construcción propia, a partir de datos proporcionados por la Unidad de Análisis de la Gestión Parlamentaria del Departamento de Servicios Parlamentarios de la Asamblea Legislativa de Costa Rica. Noviembre, 2010

Estos datos parecen confirmar la hipótesis de que la crisis de gobernabilidad que algunos analistas sostienen que atraviesa el sistema político costarricense y, en especial, la Asamblea Legislativa, no se debe a la "excesiva" fragmentación del parlamento, sino que parece responder más a variables relacionadas con la gestión política y la capacidad de diálogo de los grupos políticos para alcanzar puntos de acuerdo. 


\section{Conclusión}

Las Comisiones Legislativas Plenas durante la primera década del siglo XXI no han tenido un fuerte impacto en la dinámica parlamentaria, y su contribución al proceso de aprobación de leyes durante este periodo resulta ser bastante puntual. Los datos expuestos permiten observar que no es la distribución del poder, ni el aumento del número de agrupaciones políticas en la Asamblea Legislativa durante este periodo lo que parece incidir de manera directa en el desempeño de estos órganos legislativos; esto lleva a pensar que las explicaciones relacionadas con la existencia de un mal desempeño o "parálisis parlamentaria" debidas a la presencia de un escenario multipartidista no parecen ser acertadas para este caso.

Muchos actores internos y externos a la Asamblea Legislativa claman por la necesidad de reformar el reglamento del Primer Poder de la República, como el medio para enfrentar los cambios en el escenario político, en procura de desempeño legislativo más eficiente (Matamoros, 2011, 30 de agosto), por lo cual incluso diputados y diputadas han tratado de promover reformas al Reglamento Legislativo para evitar acciones que ellos consideran como "filibusterismo":

Entre los principales males que le aquejan a nuestro anticuado reglamento se encuentra su permisividad al "filibusterismo", práctica en la cual un diputado o un grupo de ellos pueden paralizar la tramitación de un tema o proyecto, apoyados en la interminable discusión de los asuntos producto del uso irrefrenado de la palabra, de carretillos de mociones de reiteración y de la inexistencia de plazos de votación y caducidad de los proyectos, así como su excesivo formalismo y rigidez que atentan contra el derecho parlamentario el cual se caracteriza por ser espontáneo, dinámico y flexible (Asamblea Legislativa, Proyecto $\mathrm{N}^{\circ}$ 18.141).

No obstante, los datos analizados parecen mostrar que el proceso de toma de decisiones tanto en las Comisiones Plenas, como en general en la Asamblea Legislativa está más influenciado por la capacidad de diálogo, negociación y formación de consenso que tienen los partidos políticos representados en el congreso costarricense, que por las reglas e instancias formales que lo regulan.

Por lo tanto, parece ser que lo dispuesto hace ya diez años por Fernández (2001) sobre el origen del problema de gobernabilidad que afecta a Costa Rica según algunos grupos políticos, aún tiene validez para evaluar la dinámica legislativa costarricense en la primera década del siglo XXI: 
Los lamentos más recientes, emanados del poder y que asumen con ligereza el diagnóstico neoconservador de una ingobernabilidad en ciernes o en pleno curso, no hacen más que esconder o disfrazar la frecuente impericia o relativa incapacidad de la que parecen haber hecho gala algunos de nuestros más recientes gobernantes (Fernández. 2001, p. 570).

Por lo tanto, este autor considera que no es la fragmentación del sistema político lo que ha provocado los problemas de gobernabilidad en Costa Rica, sino la falta de capacidad o gestión política de los gobernantes para alcanzar acuerdos y llevar a buen término los procesos de negociación básicos en una democracia.

Incluso, escenarios legislativos caracterizados por una alta fragmentación y una multiplicidad de actores con poder para intervenir en la toma de decisiones parlamentarias, pueden presentar características que permitan al partido oficialista y al Poder Ejecutivo impulsar su propia agenda:

...si la fragmentación parlamentaria y la polarización sobre la agenda legislativa genera un problema en la capacidad de toma de decisiones del Ejecutivo, podría ser que, dependiendo de la multiplicidad de actores de oposición y su dispersión, del tamaño del contingente legislativo oficialista, y de los niveles de disciplina y cohesión, el presidente y su gabinete cuenten con un mayor margen de opciones para articular coaliciones parlamentarias (Vargas y Petri, 2008, p. 191).

Esto lleva a la necesidad de profundizar en los estudios sobre las capacidades de negociación y formación de consenso de las personas que ocupan una curul legislativa en los distintos periodos de gobierno, así como las estrategias y capacidades que tienen los diferentes grupos políticos de encontrar puntos de convergencia en sus propuestas políticas para el desarrollo de leyes que traten de integrar las diferentes visiones e intereses representados en la Asamblea Legislativa.

\section{Bibliografía}

Alfaro, R. (2006). Elecciones nacionales 2006 en Costa Rica y la recomposición del sistema de partidos políticos. Revista de Ciencia Políticas, 26, 125-137.

Asamblea Legislativa de Costa Rica. (2011). Proyecto No 18.141: Reforma parcial del Reglamento de la Asamblea Legislativa. 
Dubey, P. y Shapley, L. S. (1979). Mathemathical properties of the Banzhaf Power Index Mathematics of Operations Research, 4, 99131.

Fernández, O. (2000). Las reglas de representación parlamentaria: El reinicio de un debate en la Costa Rica de los años noventa. Anuario de Estudios Centroamericanos, 26, 133-145.

Fernández, O. (2001). Representación parlamentaria en la Costa Rica de hoy. En: Rovira Mas, J. (Edit.), La democracia de Costa Rica ante el siglo XXI (559-574). San José: Editorial Universidad de Costa Rica.

Matamoros, J. (2011, 30 de agosto). La necesaria reforma al reglamento legislativo. La Nación. Recuperado de http://www.nacion.com/201108-30/Opinion/la-necesaria-reforma-al-reglamento-legislativo.aspx

Muñoz, H. A. (1997). La Asamblea Legislativa en el sistema constitucional costarricense. San José: IIDH-CAPEL.

Picado, H. (2009). Diseño y transformaciones de la gobernanza electoral en Costa Rica. América Latina Hoy, 51, 95-116.

Rivas, J.A (1997). El neoinstitucionalismo y la revalorización de las instituciones. Reflexión Política, 9, 36-46.

Rojas, M. (2003). Costa Rica: Un sistema de partidos en recomposición. Recuperado en: http://www.flacso.or.cr/fileadmin/documentos/FLACSO/Manuel1.pdf

Sobrado, L. A. (2007). Democratización interna de los partidos políticos en Costa Rica. San José: FLACSO.

Vargas, J. P. y Petri, D. P. (2008). Efectividad Parlamentaria. Incentivos y restricciones coalicionales en Costa Rica y Nicaragua. San José: DEMUCA. 



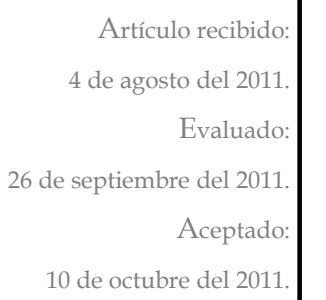

10 de octubre del 2011.

\section{Los dueños de la palabra en The Owners of the "Word" in Costa Rica en un contexto de Costa Rica from a neoliberal reforma neoliberal reform context}

RESUMEN

A partir de los 80 s, en la región centroamericana inicia un proceso de profundo cambio socio-económico, que tuvo efectos en muchas dimensiones de la vida. De la mano de estos cambios, los grupos de poder económico costarricenses se diversificaron y transnacionalizaron, modificando significativamente su lógica de operacionalización, en la cual los medios de comunicación tradicionales y masivos tienen un importante papel. Con esto, se muestran cuestionamientos en torno al poder de los medios de infocomunicación; junto a un importante vacío académico al respecto. Este artículo problematiza los grupos de poder en función de sus intereses en los medios de comunicación, e intenta abrir nuevas líneas de investigación sobre los vínculos entre la comunicación y el "nuevo" modelo económico en el contexto de la globalización neoliberal.

Palabras Clave

Grupos de poder, comunicación, cambios estructurales, transnacionalización
ABSTRACT

As of the 1980s, a profound process of socio-economic change have been taking place in the Central American region. Directly related to these changes, Costa Rican economic elite groups diversified into new activities and transnationalized, which changed significantly their logic of operation. The traditional and mass media have played, and still play, an important role in this changing scenario, which has put on the table critical questions about the power these infocommunication media have. However, the academic literature is silent on the issue. This paper does not pretend to fill this academic void, but does mean to problematize the economic and political elite in function of their vested interest in Costa Rica's media, and hopes to initiate a discussion that could lead to new research on the interactions between communication and the so-called "new" economic model in the context of neoliberal globalization.

KEY WORDS

Economic and media power groups, structural changes, transnationalization
Francisco Robles Rivera

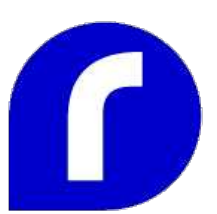

Koen Voorend
Máster en Estudios Latinoamericanos con énfasis en cultura y desarrollo por la Universidad Nacional de Costa Rica. Actualmente coordina el Programa de Nuevas Formas de Acumulación, Distribución y Desigualdad en el Instituto de Investigaciones Sociales de la Universidad de Costa Rica, donde además es docente en la Escuela de Comunicación Colectiva. Asimismo, es investigador del programa Geoestrategia Latinoamericana a principios del Siglo XXI, del Instituto de Estudios Latinoamericanos de la Universidad Nacional. Correo electrónico: franroblescr@gmail.com

Máster en Economía Internacional de la Universidad de Maastricht, Holanda, y con otra maestría en Estudios de Desarrollo, con especialización en Economía de Desarrollo, del Institute of Social Studies en la Haya, Holanda. Es docente de la Escuela de Comunicación Colectiva e investigador en el Programa de Nuevas Formas de Acumulación, Distribución y Desigualdad del Instituto de Investigaciones Sociales de la Universidad de Costa Rica. Correo electrónico: koenvoorend@gmail.com 


\section{Los dueños de la palabra en Costa Rica en un contexto de reforma neoliberal*}

\section{Introducción}

En la última década en Costa Rica hechos políticos de trascendencia histórica como el Combo del ICE, el Tratado de Libre Comercio con los EE.UU. (TLC), el memorando Casas-Sánchez, o los juicios en contra de dos expresidentes de la República han puesto de nuevo sobre el tapete los cuestionamientos en torno al poder de los medios de infocomunicación, no solo en el ámbito político, sino también económico. Sin embargo, al igual que en el caso de los estudios sobre grupos de poder económico en las ciencias sociales en general, en la comunicación este ha sido un amplio silencio en Costa Rica.

Si bien, en la última década se han dado dos importantes esfuerzos por estudiar la concentración de poder en la región y en particular en Costa Rica, el primero de ellos de Rockwell y Janus (2003) y el segundo de Segnini (2009), ambos estudios son apenas una introducción a un tema cuyo único estudio amplio data de 1979 en manos de Patricia León e Isabel Ovares. Este silencio es notable, sobre todo dado el importante papel que ha jugado la infocomunicación costarricense no solo en la formación de opinión pública, sino también en la consolidación de un modelo económico que ha traído cambios significativos a la sociedad costarricense en particular y al mundo en general.

La lógica de este nuevo modelo en las comunicaciones ha estado enmarcada en un amplio contexto de globalización neoliberal, en el cual, se ha concentrado la propiedad de los medios de infocomunicación, y se han transnacionalizado las formas y los contenidos.
* Un borrador de este artículo fue presentado por los autores en las jornadas de Investigación y Acción

Social de la Escuela de Ciencias de la

Comunicación Colectiva de la Universidad de Costa Rica, realizadas del 16 al 20 de mayo del año 2011. Otra versión fue presentada en las primeras Jornadas de Investigación de la Facultad de Ciencias Sociales de la Universidad de Costa Rica, realizadas del 31 de agosto al 2 de setiembre del año 2011. Agradecemos la valiosa colaboración y las importantes revisiones finales de la Br. Karla Venegas. 
Teniendo en cuenta lo anterior, este artículo lejos de constituirse en otra introducción al tema, busca lanzar algunas preguntas que, a criterio de los autores, podrían abrir algunos ejes de investigación de mayor trascendencia. Aquí se argumenta que es importante pensar los medios de infocomunicación en función del llamado nuevo modelo económico (Segovia, 2004), y viceversa. Más específicamente, se espera abrir la discusión sobre: el balance de los cambios en el modelo económico de Costa Rica y su(s) impacto(s) en los medios de infocomunicación; la diversificación de los dueños de los medios de comunicación en otras áreas de la economía en Costa Rica; asimismo las relaciones dineromedios-poder-política; y la concentración y el impacto de esta en el "pluralismo informativo".

Dado la anterior, en la primera parte se discute el impacto de la ruptura con el modelo económico agroexportador tradicional, así como sus ejes centrales en torno a la transnacionalización y la concentración del poder; luego se hace una breve descripción de los ganadores del período, así como la caracterización actual y general de los grupos de poder económicos en Costa Rica. Después, se analizan los cambios resultantes de esta ruptura en las economías de los medios de infocomunicación, así como una caracterización de la concentración de poder político y económico en los medios costarricenses.

\section{Ruptura(s) y cambios en el Modelo Económico en Costa Rica}

Durante los años ochenta y noventa la región centroamericana en general, y Costa Rica en particular, vivieron un período de cambios importantes en su estructura económica, social y política en consonancia con la reestructuración del capitalismo global. En Costa Rica la orientación económica y el papel del Estado cambiaron drásticamente después de la crisis de los ochenta y abrieron "el principio del fin del Estado intervencionista, para buscar un nuevo marco político-institucional en el que una nueva clase política busca nuevos referentes y estrategias distintas" (Hidalgo, 2003, p. XX).

Según Segovia (2004), se trata de un "quiebre estructural" con el modelo agro-exportador tradicional y el surgimiento de lo que algunos autores llaman un nuevo modelo económico (NME), y otros "nuevo estilo de desarrollo" (Rovira, 2004). Si bien en la literatura no existe aún consenso de cómo llamar el resultado de los cambios económicos, y se mantiene además cierta discusión del grado de ruptura con el modelo anterior, lo que sí se destaca en los trabajos académicos son los cambios importantes en la estructura económica del país y sus efectos sobre varios ámbitos diferentes, como por ejemplo los mercados laborales, el papel del Estado y la producción doméstica. 
Hidalgo (2003) explica que estas reestructuraciones económicas "suelen ser en su mayoría consecuencia de un cambio de modelo de desarrollo; es decir, suelen venir inducidos por una actuación de naturaleza política" (p. 63). En el caso costarricense, Hidalgo (2003) anota que la crisis de la deuda de los 80 y el período de intensa inestabilidad que implicó, abrieron el paso para "un grupo de políticos, los tecnócrata-políticos, [que] se hizo con el poder e iniciaron un proceso de transformación profunda del sistema inspirados en los principios del neoliberalismo. El modelo de desarrollo que esta nueva élite política ha implementado es el llamado reformismo neoliberal" (p. 64).

Este reformismo neoliberal se vio fortalecido por las políticas de instituciones financieras internacionales (IFI), y particularmente por el Banco Mundial (BM) y el Fondo Monetario Internacional (FMI), o lo que se conoce como el Consenso de Washington. Los programas de ajuste estructural que se promovieron desde este Consenso incluyeron políticas de estabilización en el corto plazo, y un paquete de ajustes estructurales en el mediano y largo plazo. A grandes rasgos, según la agenda neoliberal, estos ajustes se concentraron en la privatización de empresas públicas, la desregulación y la liberalización de mercados.

Según Segovia (2004), como resultado de estas políticas neoliberales, este "quiebre estructural, [...] por una parte provocó el colapso definitivo del modelo agroexportador tradicional; y por otra, coadyuvó al surgimiento de un Nuevo Modelo Económico" (p. 7). Este NME permitió una reestructuración de la economía, pasándose de un modelo en el cual los precios y las rentabilidades estaban destinadas al mercado interno (modelo de sustitución de importaciones), a otro en el que se ha buscado beneficiar los sectores vinculados a la actividad externa (industriales, agroindustria, turismo), profundizando la transnacionalización de la economía (Vargas, 2002; Segovia, 2004; Robinson, 2003).

Esta liberalización y la transnacionalización que implicó, se dieron por un cambio en el modelo de integración vía intercambio de bienes y flujos de capital en un mercado internacional integrado, a uno en el que los modos de producción son articulados en circuitos globales de acumulación -como el turismo y la maquila de alta y baja tecnología, por ejemplo-. (Robinson, 2003).

A diferencia de lo que sucedía con la exportación de productos tradicionales, en el cual los réditos eran utilizados en los países para las nuevas inversiones y en el sector financiero, en este nuevo modelo, buena parte de la agroindustria, la maquila y el turismo están controlados por grupos transnacionalizados tanto de "dentro" como de "fuera" del Estado. Estos réditos no estarán supeditados al Estado donde se obtengan, sino que gracias a la liberalización de la cuenta de capitales podrán ser repatriados, casi sin costo alguno (Robles, 2010). 
1. Por ejemplo Luis Liberman, Ernesto Rorhmoser, Alberto Dent, Fernando Naranjo, Samuel Yankelewitz, entre otros
De la mano de lo anterior, el NME implicó una serie de reestructuraciones legales, económicas, políticas y sociales favorables a los grupos de poder económicos nacionales y al capital transnacional metropolitano. Los ejemplos más claros son las privatizaciones de servicios públicos, la liberalización de flujos de capital y consecuentemente la entrada de bancos privados, los certificados de abono tributario como apoyo a las exportaciones y los regímenes de zona franca (Vargas, 2002). Estas reestructuraciones permitieron no solo acceder a nuevos fondos para ampliar sus inversiones, sino además a nuevos espacios en los cuales operar, producto de la privatización de los "residuos" del estadoempresario, como por ejemplo, la Corporación de Desarrollo (CODESA), Cementos del Pacífico (CEMPASA), y Fertilizantes de Centroamérica (FERTICA) (Robles, 2010).

En el caso de Costa Rica, estas reestructuraciones determinan los ganadores del período. Primero, un grupo de ganadores lo constituyeron los agroexportadores (especialmente de frutas tropicales) hacia quienes la política agrícola dio un giro, no solo en torno a exoneraciones arancelarias, sino también a través de amplias bonificaciones como los Certificados de Abono Tributario. Junto con ellos, y bajo el auspicio de la AID de los Estados Unidos, particularmente el director de ese momento, Daniel Chaij', la re-estructuración al sistema financiero costarricense permitió el "renacimiento" de una cúpula financiera privada (Sojo, 1991; Florez-Estrada, s.f.; León, 2009).

Tercero, el sector turístico en general se vio favorecido por el NME en las últimas tres décadas, el cual determinó una jerarquía empresarial de enclave favorecida con: i) la eliminación de las barreras al movimiento de capitales, ii) la concesión de exoneraciones y, iii) el otorgamiento de garantías al capital externo que ha favorecido la transnacionalización de los servicios nacionales del turismo (Ramírez, 2009).

Otro favorecido y directamente vinculado a los sectores ganadores arriba descritos, es el capital transnacional, principalmente proveniente de los EE.UU. que se ha visto beneficiado no solo por las ventas de empresas estatales, sino también, por la compra-venta de empresas tradicionalmente familiares y la ampliación de los beneficios gubernamentales a las industrias de maquila de alta tecnología y de servicios.

\section{Los grupos de poder económicos costarricenses}

Las últimas tres décadas el capital transnacional ha vivido su era de mayor expansión caracterizada por una "híper-acumulación", un período de una tasa de expansión y acumulación del capital sin precedentes en la historia contemporánea, facilitada por nuevas tecnologías, las políticas neoliberales y nuevas modalidades de movilidad y explotación de la mano de obra global (Robinson, 2010). En este contexto, en América Latina el capitalismo dependiente ha configurado una forma empresarial propia 
"caracterizada por la expansión exitosa a partir de una empresa madre que luego genera otras, convirtiéndose en el "buque bandera" de un conglomerado de numerosas empresas dirigidas por un líder familiar" (Durand y Campodónico, 2010, p. 51).

En el caso de Costa Rica y de la región centroamericana estos grupos han suplantado poco a poco a las familias oligárquicas tradicionales a través de su propia modernización y la modernización de sus empresas. Además, las reestructuraciones legales, económicas y políticas producto del ajuste estructural han promovido la integración real, la cual ha tenido lugar "fuera de la institucionalidad de integración establecida por los gobiernos del área en las últimas décadas" (Segovia, 2005, p. 35). Esta integración permitió a estos grupos re-orientar sus inversiones en la región, proceso facilitado a su vez por las similitudes sociales y culturales entre los países del istmo. Su poder económico, también les ha otorgado un "derecho de picaporte", es decir:

Facilidades para acceder a las diversas instancias del aparato estatal, como consecuencia de una compleja pero bien tejida red, que incluye desde las estrechas relaciones familiares y económicas entre los principales grupos nacionales, hasta el financiamiento de las campañas políticas de los partidos en el poder, incluso, con aportaciones millonarias a más de una organización, lo que amplía los círculos de influencia en futuros gobiernos (Segovia, 2005, p. 109).

Asimismo, la integración real de la región ha sido facilitada además por amplios procesos de compra-venta de empresas tradicionalmente familiares o públicas/estatales y el financiamiento de las economías en la región.

En el caso centroamericano, hay una amplia remodelación normativa de los Estados, a partir de la firma de sendos y amplios tratados de libre comercio, mediante los cuales se garantiza: i) la apertura de los "reglones relacionados con el principio constitucional de dominio directo de la nación y la propiedad, así como la jurisdiccionalidad del Estado sobre áreas y aspectos vitales como la industria petrolera, la electricidad, las telecomunicaciones, los ferrocarriles, entre otros" (Saxe, 2002, p. 193) y, ii) la ampliación y el fortalecimiento de los derechos de inversionistas nacionales y extranjeros con el supuesto fin de atraer más inversión, a través de un "nuevo" Acuerdo Multilateral de Inversiones (Mora, 2006).

En este contexto, los grupos de poder costarricenses han cambiado según las lógicas volátiles del capitalismo global, acrecentando su participación en aquellos sectores a los cuales se les ha apostado nacionalmente como el sector financiero, inmobiliario y turístico, pero además han dado paso a la compra-venta de empresas tradicionalmente familiares, la consolidación de oligopolios privados transnacionales y a procesos de "gerentización" de las elites económicas. Estos procesos han 
implicado que formalmente las familias pierdan la propiedad del negocio, pero no necesariamente el control, dado que se insertan en las nuevas empresas transnacionales a nivel de gerencia, lo que en buena medida limita su poder real en las decisiones de las empresas.

En el caso de la financialización de la economía y de los grupos de poder económico en Costa Rica, esta ha estado determinada pues "el bloque en el poder y los grupos de poder económico vinculados a las finanzas han tenido una mayor capacidad de hegemonizar sus intereses dentro de las pugnas propias del estilo de desarrollo que otros grupos" (León, 2009, p. 162). Esto ha sido favorecido por su intensa labor de cabildeo con políticos cercanos durante la aprobación de leyes, decretos y políticas económicas favorables; su férrea oposición al cobro de impuestos (encajes bancarios, renta, renta mundial); y el posicionamiento de colaboradores/socios cercanos en puestos del gobierno, por ejemplo: El Ministerio de Hacienda (Dent, Baruch, Bolaños, Vargas), El Banco Central (Lizano, de Paula Gutiérrez, Bolaños), la Superintendencia de Entidades Financieras, el Consejo Nacional de Supervisión del Sistema Financiero (Dent), y en los propios bancos públicos (Volio, Arguedas, Naranjo, Pacheco) (Robles, 2011-en prensa).

Esta consolidación de la clase financiera en Costa Rica debe parte de su éxito al crecimiento del ámbito financiero como principal motor de la economía costarricense, favorecido por un aumento sostenido de la riqueza financiera en los últimos veinte años, por crecimientos sumamente dinámicos en los flujos de capital, y por el aumento de créditos para sectores de la economía como vivienda, comercio y consumo (León, 2009; Vargas, 2008).

Bajo esta misma centralidad volátil, en el sector inmobiliario y turístico han estado las apuestas por otra parte de los grupos de poder económico costarricenses, para quienes la burbuja inmobiliaria en los EE.UU (Voorend y Robles, 2011), permitió sobre todo en la zona de Guanacaste la apertura, construcción y desarrollo de amplios complejos turísticos y residenciales. Junto con la burbuja inmobiliaria, la apuesta al sector turístico basado en exoneraciones e incentivos ha dado lugar al establecimiento de alianzas inter-grupos empresariales en el desarrollo y construcción de complejos turísticos y hoteleros.

Las mismas lógicas de la transnacionalización de la economía costarricense han implicado una ampliación en los procesos de compraventa de empresas que tradicionalmente estaban en manos del Estado o en manos de los grupos de poder nacionales. En este último caso, los actores de los grupos de poder nacionales típicamente llevan puestos en la gerencia de estas empresas ahora transnacionales, un proceso que en este trabajo se nombra como gerentización.

Durante los años setentas y ochentas existió un importante debate en torno a la asunción de gerentes de las Corporaciones Transnacionales Metropolitanas de los recientemente modernizados grupos de poder 
económicos. No obstante, esta nueva gerentización da lugar a tres procesos importantes. En primer lugar, a la venta que hacen o favorecen las elites modernizadas de empresas tradicionalmente familiares (Corporación de Supermercados Unidos, Abonos Agro, diario La República, Pozuelo, Monumental-Reloj, entre otras) y/o estatales (Instituto Nacional de Seguros, Instituto Costarricense de Electricidad para el caso costarricense).

En segundo lugar, esas ventas han dado lugar a la entrada y consolidación de grandes monopolios regionales o transnacionales metropolitanos en los mercados nacionales (Wall Mart, Grupo el Progreso, Aliaxis, Hollinger Inc., Ángel González, entre otros). Y, en tercer lugar, estas compra-ventas han provocado movimientos en los puestos de mando de esas empresas, movilizando a las elites modernizadas a puestos gerenciales y no necesariamente de "poder duro"2.

En el caso costarricense estos procesos de compra-venta de empresas tradicionalmente familiares han implicado el desplazamiento de las élites modernizadas en el mejor de los casos al de socios menores y por otro lado ha implicado la diversificación de las inversiones de estos grupos de poder en otras áreas de la economía.

\section{Los grupos de poder mediáticos costarricenses}

Si no existe mucha información sobre los grupos de poder en Costa Rica, menos se sabe sobre sus vínculos con los medios de comunicación, sus intereses, y el papel que estos últimos juegan en las estrategias económicas de los primeros. Sin embargo, es importante pensar los medios de comunicación en función del nuevo modelo económico, porque si bien los medios existían mucho antes de las reestructuraciones económicas, estos han desempeñado un papel importante en su justificación, como actores articuladores del modelo (Sandoval, 2007). El posicionamiento de los medios de comunicación masiva en los meses próximos al referéndum sobre el TLC con Estados Unidos fue un claro ejemplo de esto (Molina, 2007).

En el caso de los grupos de poder y medios de comunicación en Costa Rica, la concentración de la propiedad de los medios ha estado determinada al menos por dos hechos relevantes. El primero es el nacimiento de los dos más grandes e importantes medios de comunicación: La Nación (1946) y Teletica (1958), que nacen no solamente para ser la voz de los partidos políticos, sino para ser desde ese momento la voz de las élites agrícolas y conservadoras de Costa Rica (Rockwell \& Janus, 2003). El segundo hecho está determinado por la sentencia de la Sala IV N05965, del 11 de octubre de 1994, a través de la cuál se elimina el Artículo 2 de la Ley 6220, encargada de regular los medios de difusión y en el cual se señalaba la propiedad nacional de los medios de difusión y agencias de publicidad.

\author{
2. Es decir, que este poder \\ duro o de toma de \\ decisiones está \\ concentrado en los centros \\ neurálgicos de las \\ empresas, principalmente \\ en los países \\ metropolitanos, y no en las \\ periferias.
}


3. Esta empresa perteneciente

tradicionalmente a Calixto Chaves, fue vendida en el 2004 al Grupo Sama.
En las últimas décadas, al igual que en el caso de los grupos de poder costarricenses anteriormente descritos, los grupos de poder dueños de los medios de comunicación en Costa Rica se han modernizado consecuentemente. Esta modernización ha estado determinada por la "formación de unidades empresariales dirigidas con métodos administrativos y gerenciales modernos" (Durand \& Campodónico, 2010, p. 63) y por la incorporación y las alianzas estratégicas con otros grupos de poder, que teniendo sus actividades económicas principales en otros sectores, poseen hoy importantes inversiones en medios de comunicación (Durand \& Campodónico, 2010).

Esta modernización de los medios es acompañada de un aumento en la concentración de propiedad en las últimas dos décadas (Segnini, 2009). El eje particular del aumento en la concentración está determinado por la transnacionalización de los medios de comunicación, los cuales, luego de distintos procesos de compra-venta, fusiones y adquisiciones han pasado a formar parte de grandes conglomerados transnacionales.

Un ejemplo de la transnacionalización de los medios es el caso de Ángel González, dueño de al menos 30 canales de televisión y 70 radios en América Latina y que no ha dejado fuera a Costa Rica. En la televisión su grupo Repretel es dueño de los canales 4, 6 y 11 y "algunos artículos periodísticos lo señalan también como propietario de los canales 9 y 2" (Segnini, 2009, p. 71). En radio, tras la compra del Grupo de Comunicación Monumental ${ }^{3}$ en 2006, se afianzó su control sobre nueve radios en frecuencia modulada (f.m.) y cuatro en amplitud modulada (a.m.) en lo que actualmente se conoce como Central de Radios (ver tabla 1).

Otro ejemplo, es la asociación del Grupo Nación con el grupo español PRISA y Caracol de Colombia, que ha dado lugar a la creación del Grupo Latino de Radiodifusión de Costa Rica (GLR) que agrupa tres emisoras de radio.

En materia de radio, 35 emisoras están en manos de cinco grupos radiofónicos, mientras el Estado es dueño únicamente de un $11 \%$ de las licencias de radio (Tabla 1). Una particularidad de lo señalado por Segnini (2009), tiene que ver con la relación de que a mayor audiencia mayor es la concentración en la publicidad, situación que excluye a otros del mercado.

En televisión abierta compite junto con Ángel González, la empresa TELETICA de la familia Picado Cozza que controlan los canales 7 y 33, la cual es dueña también de las empresas de televisión por cable Cable Tica y Cable Color. De acuerdo con Segnini (2009), los canales 6 y 11 representan un $37,8 \%$ y canal 7 un $25,0 \%$ de la audiencia, es decir un $62 \%$ de la audiencia nacional. 
Tabla 1.

Grupos de Poder Mediáticos en Radio, Costa Rica.

\begin{tabular}{|c|c|c|}
\hline Grupo Radial & Emisoras de Radio & Propietario(s) \\
\hline Central de Radios & $\begin{array}{l}\text { Best F.M.; Radio Reloj; } \\
\text { Monumental; Radio Disney; } \\
\text { EXA; La mejor; Sonora; Joya; } \\
\text { Zeta; Alajuela, Heredia, Pacífico } \\
\text { y Managua (13) }\end{array}$ & Ángel González \\
\hline $\begin{array}{l}\text { Grupo Latino de } \\
\text { Radiodifusión }\end{array}$ & $\begin{array}{l}\text { ADN; Bésame y Los } 40 \\
\text { principales (3) }\end{array}$ & $\begin{array}{l}\text { Manuel Fco. Jiménez Echeverría } \\
\text { Familia De Polanco (España) } \\
\text { Julio Mario Santo Domingo } \\
\text { Pumarejo (Colombia) }\end{array}$ \\
\hline Grupo Omega & $\begin{array}{l}\text { Radio Omega; Vox; IQ; Tú } \\
\text { Radio (4) }\end{array}$ & Jorge Hernández Ramírez \\
\hline $\begin{array}{l}\text { Cadena Radial } \\
\text { Costarricense }\end{array}$ & $\begin{array}{l}\text { 94, 7; Azul; 91.5; 103.1; 95.9; } \\
\text { 89.1; 979; 90.3; Radio La } \\
\text { Libertad (10) }\end{array}$ & $\begin{array}{l}\text { Alexander Tena Sotela } \\
\text { Roxie Blen } \\
\text { Andrés Quintana }\end{array}$ \\
\hline $\begin{array}{l}\text { Cadena de } \\
\text { Emisoras Columbia }\end{array}$ & $\begin{array}{l}\text { Radio Puntarenas; Columbia; } \\
\text { 95.5 Jazz; } 911(5)\end{array}$ & $\begin{array}{l}\text { Carlos Alberto Alfaro Mcadam } \\
\text { Arnoldo Alfaro Chavarría }\end{array}$ \\
\hline
\end{tabular}

Fuente: elaboración propia a partir de datos en línea de cada empresa

En el caso de la familia Picado Cozza ${ }^{4}$, esta ha ampliado sus horizontes empresariales en turismo (Hotel Punta Islita), el fútbol (Deportivo

4. Olga Cozza de Picado, René Picado y Paula Picado. Saprissa) y en asociación con Manuel Francisco Jiménez Echeverria accionistas de JBQ) en la empresa Producciones Talamanca Verde S.A. (Murillo, 2004; Chaves, 2011).

En prensa escrita la realidad tampoco es prometedora. La República que nació en 1950, inició un proceso de venta desde el año 1992 hasta su compra total en 1996 por parte de la corporación canadiense Hollinger, Inc. Sin embargo, en el año 2007 esta corporación canadiense vendió toda su participación a SRB CR Limitada, propiedad de Alfred Blase y su esposa Rosemary Flemming Engels (Rojas, 2007).

El Grupo Extra, propiedad de William Gómez posee El Diario Extra y la Prensa Libre, que junto con el canal Extra TV 42 y Radio América constituyen un fuerte grupo mediático que en el mediano plazo ha venido pisando los talones del Grupo Nación.

El auge sobre todo del Diario Extra, ha hecho que el Grupo Nación haya recurrido a la apertura del diario La Teja, con el fin de someter al primero a una estrategia de desplazamiento horizontal. Junto con La Teja, el Grupo Nación controla La Nación, Al Día y el semanario El Financiero, así como una línea importante de producción de revistas (Soho, Perfil, Sabores, Su Casa). 
5. En 1956 la Florida Ice \& Farm Co. S.A propietaria de Traube compró la Cervecería Ortega por un monto de 12 millones de colones lo que hasta entonces era la transacción más grande vista en Costa Rica y desde ese momento consolidó el único emporio/oligopolio de producción de cerveza y alcohol no estatal en Costa Rica.

6. En julio de 2009, Los Olivos S.A. subsidiaria de La Nación vendió su participación que alcanzaba el $39,49 \%$ de las acciones.
De acuerdo con los datos aportados por Segnini (2009), el Grupo Nación controla el 63,6 \% de la circulación con sus periódicos La Nación y Al Día, mientras el Diario Extra ocupa un 31,4\%, es decir, en prensa escrita la concentración está dada por dos grupos; un oligopolio.

\section{El Grupo Nación: el que todo lo tiene y del que todo mundo habla}

Nacida del seno de una de las familias más poderosas de Costa Rica con grandes terrenos dedicados al café, la caña, el arroz, y además la producción de cerveza ${ }^{5}$, La Nación y hoy el Grupo Nación S. A. constituye el grupo de poder mediático más importante de Costa Rica. Este grupo reporta ingresos para el año 2010 de \$ 67 millones y un millón trescientos mil lectores de sus tres periódicos base (La Nación, Al Día y La Teja), 113,130 visitas únicas diarias a su portal digital, utilidades netas de $\$ 8,5$ millones en 2009 y $\$ 4,5$ millones en 2010, el Grupo Nación aglutina a buena parte de los grupos de poder económico más importantes en Costa Rica (Grupo Nación, 2010).

Además de sus alianzas con Prisa y Caracol, ha expandido su capital en la región, en Guatemala (Siglo XXI y Al Día ${ }^{6}$ ), en Panamá (Nueva Prensa Económica S.A. y Bloque Activo Centroamericano S. A.); Honduras (ABC de Honduras); El Salvador (Comunicación Integral El Salvador S. A.) y Nicaragua (Distribuidora de Papeles y Cartones).

A nivel nacional, sus principales accionistas (Familia Jiménez) han ampliado sus inversiones en la industria inmobiliaria y turística (Ecodesarrollo, Desarrollo Hoteleros Guanacaste Reserva Conchal, el Hotel Four Seasons; Los Olivos Desarrollo Inmobiliario), la importación y venta de vehículos de lujo (EUROAUTOS y Automotriz Alemana); papel y cartón (PAYCA) y en los dispositivos de navegación satelital (Navegación Satelital S. A.) (Fournier, 2009; Grupo Nación, 2010).

También, y en la lógica de la creciente financialización de los grupos de poder, el Grupo Nación y en particular sus principales accionistas (Familia Jiménez) han constituido históricamente la base de la elite financiera y bancaria nacional ${ }^{7}$ y ha logrado aglutinar a un buen número de "banqueros y financistas criollos" entre sus filas (Liberman, Baruch, Dent, Vargas, de Paula, Guzmán Chacón, Chavez Bolaños, Montealegre Saborío, entre otros) (ver Tabla 2). 
Tabla 2

Miembros de Junta Directiva del Grupo Nación y su relación con puestos públicos

\begin{tabular}{|c|c|c|c|}
\hline Nombre & $\begin{array}{c}\text { Cargos Grupo } \\
\text { Nación }\end{array}$ & Actividad Económica - Empresas & Cargo Público \\
\hline Eduardo Lizano Fait & $\begin{array}{l}\text { Vicepresidente } \\
\text { Prensa } \\
\text { Económica S. A. }\end{array}$ & $\begin{array}{l}\text { Miembro fundador Academia } \\
\text { Centroamericana }\end{array}$ & $\begin{array}{l}\text { Presidente del Banco Central. } \\
\text { Coordinador del Equipo } \\
\text { Económico del Gobierno } \\
\text { Pacheco de la Espriella }\end{array}$ \\
\hline $\begin{array}{l}\text { Eduardo René } \\
\text { Ulibarri Bilbao }\end{array}$ & $\begin{array}{l}\text { Director de La } \\
\text { Nación } \\
\text { Vocal }\end{array}$ & Vocal Grupo Aldesa & $\begin{array}{l}\text { Embajador de Costa Rica ante } \\
\text { la ONU } \\
\text { Miembro del Sistema Nacional } \\
\text { de Acreditación de la Educación } \\
\text { Superior, SINAES. } \\
\text { Vicepresidente de PANIAMOR }\end{array}$ \\
\hline $\begin{array}{l}\text { Francis Durman } \\
\text { Esquivel }\end{array}$ & Vocal & $\begin{array}{l}\text { Durman Esquivel Industrial de } \\
\text { Nicaragua S. A. } \\
\text { Inversiones Suramericanas S.A. } \\
\text { Extruvensa S. A. } \\
\text { Transworld Industries Corporation } \\
\text { De Investment Group Sarl } \\
\text { PANEL -EX S. A. } \\
\text { Durman Esquivel S. A., (Panamá) } \\
\text { Durman Esquivel S. A., (Honduras) } \\
\text { Durman Esquivel S. A. DE C.V. } \\
\text { (México) } \\
\text { Inmobiliaria Interandina (Perú) } \\
\text { Perforación y Conducción de Aguas } \\
\text { S.A. PERCASA) } \\
\text { Corporación Dureco S. A. } \\
\text { (Guatemala) } \\
\text { Provinil (Brasil) } \\
\text { PVC Celta (Colombia) }\end{array}$ & ------ \\
\hline $\begin{array}{l}\text { Francisco de Paula } \\
\text { Gutiérrez }\end{array}$ & $\begin{array}{l}\text { Secretario Prensa } \\
\text { Económica S. A. }\end{array}$ & $\begin{array}{l}\text { Directivo de Banco de COFISA, } \\
\text { Costa Rica, Directivo de FUNDES, } \\
\text { Costa Rica Directivo de ACORDE, } \\
\text { Costa Rica. } \\
\text { Directivo de Atlas Eléctrica, Costa } \\
\text { Rica, Directivo de RICALIT S.A. } \\
\text { Presidente de la Junta Directiva de } \\
\text { las empresas del Grupo Financiero } \\
\text { SAMA } \\
\text { Miembro de la Junta Directiva de la } \\
\text { Corporación INCSA } \\
\text { Miembro firma Consejeros } \\
\text { Económicos y Financieros S.A. } \\
\text { (CEFSA) }\end{array}$ & $\begin{array}{l}\text { Presidente del Banco Central de } \\
\text { Costa Rica } \\
\text { Ministro de Hacienda } \\
\text { Directivo de Banco de Fomento } \\
\text { Agrícola, Costa Rica }\end{array}$ \\
\hline $\begin{array}{l}\text { Francisco Guzmán } \\
\text { Chacón }\end{array}$ & Tesorero & $\begin{array}{l}\text { Tesorero Corporación Financiera } \\
\text { Miravalles }\end{array}$ & ------ \\
\hline $\begin{array}{l}\text { Jaime Manuel } \\
\text { Jiménez Solera }\end{array}$ & Director & $\begin{array}{l}\text { Presidente Jotabequ } \\
\text { Veintiuno Bienes Raíces S.A. }\end{array}$ & ----- \\
\hline $\begin{array}{l}\text { Javier Chávez } \\
\text { Bolaños }\end{array}$ & Vocal & $\begin{array}{l}\text { Presidente ALDESA ACORDE, } \\
\text { ECOANALISIS } \\
\text { EL FINANCIERO, Agencia de viajes } \\
\text { ALDESA TURISMO S.A., FUCODES, } \\
\text { ALDESA VALORES }\end{array}$ & $\begin{array}{l}\text { Ministro de Obras Públicas y } \\
\text { Transportes. Además, fue } \\
\text { miembro de las siguientes } \\
\text { organizaciones: Junta Directiva } \\
\text { de Recope, la Bolsa Nacional } \\
\text { de Valores. }\end{array}$ \\
\hline
\end{tabular}




\begin{tabular}{|c|c|c|c|}
\hline $\begin{array}{l}\text { Luis Liberman } \\
\text { Ginsburg }\end{array}$ & $\begin{array}{l}\text { Vicepresidente } \\
\text { Prensa } \\
\text { Económica S.A. } \\
\text { Miembro Junta de } \\
\text { Vigilancia }\end{array}$ & $\begin{array}{l}\text { Gerente General Scotiabank } \\
\text { Presidente de Interfin } \\
\text { Presidente de CEFSA. } \\
\text { Socio Academia Centroamericana. }\end{array}$ & $\begin{array}{l}\text { Vicepresidente de Costa Rica } \\
\text { (2010-2014) } \\
\text { Consultor del Banco Mundial } \\
\text { Asesor económico del BID } \\
\text { Viceministro de Hacienda } \\
\text { (1977-1978) } \\
\text { Miembro del Consejo del } \\
\text { Sistema Nacional de } \\
\text { Acreditación de la Educación } \\
\text { Superior (SINAES) } \\
\text { Director de la Asociación } \\
\text { Bancaria Costarricense } \\
\text { Vicepresidente de la Compañía } \\
\text { Nacional de Fuerza y Luz } \\
\text { miembro de la Junta Directiva } \\
\text { del Instituto Costarricense de } \\
\text { Electricidad }\end{array}$ \\
\hline $\begin{array}{l}\text { Mario Montealegre } \\
\text { Saborío }\end{array}$ & Secretario & $\begin{array}{l}\text { Vicepresidente ALDESA } \\
\text { Director de las compañías Ernesto J. } \\
\text { Montealegre Sucs. Ltda., } \\
\text { Montealegre Saborío Ltda., } \\
\text { Beneficiadora San Pablo S.A. e } \\
\text { Inversiones Monsa S.A., Sur Química } \\
\text { S.A. (Pinturas Sur), Tiendas La } \\
\text { Gloria S.A., y de la Cámara } \\
\text { Costarricense de Emisores de Títulos } \\
\text { Valores. } \\
\text { Gerente general del Banco de San } \\
\text { José S.A. }\end{array}$ & ------ \\
\hline $\begin{array}{l}\text { Thomás Dueñas } \\
\text { Leiva }\end{array}$ & Vocal & Presidente ESCO & $\begin{array}{l}\text { Embajador en Estados Unidos } \\
\text { Ministro de Economía, Industria } \\
\text { y Comercio y Ministro de } \\
\text { Comercio Exterior. } \\
\text { Presidente de la Junta Directiva } \\
\text { de la Promotora de Comercio } \\
\text { Exterior (PROCOMER). } \\
\text { Presidente CINDE } \\
\text { Vicepresidente de la } \\
\text { Organización Mundial de } \\
\text { Comercio (OMC). }\end{array}$ \\
\hline $\begin{array}{l}\text { Thomás Gilmore } \\
\text { Miller }\end{array}$ & Director & Presidente Sardimar & ------ \\
\hline
\end{tabular}

Fuente: Elaboración propia 
También el Grupo Nación se ha caracterizado por sus vínculos con los partidos políticos y en específico con gobiernos, ya no solo del Partido Unidad Social Cristiana (PUSC), sino también y muy especialmente en las últimas dos administraciones de su histórico rival, el Partido Liberación Nacional (PLN). Así, por ejemplo, en las filas del actual gobierno del PLN y de Laura Chinchilla encontramos al antiguo director del periódico Eduardo Ulibarri hoy embajador ante Naciones Unidas y a Luis Liberman, exvicepresidente de Prensa Económica S. A., en la actualidad primer vicepresidente de la República.

Entre sus accionistas el Grupo Nación da acogida también a buena parte de la élite económica costarricense cuyas operaciones principales no están ligadas específicamente a los medios de comunicación, como por ejemplo Thomás Gilmore (industria de alimentos enlatados); Jaime Jiménez Solera (relaciones públicas y publicidad); Francis y George Durman Esquivel (materiales para la construcción); Rodolfo Jiménez Borbón (industria de bebidas alcohólicas y no alcohólicas); Marcelo Lebendiker Fainstein (parques industriales); Walter Kissling Gam (HB Fuller y Atlas electrodomésticos), entre otros.

Esta compleja red entre relaciones económicas, políticas y hasta familiares con los grupos de poder económicos hegemónicos en el país ha determinado que su agenda y sus acciones, como señala Fournier (2009), estén orientadas a la ampliación de los beneficios de sus asociados y a la consolidación del proyecto neoliberal.

De lo anterior, es clarísimo el papel desempeñado por el diario La Nación durante el año 2007, año del referéndum en el cual Costa Rica decidía votar sí o no al Tratado de Libre Comercio con los EE.UU (TLC). De acuerdo con Fournier (2009), La Nación fue el medio impreso que más favoreció por un lado su aprobación y por otro lado mejor silenció a la oposición utilizando mecanismos de persuasión posicionando los discursos del miedo como tecnología de poder. "En esta coyuntura del TLC, el Sí no ha sido la bandera de un partido. Lo ha sido de élites empresariales y corporativas cuyo portavoz y en ocasiones articulador es La Nación" (Sandoval, 2007. Citado en Fournier, 2009, p. 18).

\section{Perspectivas}

Los profundos cambios estructurales en la economía costarricense a partir de los 80, implicaron un quiebre estructural con el anterior modelo agroexportador. Esto ha tenido amplias repercusiones en muchas dimensiones de la vida. Si bien existe literatura importante que analiza estos cambios, los grupos de poder en Costa Rica en general, y sus vínculos con los medios de comunicación masiva en particular, no han sido estudiados con detenimiento. Sin embargo, con este artículo se quiere estimular un debate que podría conllevar a nuevas líneas investigativas que problematizan el papel de los medios de comunicación masiva en función del modelo económico. 
Pensar, por ejemplo, los cambios en las relaciones entre los partidos políticos y los medios de comunicación desde una perspectiva comparativa durante los períodos en que los medios impresos eran una voz particularizada de los partidos políticos (período pre 1948) y durante el período en el cual los medios de comunicación fundan contradictorias relaciones con los gobiernos (período post 1948) ¿Cuáles eran y cuáles son ahora, los intereses de las élites económicas y políticas en el control de los medios de comunicación? ¿Hasta qué punto corresponden sus lógicas a lo nacional o, más bien, a lo transnacional? ¿Dónde están las fronteras entre libertad de prensa y libertad de discurso? ¿Cuánto sí o cuánto no determina el capital el establecimiento de agenda en los medios de comunicación en Costa Rica? ¿Cuál es su papel en la "derechización" de Costa Rica? Estas y otras preguntas podrían hacerse en futuras investigaciones que enlacen el tema de los grupos de poder y los medios de comunicación, su transnacionalización, mediada ya no únicamente por la propiedad, sino también por las fuentes y los contenidos.

Este primer abordaje al tema de la nueva economía y administración gerencial de los medios de comunicación da para pensar que quienes administran hoy los medios de comunicación no responden a estructuras añejas, sino, por el contrario, demuestran su constante renovación en torno no solo a sus productos, sino también sus inversiones y sus alianzas.

El tema de las alianzas inter-elites aunado a la diversificación de las inversiones y el posicionamiento de un "nosotros particular", junto con una agenda mediática determinada, asegura y limita horizontes en torno a noticias e informaciones restringidas a los intereses de los grupos y no necesariamente a los intereses del país.

Asimismo, queda demostrado que los procesos de transnacionalización de la economía en Costa Rica durante el NME no han excluido a las economías de los medios de comunicación costarricenses, los casos particulares de Ángel González y las alianzas del Grupo Nación con el Grupo Prisa dejan constancia de lo anterior.

Cabría preguntarse entonces el por qué de los silencios en torno a los grupos de poder en los medios de comunicación y en el nuevo modelo económico. Por ahora, esta investigación abre una puerta para su discusión.

\section{Bibliografía}

Chaves, A. (11 de enero del 2011). Inauguración del Estadio Nacional, negocio de pocos. Recuperado de http://www.diarioextra.com/2011/enero/11/espectaculos01.php 
Durand, F. \& Campodónico, H. (2010). Poder empresarial y sociedad civil en Suramérica. Entre el diálogo y el enfrentamiento. Lima: CEDAL.

Fournier-Pereira, M. (2009). Persuasión y discurso. Análisis comparativo en prensa nacional en torno a noticias sobre el Tratado de Libre Comercio. (Tesis inédita para optar por el grado de licenciatura). Universidad de Costa Rica, San José, Costa Rica.

Grupo Nación. (2010). El crecimiento sostenible se abona con resultados. Informe Anual La Nación S.A. y sus Subsidiarias.

Hidalgo, A. (2003). Las políticas de ajuste estructural. En: Costa Rica en evolución. Política económica, desarrollo y cambio estructural del sistema socioeconómico costarricense (1980-2002). San José: Editorial de la UCR.

León, A. (2009). Los grupos de poder económico costarricenses ¿Quiénes y cómo son?: el caso del sector financiero. (Informe Final de Investigación). San José, Costa Rica: Instituto de Investigaciones Sociales de la Universidad de Costa Rica, Mimeo.

Molina, X. (2007). Medios de comunicación y TLC. Recuperado de http://www.una.ac.cr/campus/ediciones/2007/marzo/2007marzo_p ag19b.html

Mora, H. (2006). Los acuerdos de inversión en los Tratados de Libre Comercio: de vuelta al AMI. El caso del TLC entre los Estados Unidos y los países de Centroamérica. Revista de Relaciones Internacionales, 71-72, 25-53.

Murillo, M. (2004). La Nación y Canal 7 poseen una empresa junta. Recuperado de http://esociales.fcs.ucr.ac.cr/biblioteca/boletin_esoc/alfabet/M/Medi os $\% 20 \mathrm{de} \% 20$ comunicacion $\% 20$ corruptos.pdf

Ovares, I \& León, P. (1979). La estructura de poder en los medios de comunicación en Costa Rica. (Tesis de licenciatura). Universidad de Costa Rica, San José, Costa Rica.

Ramírez, A. (2009). La gota que derramó el vaso: caracterización del desarrollo y la conflictividad socio ambiental vinculada a los recursos hídricos en Guanacaste. Costa Rica: Mimeo.

Robinson, W. (2003). Transnational conflicts. Central America, Social Change and globalization. Londres: Verso editorial.

Robinson, W. (2010). Global capitalism. Theory and the emergence of transnational capitalist class. Baltimore: The Johns Hopkins University Press. 
Robles, F. En prensa (2011). Los de entonces, ya no son los mismos. Acumulación por desposesión en El Salvador y Costa Rica en la última década. Anuario de Estudios Centroamericano $\mathrm{N}^{\circ} 37$.

Robles, F. (2009-2010). Nuevos espacios de acumulación: modelo de ajuste estructural en El Salvador y Costa Rica (1980-1999). Revista de Ciencias Sociales, 128-129.

Rockwell, R \& Janus, N. (2003). Media Power in Central América. Urbana: University of Illinois Press.

Rojas, J. (10 de abril del 2007). Canadienses venden su parte de La República. http://wvw.nacion.com/ln_ee/2007/abril/10/economia1057472.html

Rovira, J. (2004). El nuevo estilo nacional de desarrollo de Costa Rica y el TLC. En Florez-Estrada, M. \& Hernández, G. (Eds.), TLC con Estados Unidos. Contribuciones para el debate. ¿Debe Costa Rica aprobarlo? (pp.309-346) San José, Costa Rica: Instituto de Investigaciones Sociales de la Universidad de Costa Rica.

Sandoval, C. (2007). Vísperas del Reférendum: la posición de los medios. Revista Envío, 306.

Saxe, J. (2002). La compra-venta de México. México D.F.: Editorial Plaza $\&$ Janés.

Segnini, G. (2009). Los monopolios de la verdad en Centroamérica. Buenos Aires: Prometeo Libros.

Segovia, A. (2004). Centroamérica después del café: El fin del modelo agroexportador tradicional y el surgimiento de un nuevo modelo. Revista Centroamericana de Ciencias Sociales, I (2) ,5-38.

Segovia, A. (2005). Integración real y grupos de poder económico en Centroamérica: implicaciones para el desarrollo y la democracia de la región. San José: Fundación Friedrich Ebert.

Sojo, C. (1991). La utopía del estado mínimo: Influencia de la AID en Costa Rica en los años ochenta. San José: CRIES/CEPAS.

Sojo, C. (1992). La mano visible del mercado. San José: CRIES/CEPAS.

Sojo, C. (Comp.)(2006). Pobreza, exclusión social y desarrollo. Visiones y aplicaciones en América Latina. Cuadernos de Ciencias Sociales, N¹42. San José: FLACSO.

Vargas, L. (2002). Costa Rica: liberalización y ajuste o la autodestrucción del neoliberalismo. San José: EUNED. 
Vargas, L. (2008). La economía costarricense en los inicios del siglo XXI. En Santana, A.(coord.), Costa Rica en los inicios del siglo XXI (pp. 99-126). México: Centro de Investigaciones sobre América Latina y el Caribe (CIALC) de la Universidad Nacional Autónoma de México.

Voorend, K \& Robles, F. (2011). La mano de obra inmigrante en la economía costarricense en tiempos de crisis. La demanda de mano de obra migrante y las condiciones laborales de las personas inmigrantes en construcción, agricultura y transporte. San José: Organización Internacional para la Migración (OIM). Ministerio de Trabajo y Seguridad Social (MTSS). 


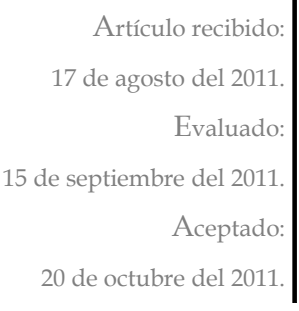

20 de octubre del 2011.

\section{El fenómeno del cambio Climate Change: A critical climático: Un análisis crítico analysis from Ecological desde la perspectiva de la Economy Economía Ecológica}

RESUMEN

Este es un análisis crítico $y$ It is a critical and comparative analysis comparativo entre la Economía between environmental economics and Ambiental y la Economía Ecológica, ecological economics, and then para luego establecer las implicaciones establish the implications for policy sobre los instrumentos de política a fin instruments to deal with the enfrentar el fenómeno del cambio phenomenon of climate change. From climático. A partir de la comparación se the comparison looks at some tools analizan algunos instrumentos used by the Environmental Economics empleados por la Economía Ambiental for Decision-making, given the specific para la toma de decisiones, que dadas environmental problems and limitations las particularidades de los problemas of neoclassical economics in the ambientales y las limitaciones del economic field does not provide the pensamiento neoclásico en el campo desired results. From Ecological económico no brinda los resultados Economics approaches are how deseados. Desde la Economía decisions must be made in the Ecológica se hacen planteamientos de economic field, which goes largely a cómo deben tomarse decisiones en el return to the consideration of the campo económico, lo cual pasa en physical world and not focus on the gran medida por un retorno a la exchange consideración del mundo físico y no concentrarse en el intercambio.

Palabras Clave

KEY WORDS

Economía ambiental, economía ecológica, ecosistema, leyes de la termodinámica, toma de decisiones, políticas ambientales

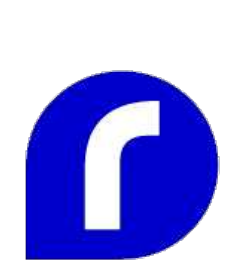

Roberto Jiménez Gómez
Doctor en Gobierno y Políticas Públicas, Universidad de Costa Rica (UCR). Máster en Política Económica en el Centro Internacional en Política Económica para el Desarrollo Sostenible. Licenciado en Economía, Universidad Nacional (UNA). Director Planeamiento Ambiental del Instituro Costarricense de Electricidad (ICE). Investigador del Centro en Investigación en Cultura y Desarrollo (CICDE) de la Universidad Estatal a Distancia (UNED) en temas de cambio climático y desarrollo económico. Correo electrónico: robertojg@racsa.co.cr 


\title{
El fenómeno del cambio climático, un análisis crítico desde la perspectiva de la Economía Ecológica
}

\begin{abstract}
Introducción
El presente trabajo tiene como objetivo analizar algunos de los postulados fundamentales de la Economía en el campo ambiental desde la perspectiva de la Economía Ambiental y la Economía Ecológica y las implicaciones que estos tienen sobre las propuestas de política planteadas para enfrentar el fenómeno del cambio climático. El trabajo inicia planteando la problemática del deterioro ambiental y cómo este se asocia con el patrón de crecimiento económico de los últimos dos siglos de la humanidad. La segunda sección analiza algunos conceptos básicos que distinguen la perspectiva de la Economía Ecológica y la Economía Ambiental.
\end{abstract}

La tercera sección, busca asociar la problemática del crecimiento económico con la demanda energética a partir de algunos de los postulados centrales de la Economía Ecológica. Seguidamente, en la sección cuarta, se hace el análisis crítico de los conceptos o variables esenciales aplicados en la Economía para la toma de decisiones que tienen una importante incidencia en la sostenibilidad ambiental local y planetaria.

Por último, se plantean algunas consideraciones finales en las cuales se destacan las diferencias conceptuales y metodológicas y la dificultad para que la Economía Ambiental y la Economía Ecológica puedan lograr una síntesis teórica metodológica, al basarse en premisas sustancialmente distintas, pese a que tienen un objeto de estudio común. 


\section{El deterioro ambiental y la Economía}

La Economía en su raíz epistemológica tiene que ver con el cuidado de la casa, es decir, del entorno en donde los seres humanos (esta por naturaleza es antropocéntrica). Sus logros en esa tarea principal que se le ha fijado de cuidar el espacio, los ecosistemas y los recursos para las actividades y la vida humana, han sido pocos.

La Economía, como ciencia, desarrolló una serie de instrumentos e ideas en diversos ámbitos, no siendo el campo ambiental y sus limitaciones un elemento relevante en sus preocupaciones, conforme se fue consolidando el pensamiento económico actual. De igual forma, los procesos de crecimiento económico fueron dejando su huella en el planeta, sin que la Economía pudiera integrar el daño que los seres humanos causaban de forma más intensa e insostenible sobre el entorno ambiental.

La Economía ha asumido por lo general, el supuesto implícito de que las actividades económicas se realizan en un ecosistema infinito, separado del mundo físico, por ello no ha tenido presente la posibilidad de:

a) Agotamiento de los recursos naturales.

b) Alcance de los límites de capacidad de asimilación del ecosistema.

c) Afectación significativa de la calidad ambiental y la vida misma.

d) Manifestación de daños irreparables en el planeta, por ejemplo por el cambio climático.

Las transformaciones que el sistema económico ha llevado a cabo en los últimos 200 años, producto de la industrialización, son de una magnitud y características tan especiales que han generado efectos significativos en el planeta, cuyas consecuencias son cada vez más evidentes, poniendo en peligro la reproducción de ecosistemas sustentadores de la vida misma y por ello del sistema económico.

Los análisis históricos de nuestras culturas tienen una absoluta desconsideración del tiempo biológico. El tiempo biológico es la escala de medición de la evolución biológica y sus unidades de medida, al estudiar el pasado, son del orden de millones de años (Elizalde, 1997, párrafo 6).

En términos ecológicos, la situación del hombre en la Tierra ha pasado de un joven "mundo vacío" (vacío de gente y sus artefactos), pero lleno de capital natural, a un "mundo lleno" maduro, donde las necesidades, percibidas o no, conllevan a una mejora cuantitativa de la conexión entre sus componentes (desarrollos), alianzas cooperativas y flujos de desechos reciclados en un "circuito cerrado". El concepto de capital natural parte de una concepción antropocéntrica, la cual por sí misma es la visión de la mayoría de enfoques que desde la economía se tiene, es una concepción interesada, desde la perspectiva de los seres humanos 
en sociedad y llevando a cabo actividades económicas. (Costanza, Cumberland, Daly, Goodland y Norgaard, 1999).

Del mismo modo, la materia y la energía no se crean ni se destruyen, solo se transforman (ley de la conservación). La generación de residuos es algo inherente a los procesos de producción y consumo. La segunda ley, la entropía, plantea que la materia y la energía se degradan continua e irreversiblemente desde una forma disponible a otra no disponible, o de una forma ordenada a otra desordenada, independientemente de si la usamos o no. Estos aspectos básicos de la física no han sido considerados por la teoría económica convencional, por el contrario, esta se ha concentrado en las señales de precios que no muestran los daños a los ecosistemas.

Por lo anterior la dotación natural de energía disponible se compone de dos elementos esenciales distintos. El stock de baja entropía (o energía libre u ordenada) en la esfera terrestre y el flujo de energía solar. Ambos están sujetos a degradación, se usen o no. El uso del stock de energía se da con mucha más intensidad en el planeta a partir de la revolución industrial. El capital natural, con sus reservas de recursos fósiles, ha sido explotado sin que se tenga en cuenta de forma seria las formas, si existen, de sustitución de este (Common y Stagl, 2008).

Para Common y Stagl (2008) el ecosistema es un conjunto de poblaciones de organismos que interactúan entre sí y su medio abiótico. Por otra parte, indican que la biosfera ha recibido los mayores impactos por las actividades humanas, por lo cual ha recibido una atención especial por parte de enfoques como el de la Economía Ecológica. Para estos autores la biosfera es el ecosistema global considerado en su totalidad, el cual ha evolucionado durante la existencia de la Tierra y lo seguirá haciendo.

El subsistema económico ya ha alcanzado o excedido importantes límites en lo que se refiere a la capacidad de uso de los recursos y la capacidad de asimilación de los vertederos. Evidencia de ello es, de acuerdo con Common y Stagl (2008):

1. La apropiación humana de la biomasa.

2. La degradación de la tierra.

3. La ruptura de la capa de ozono.

4. La extensión del subsistema económico muy grande con relación al ecosistema global.

5. Del ecosistema depende la capacidad de regeneración y de asimilación de los recursos.

6. La capacidad de asimilación de los vertidos está siendo sobrepasada.

7. El crecimiento aconsejado por diversos convenios e informes científicos escapa incluso a los límites citados anteriormente.

8. Hay una persistente pérdida de la biodiversidad 
Sin duda los procesos de producción y consumo que la humanidad y en especial algunos países han establecido llevan a serios efectos ecológicos. Dentro de las razones que explican esta situación se destacan las siguientes (Constanza, et tal, 1999):

- $\quad$ Los patrones de evolución de la naturaleza tienen ritmos, patrones y características muy distintas de los procesos cada vez más intensos, complejos y de mayor magnitud que tienen las actividades económicas, las cuales tienen diversos efectos ambientales.

- $\quad$ La ausencia de consideración de los aspectos ambientales en los temas de crecimiento y desarrollo, ha llevado a dejar de lado los límites físicos y las consecuencias que sobre el mismo ser humano podrían tener las transformaciones y la destrucción de los ecosistemas naturales.

- El crecimiento económico y la calidad de vida no consideran como un determinante crítico la magnitud y relaciones de los ecosistemas, llevando a que diversos ambientes frágiles, recursos naturales y la calidad ambiental sean groseramente afectados e incluso destruidos.

Estos hechos hacen necesario replantear el sistema económico, para tratar de hacerlo más sostenible, desmaterializado, mediante nuevas formas de realización y mejoramiento de la calidad de vida, congruentes con un planeta que requiere tener presente las restricciones que el ecosistema plantea.

Contrario a las prioridades que la Economía Neoclásica tradicional ha dado a estos elementos (relación actividades humanas y ambiente), están en el fundamento mismo de la Economía como ciencia, el tener recursos limitados, usos alternativos, la satisfacción, el bienestar, las posibilidades de producción presentes y futuros, el capital creado por el hombre (aquellas que con base en insumos del planeta, el trabajo y conocimiento humano permiten contar con herramientas de trabajo, equipos, infraestructura y entornos artificiales) y el capital natural (conjunto de ecosistemas naturales, recursos naturales, entorno natural existente en el planeta por procesos ecológicos, climáticos y geológicos naturales).

Los objetos de estudio indicados previamente son intrínsecos a la ciencia económica, más allá de visiones limitadas de esta ciencia, que la han llevado a un pensamiento restringido y a ver únicamente los valores de cambio, es decir, la apariencia y no la esencia de la Economía (sector real, la distribución y su relación con el ecosistema). Esta situación en nada le ha ayudado a la Economía a su desarrollo y a su aporte a la solución de los grandes problemas de la sociedad actual.

La ingente necesidad de contar con un abordaje desde la Economía de los temas ambientales fundamentales en la sociedad actual, ha llevado a que se den diferentes visiones de cómo considerar el ambiente en la 
Economía. En la siguiente sección se hará una comparación de las categorías básicas que diferencian la Economía Ambiental de corte neoclásico y la Economía Ecológica cuyos fundadores han querido ver como un campo de conocimiento transdisciplinario.

\section{Los fundamentos de la Economía Ecológica y la Economía Ambiental y sus implicaciones de política}

La forma en que se aborde la problemática ambiental, su importancia y métodos tienen importantes efectos sobre las actuaciones de los seres humanos y sobre las medidas que las sociedades puedan tomar para prevenir, mitigar o compensar potenciales efectos ambientales negativos causados por las actividades humanas. Para esclarecer desde la perspectiva teórica estos aspectos, a continuación se analizan los fundamentos de la Economía Ecológica y Ambiental en su relación con el ecosistema global.

La Economía Ambiental. El pensamiento económico neoclásico ha desarrollado sus planteamientos y propuestas para la relación entre las actividades económicas y el ambiente haciendo uso del análisis marginalista (Azqueta y Field, 1996). Similar a otros objetos de estudio, estos planteamientos generan una serie de aplicaciones al campo ambiental, cuyos fundamentos y supuestos llevan a un tipo de soluciones cuestionables para los problemas ambientales que surgen de las actividades económicas.

En síntesis los postulados básicos que se pueden deducir relacionados con el ambiente en la Economía Neoclásica establecen, según Common y Stagl (2008):

- El precio mide la escasez relativa (oferta, demanda).

- Se basa en el análisis marginal.

- Se dejó de lado modelos de crecimiento a largo plazo.

- Su objetivo es definir las leyes que rigen la actividad económica en una situación particular, la Economía de mercado o capitalista.

- Se parte de que las personas son racionales en el proceso de decisión y egoístas en tanto buscan optimizar sus beneficios, sin considerar la colectividad.

- Hay un óptimo paretiano, que define un nivel máximo de bienestar social para la sociedad.

- El Estado interviene por fallas del mercado, para bien público, lo cual se considera una situación particular y no común.

- Las personas no se ven con obligaciones éticas o morales.

Para la Economía Neoclásica, la intervención del Estado se justifica únicamente por la existencia de fallos del mercado, es decir, actividades o sectores de actividad, donde la Economía libre de mercado no logra satisfacer las necesidades de la sociedad, o no puede hacerlo en forma 
eficiente. Esto es visto como una situación particular no generalizada. Esta situación implica que los costos y beneficios de las actividades económicas no son consideradas de forma precisa, generando un incorrecto uso de los recursos. Dentro de las fallas del mercado se encuentran: competencia imperfecta, bienes públicos, externalidades, costos de transacción y asimetrías de información (Stiglitz, 1998).

En las actividades económicas y su relación con el ambiente surge de forma más generalizada lo que la Economía Neoclásica reconoce como externalidades, en especial las negativas. Una externalidad se da, cuando la producción o el consumo de un bien afectan directamente a consumidores o empresas que no participan en su compra ni en su venta, y cuando esos efectos no se reflejan totalmente en los precios de mercado.

Otra forma de definir las externalidades es como actividades que afectan a otros para mejor o para peor, sin que los responsables paguen por ellas o los afectados sean compensados (Lozeco, Tarragona y López, 2010).

Es importante recordar los teoremas sobre los cuales se fundamenta la Economía del bienestar. En primera instancia debe plantearse en qué sentido y en qué condiciones conducen los mercados competitivos a la eficiencia económica: la respuesta se basa en los dos teoremas fundamentales de la Economía del bienestar. El primer teorema establece que en determinadas circunstancias, los mercados competitivos dan lugar a una asignación de los recursos que tiene una propiedad muy especial: no existe ninguna reasignación de los recursos (ningún cambio en la producción y del consumo) que pueda mejorar el bienestar de una persona sin empeorar, al mismo tiempo, el de otra.

Las asignaciones de los recursos que tiene la propiedad de no poder mejorar el bienestar de una persona sin empeorar el de alguna otra se denominan asignaciones eficientes en el sentido de Pareto/óptimos de Pareto (la eficiencia en el sentido de Pareto es el concepto al que suelen referirse los economistas cuando hablan de la eficiencia).

Un segundo teorema indica que decir que la Economía es óptima en el sentido de Pareto no dice nada sobre cómo se lleva a cabo la distribución de la renta. Si no satisface la distribución de la renta que genera el mercado competitivo, no es necesario dejar de utilizarlo. Lo único que hay que hacer es redistribuir la riqueza inicial y dejar actuar al mercado competitivo.

Cada uno de estos elementos está sujeto a una gran polémica desde la perspectiva ética, epistemológica y práctica. En primera instancia, pensar que es posible darle valor por medio de precios a los componentes del medioambiente es una atribución que tiene una fuerte connotación ética, para muchos este tiene un valor intrínseco y no debe expresarse en 
términos monetarios. Una perspectiva antropocéntrica, indicaría que las cosas, incluido el medioambiente, tienen valor en tanto el ser humano se los dé (Azqueta, 1994).

Ahora bien, si son los seres humanos los que pueden dar valor al ambiente, surge la pregunta de si son todos por igual los que pueden dar ese valor o si existen reglas diferenciales para ello.

En primera instancia la Economía Neoclásica asume que el valor es igual al precio. Así pues, quienes pueden expresar sus preferencias en motivaciones por tener o mantener los recursos naturales y el ambiente son aquellos que según la Economía Neoclásica, en su expresión de la Economía Ambiental, tienen derechos para disponer en el presente o el futuro de ellos, sea derechos de propiedad, de explotación, concesión o algún tipo de permiso.

Las votaciones que deciden qué recursos y ambiente son importantes, están ponderadas por la dotación de recursos económicos, dinero que permite adquirir derechos de posesión de los recursos o bien adquirir bienes y servicios. El valor se lo dan los agentes económicos por medio de su dotación de dinero y otros recursos económicos, no es un acto democrático ni equitativo, tanto en el ámbito social, internacional o intergeneracional.

A partir de estos elementos básicos que sustentan el pensamiento económico neoclásico se observa cómo dentro de esa perspectiva teórica se ha buscado dar solución a los problemas ambientales. Para ello hay dos perspectivas en la Economía Neoclásica. Por una parte, la Economía de los recursos naturales que se ocupa principalmente de lo que la Economía extrae del medioambiente y de los problemas asociados con el uso de los recursos naturales y, por otro lado, la Economía Ambiental, que tiene como áreas de interés de lo que la economía introduce en el medioambiente y de los problemas de contaminación ambiental (Common y Stagl, 2008). Nos concentraremos en la Economía Ambiental. Según Azqueta y Field (1996):

La Economía Ambiental trata del estudio de los problemas ambientales con la perspectiva analítica de la Economía. Se pudo haber pensado que la Economía se ocupa en su mayor parte de decisiones de negocios y de cómo obtener rendimientos en un sistema capitalista. Este no es el caso, ya que la Economía es, más bien, el estudio de cómo y por qué "las personas", bien sea consumidores, firmas, organizaciones sin ánimo de lucro 0 agencias gubernamentales, toman decisiones sobre el uso de recursos valiosos. (Azqueta y Field, 1996, p. 3).

De esta cita se pueden extraer algunos elementos relevantes. En primera instancia es importante, recalcar el hecho de que la Economía Ambiental emplea el mismo arsenal teórico y métodos de la Economía Neoclásica 
en el tratamiento de temas generales, lo que implica que los precios, la optimización basada en principios marginales, el uso de la microeconomía y econometría, entre otros, forman parte las técnicas y metodologías.

Pigou es considerado el fundador de la Economía del Bienestar y el precursor de la Economía Ambiental al establecer la distinción entre costes marginales privados y sociales, y abogar por la intervención del Estado mediante subsidios e impuestos para corregir los fallos del mercado e internalizar las externalidades.

Esa distinción entre costos privados y sociales llevó a que, ante las externalidades que se dan, se planteara la posibilidad de intervención del Estado con el fin de restablecer el óptimo económico, confiando en la capacidad de un Estado que actuaría sin errores en la búsqueda del bien común. Para ello partió de una situación ideal del modelo neoclásico que le permitía establecer ese nivel óptimo. Implícitamente en este enfoque se parte que se tiene la posibilidad de aplicar una política económica que, bajo rigurosos análisis, dé solución a los problemas, en este caso los ambientales (Lozeco, Tarragona y López, 2010).

Pigou, según Eumed (2011), partía de que el Estado tiene la potestad de corregir esta divergencia, dada su capacidad de impulsar o restringir las inversiones en dichas actividades. Los instrumentos de política pública para concretar estas correcciones son los impuestos o primas. Esta perspectiva parte de que la externalidad contiene un carácter unilateral, ya que existía un claro agente perjudicado y uno responsable.

Contrariamente, para el Instituto Ronald Coase (2000-2011) el problema de las externalidades es visto desde una perspectiva recíproca de los efectos externos. A partir de ello plantea un cambio de enfoque respecto al intervencionismo automático del Estado, basándose en que este actor también tiene sus fallos (Stiglitz, 1998).

Ronald Coase parte de que el funcionamiento del Estado tiene múltiples imperfecciones, por lo cual prefiere la acción del mercado. Retoma por tanto, el accionar del mercado como mecanismo de solución de los problemas, postergando la intervención pública como corrección de última instancia. A partir de ello, bajo la lógica del mercado, se considera que los agentes económicos pueden establecer acuerdos que puedan llevar a una disminución de la contaminación o al menos a la integración de la externalidad en el sistema de precios.

Estos dos planteamientos, el de Pigou y el de Coase, son dos vertientes centrales de la Economía Ambiental para el diseño y aplicación de políticas económicas en el campo ambiental. Cada una tiene sus deficiencias y virtudes. En general, parte de los problemas del enfoque de Pigou son las posibles fallas del Estado, la falta de efectividad de sus intervenciones, objetivos de terceros y en algunos casos la falta de información. La perspectiva de Coase tiene su cimiento en el mercado, 
por lo cual la falta de información, así como la creencia de que existe igual información y poder entre los negociadores son elementos de fondo que se deben tomar en cuenta y que atentan seriamente contra el logro de los objetivos planteados por este autor en el mundo actual. Ambos instrumentos han sido aplicados con diferentes resultados en el ámbito internacional. Como se ha visto, un aspecto central en la Economía Ambiental es cómo lograr que los precios sean los más correctos posibles, para mostrar el valor de los bienes, servicios, recursos y calidad ambiental en general. Para esto, en el ámbito microeconómico se ha desarrollado una serie de metodologías de valoración económica del ambiente, que han suscitado esperanza en algunos y críticas y rechazo de quienes, desde otras disciplinas científicas o desde perspectivas o enfoques distintos, analizan los alcances metodológicos de estas propuestas.

La diferencia entre valor de un bien o servicio ambiental y su precio son los costos o beneficios sociales o ambientales que el sistema no ha podido integrar en los costos, subvalorando, por ende, los ecosistemas afectados, y llevando generalmente a producir más y dañar más. Esta situación ocurre porque el costo está subvaluado al no considerar el valor de los recursos naturales, la calidad ambiental y contexto sociocultural afectado en los procesos de decisión de producción y consumo.

Los fundamentos de la Economía Ecológica. La Economía Ecológica es una disciplina que surgió a finales de la década de 1980 y se ha ido desarrollando en las últimas dos décadas (Hauwermeiren, 1999).

De acuerdo con Common y Stagl (2008) "La Economía Ecológica es el estudio de las relaciones entre el gobierno de la casa de los seres humanos y el gobierno de la casa de la naturaleza. Dicho de otro modo, es el estudio de las distintas interacciones entre sistemas económicos y sistemas ecológicos." (p. 1).

Se puede decir que la Economía Ecológica es una disciplina que acepta como punto de partida que el sistema económico es un sistema abierto que se interrelaciona con los ecosistemas y con los sistemas sociales, en donde se da una influencia mutua entre estos (García, 2003).

Otra perspectiva de la Economía Ecológica es que se ve a sí misma como un sistema funcional cuyo objetivo es establecer los vínculos entre los factores físicos, ambientales, biológicos y técnicos, de acuerdo con la modalidad productiva aplicada por la sociedad para satisfacer sus necesidades.

La Economía Ecológica parte de que las actividades económicas forman un subsistema (económico) del sistema ecológico (o ecosistema global) de apoyo a la vida. Por ello incluye el manejo del ámbito de la naturaleza (ecología) y la gestión realizada por el ser humano (Economía). 
Hay en la Economía Ecológica un planteamiento de suma importancia y es que, en términos ecológicos, la situación del ser humano en la Tierra ha pasado de un joven "mundo vacío" (vacío de gente y sus artefactos), pero lleno de capital natural, a un "mundo lleno" maduro, donde las necesidades, percibidas o no, conllevan a una mejora cuantitativa de la conexión entre sus componentes (desarrollos), alianzas cooperativas y flujos de desechos reciclados en un "circuito cerrado" (Common y Stagl, 2008).

Se enfatiza por parte de la Economía Ecológica que el subsistema económico ya ha alcanzado o excedido importantes límites en lo que se refiere a la capacidad de los recursos y los vertederos, llama la atención el crecimiento acelerado en magnitud y en tiempos muy cortos, lo cual plantea serios problemas a la capacidad del ecosistema de adaptarse y subsistir ante el crecimiento constante, complejo y desmedido del subsistema económico.

Dentro de los planteamientos de la Economía Ecológica está la búsqueda de una visión de futuro de un planeta sostenible, con una alta calidad de vida para todos sus habitantes, dentro de las reservas impuestas por:

1. El reconocimiento de que en el análisis de estos sistemas complejos, la incertidumbre es grande e irreductible.

2. Las instituciones y los gestores de políticas deberían ser proactivos y producir políticas simples, adaptables y que puedan llevarse a cabo, en un entendimiento completo de los sistemas. (Constanza et al. 1999)

La Economía Ecológica plantea que el optimismo en el crecimiento económico como objetivo de política económica planteado por los neoclásicos, no es necesariamente correcto en todas partes. Las razones para ello son, de acuerdo con Common y Stagl (2008):

a. El crecimiento económico a largo plazo, tal y como se ha dado, no es factible debido a la interrelación entre la Economía y el ambiente.

b. En qué medida es deseable el crecimiento económico para todas las naciones, los economistas ecológicos cuestionan el crecimiento sin límites de las economías desarrolladas y ricas, plantean que hay otras medidas del bienestar que deben ser considerados. Están de acuerdo en el crecimiento de las economías pobres, como medio para mejorar el bienestar, dadas las carencias en aspectos básicos que estas tienen, sin pensar en que deba copiar los patrones insostenibles de consumo de las sociedades desarrolladas y ricas.

Lo antes expuesto implícitamente llevaría a replantear el modelo económico de producción y consumo prevaleciente. 
A partir de los retos actuales en el campo ambiental y su relación con las actividades humanas, hay principios que en alguna medida se han desarrollado por la Economía Ecológica, los cuales pueden ayudar a analizar la problemática actual:

a. Se tiene un sistema termodinámico cerrado y un sistema económico creciente materialmente.

b. Con la economía humana como un subsistema del ecosistema, lo cual implica límites a la economía global, dada la producción de recursos biofísicos del ecosistema. (Cobb y Daly, 1993)

Para la Asociación de Economía Ecológica de España (2010), la Economía Ecológica, además de una disciplina académica y científica, se puede considerar una forma distinta de entender la realidad. Los principios básicos establecidos por este ente se pueden resumir de la siguiente manera:

- Según esta asociación la Economía Ecológica (EE) entiende el sistema económico como un sistema más de la realidad, inserto en la Biosfera y, como tal, es considerado un sistema abierto afectado por las Leyes de la Termodinámica y todas las implicaciones que esto conlleva.

- Esta asociación considera la relación entre los diferentes sistemas que componen la realidad - territorial, institucional, monetario, tecnológico y social- y realiza un análisis de la evolución conjunta y dinámica de dichos sistemas (enfoque eco-integrador y análisis sistémico-coevolutivo).

- Indica que el análisis de la EE debe considerar la dimensión física de la realidad, no únicamente la monetaria, utilizando tanto variables cuantitativas como cualitativas.

- En el ámbito de la investigación esta asociación considera que la EE promueve la formación de grupos transdisciplinares para poder comprender el funcionamiento de la realidad.

- Además, la EE está íntimamente ligada con la Ecología Política en un intento por analizar los conflictos que se derivan de la distribución desigual de los recursos y de los residuos, así como las reglas del juego que lo permiten

Estos aspectos y principios que se han planteado de la Economía Ecológica tienen implicaciones relevantes sobre los métodos, los objetivos, los alcances y las implicaciones de los estudios y enfoque en los procesos de diseño e implementación de las políticas que se pretendan diseñar en un país y en el planeta. Unido a ello, tienen importantes diferencias con respecto al abordaje que le da la Economía Neoclásica a través de la Economía Ambiental, en secciones siguientes se compararán y analizarán estas diferencias y las implicaciones que estas pueden tener sobre las políticas. 
Los precios, el valor y el mundo físico, la no internalización del valor del ambiente. Uno de los problemas fundamentales que enfrenta la sociedad actual en su relación con el ambiente, es la falta de internalización en los precios del valor de una serie de servicios ambientales, así como recursos y funciones ecológicas. Esto hace que el sistema de precios de los bienes y servicios, no brinde las señales correctas a los agentes económicos, lo cual genera una explotación excesiva, así como la contaminación y daño de esos recursos vitales para la sostenibilidad del planeta. Esto es visto por algunos como puntuales fallas de mercado, para otros es el común denominador del sistema capitalista y de las deficiencias metodológicas más relevantes de la Economía Neoclásica.

Por esta razón, la Economía Neoclásica, por medio de la Economía Ambiental, tiene como uno de sus más grandes retos buscar que el sistema de mercado y los precios sean los apropiados para orientar las decisiones hacia un modelo de crecimiento económico más sostenible. Este método o enfoque para abordar los problemas ambientales ha generado posiciones a favor y en contra. En general, se ha podido ver que la internalización de costos ambientales va en la dirección correcta, sin embargo, es insuficiente tanto por magnitud como por ámbitos que puede considerar para modificar de forma significativa los patrones de inversión, producción, consumo y ahorro de los agentes económicos.

La Economía convencional, al centrarse en los valores de cambio y dejar de lado la dimensión física sobre la cual se sustenta el subsistema económico, busca soluciones al margen o en aspectos no sustantivos de lo que suceda en la realidad biofísica. Al no considerar la realidad física (ecosistema y sus interacciones), la cual no se transa en un mercado, el ecosistema pierde importancia en las decisiones de los agentes económicos y de la colectividad, pudiendo llevar a daños irreparables en la base material sobre la cual se sustenta la sociedad humana.

Para subsanar la falta de consideración de los aspectos del ecosistema en las decisiones económicas, se han buscado formas parciales e insuficientes desde la Economía convencional. La forma en que se ha hecho, es a partir del reconocimiento de lo que se ha denominado externalidades negativas, como una forma de fallas del mercado. Dentro de ello ha asumido un papel central la valoración económica del ambiente, por medio de una serie de metodologías, algunas de las cuales han suscitado importantes críticas y debates (Azqueta y Field, 1996).

Para muchos, la externalidad va más allá de una falla, tiene que ver con la misma lógica del sistema económico que no ha tenido en cuenta todos los elementos requeridos para la reproducción de la base biofísica. Una expresión de esta situación es el cambio climático, asociado a las actividades humanas, que se ha podido percibir en las últimas décadas. 
Parte de la problemática que subyace es que el diseño de las políticas públicas es un proceso social y político, en donde los diferentes sectores sociales y económicos buscan posicionar sus criterios de acuerdo con los intereses económicos en juego. Esta situación plantea un reto adicional, el lograr tener buenas herramientas y políticas para la sostenibilidad, pero que además mediante procesos de participación social, logren el apoyo suficiente y la presión para que tengan la posibilidad de ser implementadas. Un caso relevante para Costa Rica ha sido el proyecto de ley de Recursos hídricos que diferentes sectores empresariales rechazan por la aplicación de canon de vertido y de aprovechamiento'.

Comparación entre la Economía Ambiental y la Economía Ecológica, algunos elementos básicos. A continuación se realiza una comparación general de los postulados considerados relevantes entre la Economía Ambiental y la Economía Ecológica, como dos de las principales propuestas para abordar la Economía y el ambiente.

Con respecto a la economía y el abordaje del tema ambiental, hay que considerar que:

a) La Economía convencional o neoclásica, pese a tener un objeto de estudio multidimensional, tiende a trabajar con un solo objetivo: la eficiencia económica. La Economía Ecológica, en cambio, tiene múltiples objetivos.

b) En la Economía Neoclásica el ambiente es considerado dentro de un sistema de preferencia de los agentes económicos. La pregunta que surge es ¿Qué pasa si no tiene valor algún recurso o hábitat, pero esto es relevante para la sostenibilidad? La Economía Ecológica busca una nueva ética global, en donde los precios no son determinantes para las decisiones de inversión y consumo.

c) En la Economía convencional no parece que se tenga un "teorema de existencia", como asegurar que el diseño de la economía sea ecológicamente sostenible. Hay un divorcio entre los óptimos marginales y lo que la realidad biofísica podría estar expresando, con respecto a las posibilidades de sostenibilidad de los ecosistemas. La Economía Ecológica por el contrario, enfatiza en la consideración de la dimensión física, de tal manera que los óptimos son establecidos en el ámbito de las relaciones de los ecosistemas y no en el intercambio expresado por el dinero.

d) La Economía Ecológica tiene como elemento central de estudio el mundo físico, el ecosistema global y los efectos e interacciones que tiene el subsistema económico, reconociendo que hay serias limitaciones en el crecimiento de este subsistema. La Economía Ambiental sigue encontrando óptimos en el mundo del intercambio, sin considerar suficientemente las variables físicas, los efectos y limitaciones del ecosistema global para con el subsistema económico.
1. El canon de vertidos es el cobro que al usuario de un cuerpo de agua se le aplica por las partículas físicas o químicas permitidas que agregue a este.

El canon de aprovechamiento es el monto cobrado por el uso del agua, según parámetros establecidos, para diferentes usuarios de recurso hídrico.

Todo lo anterior según el decreto ejecutivo $32868 \mathrm{del}$ Ministerio de Ambiente y energía del 30 de enero del 2006 . 
e) La base del análisis de la Economía Ambiental sigue siendo el mercado, en él y con él se buscan las soluciones por medio de diferentes instrumentos que buscan subsanar los problemas que este tiene para integrar el ambiente en sus procesos de decisión. La Economía Ecológica parte de considerar que el mercado es un medio insuficiente e imperfecto para dar solución a los problemas ambientales y que muchos de los más graves problemas del ecosistema global se deben a su aplicación, sin tomar medidas de otra índole, por parte de los países y las organizaciones internacionales.

f) La Economía Ecológica y la Economía Ambiental han desarrollado sus doctrinas partiendo de los mismos problemas. Dado que tratan problemas semejantes, aparentemente, buscan un punto de confluencia. Las diferencias en los postulados que plantean y la metodología que aplican en sus análisis parecen, todavía, muy disociados.

En esta sección se han planteado de forma general los fundamentos teóricos y las diferencias entre la Economía Ecológica y Ambiental para abordar los problemas ambientales por parte de la Economía. Estos aspectos teóricos y metodológicos tienen una relevante incidencia en la problemática del cambio climático, sus causas, sus efectos y las políticas propuestas para su mitigación y adaptación en el ámbito internacional. Un elemento central de ello es el patrón de crecimiento económico y la alta demanda de energía fósil, tal y como veremos a continuación.

Tabla 1

Comparación de variables básicas entre la Economía Ambiental y la Economía Ecológica

\begin{tabular}{|c|c|c|}
\hline Variable & Economía ambiental & Economía ecológica \\
\hline Precio & $\begin{array}{l}\text { Como parte de la Economía } \\
\text { Neoclásica es el asignador de los } \\
\text { recursos, si esta distorsionado busca } \\
\text { internalizar los costos y beneficios } \\
\text { (externalidades) para que sea mejor } \\
\text { indicador. }\end{array}$ & $\begin{array}{l}\text { Plantea las limitaciones de los precios } \\
\text { y el mercado para asignar los recursos. } \\
\text { El precio de los recursos naturales y el } \\
\text { ambiente, por lo general, no considera } \\
\text { su verdadero valor, llevando a una } \\
\text { asignación incorrecta. }\end{array}$ \\
\hline Valor & $\begin{array}{l}\text { Asume que es igual al precio, con } \\
\text { excepción de las fallas del mercado } \\
\text { por externalidades }\end{array}$ & $\begin{array}{l}\text { Debería ser la base para orientar la } \\
\text { Economía, debe incluir los costos } \\
\text { financieros, sociales y ambientales de } \\
\text { tal forma que aseguren la } \\
\text { sostenibilidad a largo plazo del } \\
\text { ecosistema. }\end{array}$ \\
\hline Capital natural & $\begin{array}{l}\text { No hay una clara distinción de este, se } \\
\text { ve como un insumo productivo, sin } \\
\text { tener en cuenta su vulnerabilidad. }\end{array}$ & 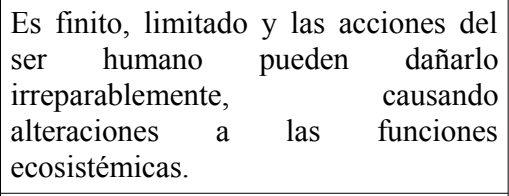 \\
\hline $\begin{array}{l}\text { Capital creado } \\
\text { por el hombre }\end{array}$ & $\begin{array}{l}\text { Le da gran importancia, se le asigna } \\
\text { una alta posibilidad de sustituir el } \\
\text { capital natural. }\end{array}$ & $\begin{array}{l}\text { Útil, necesario, pero necesita el } \\
\text { complemento del capital natural, baja } \\
\text { capacidad de sustitución del capital } \\
\text { natural. }\end{array}$ \\
\hline
\end{tabular}




\begin{tabular}{|c|c|c|}
\hline Tecnología & $\begin{array}{l}\text { Hay una gran confianza en la } \\
\text { evolución de la tecnología y que esta } \\
\text { dará soluciones a grandes problemas } \\
\text { ambientales, sociales y de aumentar el } \\
\text { bienestar. }\end{array}$ & $\begin{array}{l}\text { Necesaria, pero en algunos casos } \\
\text { puede generar problemas ambientales } \\
\text { más complejos. Se le ve con cuidado y } \\
\text { algunas corrientes lo consideran un } \\
\text { posible problema ambiental por tener } \\
\text { mayores entropías y contaminación. }\end{array}$ \\
\hline Ecosistema & $\begin{array}{l}\text { No hay una definición del mundo } \\
\text { físico, se concentra en el intercambio. }\end{array}$ & $\begin{array}{l}\text { Parte de que este es finito, que hay } \\
\text { restricciones al crecimiento desmedido } \\
\text { del subsistema económico. }\end{array}$ \\
\hline $\begin{array}{l}\text { Sistema } \\
\text { económico }\end{array}$ & $\begin{array}{l}\text { No le establece límites, sería un } \\
\text { sistema sin restricciones. Se concentra } \\
\text { en el estudio de este y sus relaciones } \\
\text { con el ambiente. }\end{array}$ & $\begin{array}{l}\text { Plantea la necesidad de cambios en los } \\
\text { patrones de crecimiento y que hay } \\
\text { límites a su crecimiento por factores } \\
\text { físicos y ambientales. }\end{array}$ \\
\hline Bienestar & $\begin{array}{l}\text { Se tiende a medir en términos } \\
\text { cuantitativos a través de indicadores } \\
\text { como el PIB per cápita. }\end{array}$ & $\begin{array}{l}\text { Es subjetivo, entran en juego aspectos } \\
\text { materiales como la dotación de } \\
\text { recursos e ingresos, pero considera } \\
\text { que a partir de cierto momento el } \\
\text { bienestar depende de aspectos } \\
\text { subjetivos, como la calidad ambiental, } \\
\text { la cultura, entre otros. }\end{array}$ \\
\hline Sostenibilidad & $\begin{array}{l}\text { Se puede lograr, mediante ajustes en el } \\
\text { sistema de precios (con el uso e } \\
\text { instrumentos económicos de } \\
\text { mercado), que llevarían a } \\
\text { modificaciones en las decisiones } \\
\text { económicas, no hay una clara relación } \\
\text { con la sostenibilidad biofísica. }\end{array}$ & $\begin{array}{l}\text { Está ligado a la base material biofísica } \\
\text { del planeta, de tal manera que los } \\
\text { procesos económicos no pongan en } \\
\text { peligro el capital natural y las } \\
\text { relaciones ecosistémicas en el futuro, } \\
\text { permitiendo la vida. }\end{array}$ \\
\hline $\begin{array}{l}\text { Generaciones } \\
\text { futuras }\end{array}$ & $\begin{array}{l}\text { Las decisiones racionales de los } \\
\text { agentes económicos y sus prioridades } \\
\text { al optimizar su función de utilidad } \\
\text { integrarían o no a las generaciones } \\
\text { futuras. }\end{array}$ & $\begin{array}{l}\text { Es una preocupación central cómo } \\
\text { lograr que las decisiones presentes no } \\
\text { afecten significativamente a las } \\
\text { personas en el futuro, esto mediante el } \\
\text { mantenimiento de las condiciones } \\
\text { ambientales básicas para sostener la } \\
\text { vida. Parte para ello de una nueva } \\
\text { ética en la relación con la naturaleza, } \\
\text { para considerar su sostenibilidad y el } \\
\text { derecho de los seres humanos sobre } \\
\text { estos en el futuro. }\end{array}$ \\
\hline
\end{tabular}

Fuente: Elaboración propia.

\section{La problemática del crecimiento y la demanda energética desde la Economía Ecológica en la era de la energía fósil}

El crecimiento económico que se dio a partir de la revolución industrial marcó un cambio significativo en los sistemas de producción y transporte, basado en el uso de los motores de combustión interna. La energía fósil ha sido vital para el crecimiento y los logros del crecimiento económico alcanzado desde entonces.

El empleo de fuentes fósiles acumuladas por miles de años en el planeta, ha suscitado una serie de alteraciones en períodos muy cortos para los ecosistemas. 
Georgescu-Roegen (1971), uno de los pioneros de los fundamentos de la Economía Ecológica, hizo un importante aporte al indicar que el sistema económico es subsistema de un sistema mayor abierto condicionado a leyes de la termodinámica. Toda actividad requiere de energía y materiales, y es necesario recordar que las leyes de la termodinámica gobiernan lo que pasa con la energía y materiales usados por el proceso económico.

La segunda ley (entropía) identifica a la Economía como un proceso que incrementa la entropía de la naturaleza, produciendo una muerte lenta. Esta argumentación es en la actualidad necesaria de considerar, sobre todo para el planteamiento de soluciones tecnológicas sostenibles, el reciclaje y el aprovechamiento de fuentes de energía no convencionales, pues en muchos casos estas leyes establecen limitaciones a la viabilidad a dichas alternativas o justifican su empleo (Cobb y Daly, 1993).

Una característica de la Revolución Industrial cuyas implicaciones no se aprecian suficientemente es el cambio al uso de combustibles fósiles y de materiales minerales. Este es un cambio de la explotación de la superficie de la Tierra a la explotación del subsuelo; como dice Georgescu-Roegen (1971), es un cambio de la dependencia de la energía proveniente a cada momento del Sol a la energía almacenada en la Tierra. (Daly y Cobb, 1993)

El crecimiento económico experimentado en los últimos 200 años ha tenido como fuente energética el consumo de la energía fósil acumulada por millones de años. Las tasas de crecimiento de la demanda de esta energía han sido, por mucho, superiores a la reproducción de esta, lo cual ha ido llevando a la disminución del acervo existente en el planeta. Cada vez se tienen que buscar nuevas reservas, con costos de extracción más altos y con mayores efectos ambientales en los procesos de extracción.

El cuarto reporte del Panel Intergubernamental de Cambio Climático encuentra que las concentraciones Gases Efecto Invernadero (GEI) y los aerosoles han aumentado considerablemente por efecto de las actividades humanas desde el año 1750. El aumento de las concentraciones de dióxido de carbono $\left(\mathrm{CO}_{2}\right)$ se debe principalmente al uso de combustibles de origen fósil, con una aportación menor aunque perceptible de los cambios del uso de la tierra. (CEPAL, UKAID, CCAD y SICA, 2010).

Se ha producido una gran entropía (energía que no se puede utilizar o energía en desorden) y se han generado emisiones en la atmósfera en forma de Gases Efecto Invernadero (GEI), por encima de la capacidad de asimilación del ecosistema. Por ello se han ido creando las condiciones para el calentamiento global (Common y Stagl, 2008). 
La industrialización basada en los combustibles fósiles, ha sido central para movilizar maquinarias, el uso de nuevas tecnologías, el transporte y la provisión de diferentes insumos. Esta situación ha llevado a que en poco tiempo, según la escala temporal de los ecosistemas naturales, el subsistema económico llene de infraestructura, materia, población y flujos de insumos, residuos. Contaminación, a tal grado, que la capacidad de recuperación del capital natural y de asimilación de los ecosistemas no se ha dado al ritmo y condiciones requeridas para la reproducción de los diferentes componentes sustentadores de la vida en el planeta (Pearce y Turne, 1995).

Para algunos, la falta de conocimiento de los efectos de las emisiones de GEI en un inicio, la despreocupación posterior y la falta de consideración de los costos sociales que estas acciones tenían, al no integrarse las externalidades en el sistema de precios, ha llevado a estos efectos negativos. Para otros, el cambio climático es una expresión de un camino incorrecto que la forma de organización social capitalista ha asumido, en donde el crecimiento, sin considerar los límites, tendría graves consecuencias. Desde la perspectiva de la Economía Ecológica, se diría que no se tuvo en cuenta los límites del ecosistema para soportar y asimilar apropiadamente la contaminación generada por los GEI, originada en el subsistema económico.

En general la civilización actual ha ido aumentando el consumo de energía, además ha agrandado su dependencia de la provisión de energía, generalmente fósil para sus procesos vitales. Por ejemplo, la revolución verde se basó en el uso de fertilizantes sintéticos, en la actualidad la producción mundial de alimentos depende de estos fertilizantes derivados del petróleo, del transporte internacional, pues incluso comunidades rurales se han convertido en dependientes de alimentos producidos a gran escala en otras regiones. Unido a ello, la calefacción, el transporte y el suministro eléctrico dependen, en una alta proporción, de los combustibles fósiles.

Lo anterior, lleva a cuestionarse si el modelo de crecimiento económico y los hábitos urbanísticos de consumo y producción son viables en el mediano y largo plazo para la sociedad moderna. El crecimiento exponencial de la demanda energética, así como la vulnerabilidad ante eventos naturales y otras situaciones que tienen las grandes ciudades, plantea a la sociedad actual un reto de sobrevivencia complejo y ante el cual aún no hay respuestas en nuevas tecnologías o fuentes energéticas.

El fuerte crecimiento energético está orientado por un conjunto de criterios que rigen la toma de decisiones económicas relacionadas con los efectos ambientales y que no contribuyen a que estas tengan en cuenta estos efectos y los límites que el crecimiento económico tiene en los ecosistemas. Algunos de los aspectos centrales que inciden en esas decisiones se analizan a continuación. 


\section{Análisis de conceptos básicos aplicados en la Economía y la toma de decisiones relacionadas con el ambiente}

A continuación se analizan varios aspectos que inciden en la forma en que la Economía convencional toma las decisiones sin considerar de manera apropiada el ambiente y sus múltiples interacciones.

La medición del bienestar y la sostenibilidad. El empleo del Producto Interno Bruto (PIB) o Producto Nacional Bruto (PNB) ha sido cuestionado como medida del bienestar de la sociedad por diferentes razones. La primera tiene que ver con la forma en que el producto se distribuye entre los miembros de la sociedad, un segundo aspecto es que hay efectos sobre los ecosistemas o lo que se ha llamado Capital Natural que no es considerado apropiadamente. Según Constanza et al. (1999) el Capital Natural se compone de los recursos naturales y sus interacciones ecosistémicas, y se contrapone al capital creado por el ser humano que es aquel que ha sufrido procesos de transformación en los procesos económicos para disponer de ellos de forma útil.

Parte del problema ha sido que se puede extraer parte de este Capital Natural, es decir, este puede agotarse, dañarse y transformarse, pero es mostrado como parte del crecimiento económico, es decir, se convierte en variable de flujo perdiéndose el stock existente que puede cumplir funciones relevantes para el planeta y las mismas actividades económicas futuras. Un ejemplo de ello es el cambio del uso del suelo, para el caso de Costa Rica, tierras de bosque primario, secundario o tacotales han sido transformados en plantaciones de monocultivo de piña o banano. Las erogaciones para destruir esos recursos naturales son contabilizadas como parte de la producción nacional, junto con la madera si esta es utilizada sin tener en cuenta la destrucción de estos recursos naturales y sus ecosistemas. Es decir, entra en la corriente de flujo, el dinero pagado para destruir esos ecosistemas (pago de maquinaria, insumos y mano de obra), el precio de mercado de la madera si se utiliza, pero sin restar la disminución del stock del bosque y sus interacciones ecológicas. Si esto se hiciera, las cuentas nacionales podrían revelar situaciones muy distintas de lo que los datos oficiales muestran.

Otro elemento relevante a considerar son las mediciones de bienestar empleando el PIB. Entran en dicha cuantificación bienes y recursos que no necesariamente contribuyen al mejoramiento de la vida, tales como el tabaco y las drogas en general (que tienen costos por enfermedades y otros efectos indirectos negativos para la sociedad), mientras que se dejan de lado aspectos fundamentales para la vida como la calidad del agua o del aire.

En general, al comparar países y su evolución en el tiempo, se supondría que los individuos conforme tienen más ingresos tienden a ser más felices (una posible medida de bienestar), sin embargo, conforme aumenta el ingreso, el aumento de la felicidad no se da en la misma proporcion. Esto se debe a la adaptación y la rivalidad, que lleva a los 
individuos a compararse entre sí. Estos aspectos son ignorados por la Economía Neoclásica. Por el contrario, la Economía Ecológica no da relevancia a la búsqueda del crecimiento del PIB per cápita (Common y Stagl, 2008).

Los indicadores para la toma de decisiones. La toma de decisiones económicas ocurre en diferentes niveles. Un primer ámbito se da en las decisiones de consumo, trabajo, ocio, ahorro o inversión de cada persona. El individuo, supuestamente racional, egoísta y con información perfecta, toma las decisiones buscando su máximo beneficio personal.

En la racionalidad económica parcelaria se está fundamentando un modelo de sociedad que se revela cada vez más irracional en su conjunto, al generar conflictos ecológicos y sociales que la hacen evolucionar hacia un horizonte globalmente inviable y generalmente indeseable (Naredo, 2004).

Es posible encontrar una serie de deficiencias que se arrastran en las sociedades cuando el mercado regido por las decisiones de las personas y empresas con alto poder de mercado determina la asignación de recursos y en especial su relación con el ambiente y los recursos naturales:

a. En primera instancia el individuo en un mercado no cuestiona el precio que le brinda este, su información no es suficiente, ni le interesa distinguir entre el precio y el verdadero valor que debería tener el bien o servicio.

b. La falta de conocimiento o concientización ha llevado a que pocos tengan en cuenta que sus decisiones económicas individuales pueden tener efectos negativos sobre el ambiente y los recursos naturales.

c. La supuesta racionalidad optimizadora y egoísta no siempre permite tener en cuenta que los efectos negativos sobre estos en sus decisiones económicas pueden tener un efecto a mediano o largo plazo en su bienestar.

d. Cada agente individual busca optimizar la rentabilidad privada, sin considerar qué es lo mejor para tener una rentabilidad o procesos de rentabilidad social.

e. Hay una diferencia desproporcionada entre la información y el poder de mercado de las grandes empresas transnacionales y los de los individuos. Estas empresas pueden incidir de diferente forma sobre las personas, los gobiernos y los mercados, lo cual lleva según la situación, a que temas ambientales, entre otros, sean relegados en la búsqueda de la maximización de las ganancias.

De la supuesta racionalidad optimizadora de los individuos, hay que cuestionarse cómo el efecto demostración, el manejo de campañas de publicidad, información parcial y disímil entre personas, entre la cultura y 
otros aspectos, no necesariamente optimizadores desde la perspectiva personal y racional neoclásica, se dan.

Uno de los problemas fundamentales que enfrenta la sociedad actual en su relación con el ambiente, es la falta de internalización en los precios del valor de una serie de servicios ambientales, recursos y funciones ecológicas. Esto hace que el sistema de precios de los bienes y servicios no brinde las señales correctas a los agentes económicos, lo cual lleva a una explotación excesiva, contaminación y daño de esos recursos vitales para la sostenibilidad del planeta. Por ello el reto para la Economía Ambiental es buscar que el sistema de mercado y los precios sean los apropiados para orientar las decisiones hacia un modelo de crecimiento económico más sostenible. Este propósito lo trata de lograr mediante técnicas de valoración económica del ambiente para expresar en términos monetarios las externalidades y los servicios ecosistémicos que no se transan en un mercado (Azqueta y Field, 1996).

Para la Economía Ecológica el supuesto de que la racionalidad y egoísmo de los agentes individuales pueda llevar a resultados socialmente satisfactorios es cuestionado de forma relevante. Con ello implícitamente se hace una crítica de fondo al mercado y la forma de organización social prevaleciente, debido a los resultados poco satisfactorios que puede tener sobre la sostenibilidad planetaria.

Así, se supone que los mercados libres y competitivos permiten que la búsqueda de interés egoísta por parte de productores y consumidores dé lugar a resultados socialmente deseables, excepto donde las condiciones (rigurosas) para mercados competitivos no se logren y estén presentes fallas de mercado... (Costanza, et al. 1999, p. 217).

La Economía convencional, al centrarse en los valores de cambio, deja de lado la dimensión física sobre la cual se sustenta el subsistema económico. Por ello busca soluciones al margen de lo que suceda en esa realidad biofísica. Al no considerar esos aspectos, los cuales no transan en un mercado, el ecosistema pierde toda importancia en las decisiones de los agentes económicos y de la colectividad, pudiendo llevar al suicidio colectivo de la sociedad humana de no asumirse medidas correctivas.

Para muchos, la externalidad va más allá de una falla, tiene que ver con la misma lógica del sistema económico que no ha tenido en cuenta todos los elementos requeridos para la reproducción de la base biofísica. Una expresión de esta situación es el cambio climático asociado a las actividades humanas que se ha podido percibir en las últimas décadas.

Las decisiones de inversión son tomadas generalmente con base en el Análisis Costo-Beneficio. Para un agente privado, el análisis es realizado teniendo en cuenta los costos y beneficios privados que su proyecto de inversión tiene. En caso de que no se hayan establecido ajustes a los precios, los agentes económicos tomarán los precios de mercado y con 
base en ello decidirían sobre las bondades del proyecto. Generalmente los proyectos privados tienden a subestimar los costos sociales, dado que la mayoría de recursos y servicios ambientales tiene valor (de uso directo, indirecto y de opción) pero no tienen precio (definido en un mercado o entre comprador y vendedor).

De igual forma, hay proyectos de carácter social o de alcance nacional que, pese a que se trata de incluir algunos beneficios y costos sociales, no permiten tener criterios -Tasa Interna de Retorno (TIR) y Valor Actual Neto (VAN)- bien ajustados a la conveniencia de la sociedad en el largo plazo. En algunos casos la Economía Ambiental busca integrar la valoración económica del ambiente, internalizando costos y beneficios ambientales en el análisis, esto es positivo y va en la dirección correcta, pero es insuficiente, pues las técnicas de valoración económica del ambiente, son complejas, discutibles en algunos casos y ante todo parciales; es decir, tienden a valorar algunos aspectos del ambiente, pero no todos (Hanley y Clive, 1993).

La tasa de descuento es el valor que se le da al dinero en tiempo (Jenkis y Arnold, 1993) Esta es empleada para efectuar la evaluación de proyectos de inversión y permite descontar el valor que se le da a los flujos futuros de ingresos y costos. En el ámbito individual generalmente debe mostrar el costo de oportunidad del mejor proyecto o negocio alternativo que tenga el agente individual. Para evaluar proyectos sociales, la tasa de descuento debe ser equivalente al mejor proyecto alternativo que tenga la sociedad en cuestión. Esta tasa además expresa el valor que se le da al futuro: entre más alta sea, mayor relevancia se le da al presente a costa de los flujos de ingresos futuros (Jiménez, 2002). Muchos proyectos ambientales y sociales cuyos retornos son de largo plazo, pierden viabilidad por tener que aplicarse tasas de descuento elevadas. Esta lógica de toma de decisiones hace que diversas actividades, proyectos y tecnologías más sostenibles no puedan llevarse a cabo porque no resultan viables financieramente.

En general, la sostenibilidad está limitada por un sistema de cuentas nacionales que no valora apropiadamente los recursos naturales y el ambiente. Las decisiones de los agentes económicos se basan en precios que en muy pocas ocasiones consideran el ambiente.

Los criterios de optimización de la contaminación de la Economía Ambiental son insuficientes e inapropiados para lograr que esos equilibrios del mundo del intercambio, sean compatibles en el mundo físico. Unido a ello, las técnicas y criterios para evaluar proyectos privados y públicos de inversión tienen importantes deficiencias, que hacen que las decisiones no permitan integrar suficientemente el ambiente y los recursos naturales (Dietz, 2009). 
Equilibrios marginales. Siguiendo el marco metodológico y teórico neoclásico, la Economía Ambiental ha adaptado una serie de conceptos para aplicarlos al ambiente:

El principio equimarginal, por consiguiente, expresa que se tienen múltiples fuentes para generar determinado producto o para lograr determinada meta, y se desea minimizar el costo total que genera determinada cantidad de esa producción, se debe distribuir la producción de tal manera que se igualen los costos marginales de las fuentes de producción (Azqueta y Field, 1996, p. 69).

Este concepto de equimarginalidad es aplicado para una serie de situaciones en la economía de los recursos naturales y en la Economía Ambiental. Entre ellos, las negociaciones de óptimos de contaminación entre dos agentes, los niveles de equilibrio de la explotación de un recurso natural renovable y, como puede verse a continuación, el nivel eficiente de emisiones:

El nivel eficiente de emisiones es, entonces, el nivel en el cual dos tipos de costos exactamente se neutralizan entre sí, es decir, en el cual los costos marginales de reducción son iguales a los costos marginales de daño (Azqueta y Field, 1996, p. 111).

De la cita anterior surge una serie de cuestionamientos. Por una parte, ¿cuál es el parámetro que se utiliza?, ¿es un precio? En segundo lugar, ¿es este precio de mercado el correcto, considerando las externalidades positivas y negativas? En tercer lugar, si eso fuera correcto, ¿es ese equilibrio obtenido en el ámbito de las relaciones de cambio, el que lleva a una optimización, congruente con el mundo físico?, es decir, ¿permite ese equilibrio, logrado en el intercambio, tener las emisiones que en un horizonte temporal determinado no generen efectos negativos (aumentos de temperatura), tal y como se han indicado como causantes del cambio climático?

Resulta difícil aceptar que esos equilibrios logrados en el mundo del intercambio, puedan considerar los efectos ambientales de las actividades. En la mayoría de casos el costo que se incluye es el costo de extracción y no el de recuperación. Es difícil pensar que sin estudios, estándares y metas de política nacional y mundial los agentes económicos puedan lograr automáticamente equilibrios sostenibles ambientalmente.

El problema fundamental estriba en la no consideración de bienes, servicios, recursos y funciones ecológicas que tienen valor pero que no tienen precio, lo cual lleva a tomar decisiones incorrectas, tanto en el ámbito individual como en las decisiones colectivas nacionales e internacionales.

En las secciones previas se ha comparado el enfoque de la Economía 
Ambiental y Ecológica, unido a ello se han detallado los criterios más relevantes para la toma de decisiones económicas por parte de los agentes públicos y privados. En la siguiente sección, teniendo como marco de referencia los elementos teóricos y metodológicos antes indicados, se analizan las principales políticas internacionales para enfrentar el cambio climático.

\section{Consideraciones finales}

De la comparación de los postulados, método, alcance y objetivo de la Economía Ecológica y de la Economía Ambiental surge una serie de aspectos que deben tenerse presentes:

a. La Economía Ambiental busca emplear herramientas de mercado para lograr una asignación de los recursos que permita mayor sostenibilidad. Este objetivo se ve limitado por la gran cantidad de deficiencias de los mercados que llevan a que los bienes y servicios ambientales, el ambiente y los recursos naturales tengan valor, pero este no se ve reflejado apropiadamente en los precios de mercado.

b. Por su parte, la Economía Ecológica critica los instrumentos de mercado y ve a este como parte del problema y no de la solución al problema de la sostenibilidad global. Más allá de pretender usar el mercado, lo que la Economía Ecológica postula es la necesidad de establecer criterios físicos, basados en la capacidad de los ecosistemas, a partir de los cuales se establezcan diversos instrumentos para el logro de la sostenibilidad.

c. Pese a que en apariencia buscan un mismo objetivo, los postulados básicos y sus metodologías son muy distintas, lo cual hace difícil un acercamiento teórico y metodológico que permita lograr una síntesis.

d. Es destacable el desarrollo de instrumental por parte de la Economía Ambiental para obtener óptimos, asignar recursos considerando aspectos ambientales y la búsqueda de una mejor contabilidad social. Sin embargo, el objeto de estudio, el ambiente, tiene tales características y dimensiones éticas y valores que hacen complejo el uso de esas herramientas, o al menos son altamente cuestionados desde diferentes enfoques. Unido a ello, las limitaciones teóricas y metodológicas de la economía neoclásica se magnifican a la hora de tratar los temas ambientales, pues lo común es tener fallas de mercado, externalidades y en general precios incorrectos.

e. La Economía Ecológica ha logrado dar una perspectiva integral y plantear el problema ambiental de la humanidad en su verdadera perspectiva. Sin embargo, su arsenal metodológico y herramientas no son suficientes para poder incidir en un sistema 
económico que conoce de precios de mercado, sin que el mundo físico y sus limitaciones ecosistemas sean considerados suficientemente.

Los procesos de decisión en el campo económico han estado influenciados por una serie de indicadores y criterios que no consideran elementos fundamentales para la sostenibilidad del planeta. El criterio de bienestar a partir del PIB per cápita, el crecimiento económico en términos monetarios como indicador positivo, sin tener en cuenta el deterioro de variables biofísicas de stock, son debilidades gruesas que hacen que los países, y por ende el planeta, vayan por caminos contrarios a la sostenibilidad.

Los procesos de evaluación económica por medio del Análisis CostoBeneficio, tienen la debilidad de que consideran todo aquello que tiene precio, mientras que otros recursos y servicios que tienen valor y son básicos para la vida en el planeta, no son considerados. La valoración económica del ambiente empleada en la Economía Ambiental es un esfuerzo en la dirección correcta, pero con importantes deficiencias y limitaciones, y no es de uso común en los procesos de decisión relevantes en el campo público y menos en las evaluaciones financieras de carácter privado.

Un elemento central que incide en la viabilidad de proyectos de inversión $y$ que en muchas ocasiones hace que proyectos con beneficios ambientales y sociales no se lleven a cabo, es el valor que se le dé a la tasa de descuento. Esta tasa muestra en gran medida el valor que tiene para los tomadores de decisión el presente y el futuro. Proyectos como una plantación forestal, un proyecto con tecnologías limpias o de carácter social, al aplicarles tasas de descuento que rigen en determinados momentos en la economía, llevan a que los flujos de beneficios futuros, por ejemplo, después del año 15, sean insignificantes, pese a que para efectos de sostenibilidad y desarrollo pueden ser vitales.

Los óptimos y equilibrios marginales basados en el intercambio que se dan en un mercado, muchas veces con importantes imperfecciones, son quizás una de las limitaciones más importantes de la Economía Ambiental para analizar la problemática ambiental. Las negociaciones de emisiones o de contaminación entre dos agentes, países u organismos basados en costos y beneficios marginales, sin tener claro los límites físicos de los ecosistemas, pese a que pueden disminuir los costos de las acciones, no aseguran el logro de la sostenibilidad. Unido a ello, si no se consideran correctamente las externalidades positivas y negativas, las decisiones que se tomen en los intercambios pueden ser muy diferentes de las que el planeta requiere, dada su capacidad de asimilación, dotación de recursos y los límites físicos existentes.

Por tanto, el camino que se debe seguir es el de establecer de forma rigurosa, con base en estudios científicos, las capacidades de los ecosistemas para soportar determinadas demandas de recursos y 
contaminación, buscando los mecanismos más efectivos para cumplir con esos parámetros que se deben definir en el mundo físico y no en el intercambio. A partir de ello, la aplicación de instrumentos de mercado, de comando y control o mixtos es bien recibida, en tanto logre cumplir las metas establecidas.

La aplicación del instrumental de la teoría económica convencional, en especial los óptimos marginales y paretianos en las relaciones de intercambio, en el mejor de los casos, lleva a una optimización en el ámbito monetario. No obstante, la existencia de ecosistemas finitos, una restringida capacidad de asimilación de los ecosistemas y limitaciones en la dotación de recursos y funciones de los ecosistemas, hacen que si no media una consideración de estos aspectos fundamentales para la vida en el planeta, el mundo de la economía seguirá viendo los intercambios monetarios, mientras que la base material que sustenta todas las actividades se irá destruyendo de forma constante y, en muchos casos, más rápido de lo que la economía podría revertir.

En general, las políticas ambientales para el logro de metas que han mostrado más posibilidades de éxito han sido aquellas que combinan diferentes instrumentos. Así pues, para poder usar instrumentos económicos es básico definir una normativa regulatoria que establezca, por ejemplo, máximos de emisiones a la atmósfera. Unido a estos instrumentos, en la primera década del siglo XXI se han fortalecido los mecanismos de participación social en temas ambientales. Las personas cada vez son más conscientes, tratan de participar e incidir en diferentes acciones, cuando ven que sus intereses y los del ambiente no son considerados.

\section{Bibliografía}

Azqueta, D. (1994). Valoración Económica de la calidad ambiental. Madrid: McGraw-Hill.

Azqueta, D. y Field, B. (1996). Economía y medio ambiente. Bogotá: McGraw-Hill.

Asociación de Economía Ecológica de España. (2010). Principios de la $E E$. Recuperado de http://www.ecoecoes.es/principios-de-la-ee/

Common, M. y Stagl, S. (2008). Introducción a la Economía Ecológica. España: Editorial Reverté S.A.

CEPAL, UKAID, CCAD y SICA. (2010). La economía del cambio climático en Centroamérica, Síntesis, noviembre 2010. 
Cobb, J. y Daly, H. (1993). Para el bien común: Reorientando la económica hacia la comunidad, el ambiente y un futuro sostenible. México: Fondo de Cultura Económica.

Costanza, R. ,Cumberland, J., Daly, H., Goodland, R., Norgaard, R . (1999). Introducción a la Economía Ecológica. México: Compañía Editorial Continental, S.A.

Dietz, S. (2009). From efficiency to justice: utility as the informational basis of climate change strategies, and some alternatives. Centre for Climate Change Economics and Policy, 15, Grantham Research Institute on Climate Change and the Environment.

Elizalde, A. (1997). Ecología, ética epistemología y economía: relaciones difíciles pero necesarias. Recuperado de http://www.unida.org.ar/Bibliografia/documentos/Modulo_Basico/Li bro_El_Resignificado_del_Desarrollo_MBC/04_Ecologia_Etica_Ep istemologia_y_Economia_Relaciones_Dificiles_pero_Necesarias.. doc

Eumed.net. (2011). Grandes Economistas. Arthur Cecil Pigou, 1877-1959. Recuperado http://www.eumed.net/cursecon/economistas/pigou.htm

García, M. (2003). Apuntes de Economía Ecológica. Boletín económico de ICE número 2767, España.

Georgescu-Roegen, N. (1971). The Entropy Law and the Economic Process. Cambridge, Mass.: Harvard University Press.

Hanley, N. y Clive, L. (1993). Cost-Benefit Analysis and the Environment. Inglaterra: Edward Elgar.

Hauwermeiren, S. (1999). Manual de Economía Ecológica. ILDIS: Ediciones Abya-Yala.

Jenkis, G. y Arnold, H. (1993). Análisis de Costo-Beneficio de las decisiones de inversión. Harvard Institute for International Development. Traducción y reproducción realizada por el Instituto Centroamericano de Administración de Empresas INCAE, Alajuela, febrero de 1993.

Jiménez, R. (2002). Apuntes sobre análisis de tasa de descuento. Material docente. Maestría en evaluación de proyectos de desarrollo, Universidad de Costa Rica.

Lozeco, J., Tarragona, R. y López, A. (2010). La evolución histórica del pensamiento económico y su visión de los recursos naturales en el proceso social de producción $82^{\mathrm{a}}$ parte). Revista Ciencia y Naturaleza, 19, 46-48. 
Naredo, J. (2004). La Economía en evolución: invento y configuración de la economía en los siglos XVIII Y XIX y sus consecuencias actuales. Revista d'Història Moderna, Universidad Autónoma de Barcelona, 22, 83-117. Recuperado de http://www.ub.es/geocrit/sv-105.htm

Pearce, D. y Turner, K. (1995). Economía de los recursos naturales y del medio ambiente. Madrid: Edigrafos, S.A.

Stiglitz, J.E. (1998). La economía del sector público (3ª ed.). Madrid: Antoni Bosch.

The Ronald Coase Institute. (2000-2011). Ronald Coase. Recuperado de http://www.coase.org/index.htm 


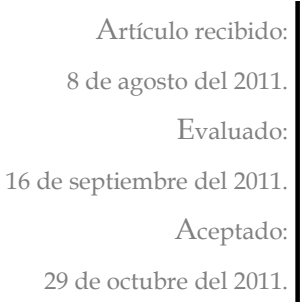

de octubre del 2011

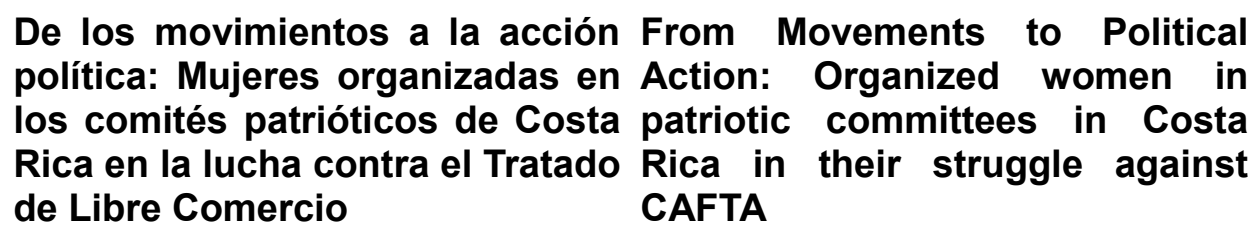
RESUMEN

En este artículo se presenta parte de los resultados de la investigación Los movimientos socioculturales contemporáneos de mujeres en Costa Rica. Siglo XXI, realizada en el Centro de Investigaciones en Cultura y Desarrollo (CICDE), entre 2009 y 2011. Al interior de los comités patrióticos, organizaciones politizadas surgidas en Costa Rica en oposición al neoliberalismo, las mujeres cumplen un papel protagónico en la lucha por la vigencia del estado social. En este artículo se considera que el fenómeno de la globalización tiene implicaciones y cambios significativos sobre las relaciones de género. Destacan en estos cambios los procesos de exclusión y desigualdad, acentuados en las condiciones de vida de las mujeres. Como conclusión, se destaca la presencia de nuevas voces de mujeres en estos grupos mixtos, y de recientes proyectos colectivos que denuncian injusticias sociales económicas, políticas y de género.

Palabras Clave

Comités patrióticos, Mujeres, Desigualdades, Relaciones de género, inequalities, gender relations, identity Identidad
KEY WORDS

ABSTRACT

This article summarizes part of the results of a research on the contemporary socio- cultural movements of women in Costa Rica20th Century, in charge of the Center for Culture and Development Research (CICDE), between 2009 and 2011. In patriotic committees -political organization born in Costa Rica to fight against neo-capitalism-women play a protagonist role in the struggle for the survival of the social state. This article considers that globalization has implications and provokes significant changes in relation to gender relations. Some of these changes are evident in exclusion and inequality processes accentuated in the living conditions of women. New voices of women in these mixed groups are highlighted, as well as recent collective projects that denunciate social, economic, political and gender injustices.

Patriotic committees, women,

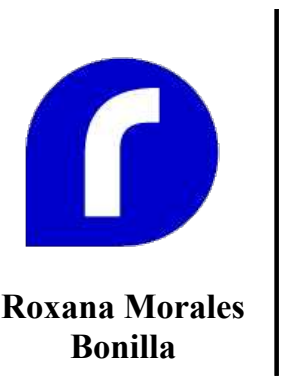

Socióloga con una maestría en Educación con especialidad en Educación de Adultos. Coordinadora del proyecto de investigación Movimientos socioculturales contemporáneos de mujeres en Costa Rica en el siglo XXI en el Centro de Investigación en Cultura y Desarrollo (CICDE). Correo electrónico: rmorales@uned.ac.cr 


\section{De los movimientos a la acción política: mujeres organizadas en los comités patrióticos de Costa Rica en la lucha contra el Tratado de Libre Comercio}

\section{Introducción}

El llamado fenómeno de la globalización se visibiliza en avances y cambios científico tecnológicos bastante acelerados, así como en determinados desarrollos del comercio y los flujos de capital. Pero el desarrollo de las sociedades globalizadas no se presenta tan sólo en la ciencia, la tecnología y la economía, sino que adquiere otra dimensión vinculada con las personas, con su cultura, personalidad, ética, filosofía, educación, sus intereses y motivaciones. El fenómeno, en las formas hegemónicas que ha asumido en los últimos decenios, trata de imponer, absolutizar y generalizar a la humanidad; así como cumplir con el mandato social y económico necesario para alcanzar el desarrollo.

Tal mandato, desde una dimensión humanista, invisibiliza la búsqueda de escenarios donde se construyen relaciones nuevas entre las personas; vínculos que se ejerzan respetando las condiciones de vida de los seres sociales, las características propias de los pueblos, sus tradiciones, costumbres y estilos de vida.

A partir del año 2009, el Centro de Investigación en Cultura y Desarrollo (CICDE) de la Vicerrectoría de Investigación de la UNED de Costa Rica, se propone "Investigar críticamente los procesos, las propuestas y las prácticas culturales e identitarias [...], desde perspectivas alternativas y contrahegemónicas [...]" (Vargas, 2009, p.7), relacionándolas con los movimientos sociales, los fenómenos nacionales, locales, regionales y mundiales. 
En este contexto académico se desarrolla la investigación Los movimientos socioculturales contemporáneos de mujeres en Costa Rica. Siglo XXI, realizada entre 2009 y 2011. El propósito de la misma es analizar críticamente la participación de las mujeres en organizaciones por la defensa de la naturaleza, en los comités patrióticos y en organizaciones artístico culturales. Lo anterior desde el punto de vista de las motivaciones de las mujeres participantes; el tipo de relaciones e interrelaciones entre mujeres y hombres a lo interno de las organizaciones y la dinámica de estos grupos, sus jerarquías y roles.

En total se entrevistó a 78 mujeres. Las mujeres organizadas en los comités patrióticos -consideradas para este artículo- fueron en total 28, entre informantes clave y mujeres integrantes de organizaciones. La información obtenida es el resultado de una metodología que recurrió a entrevistas a profundidad, grupos focales, talleres, encuentros, devoluciones, los cuales permitieron identificar, develar y relacionar sus experiencias y prácticas organizativas de formación y participación política-cultural.

\section{El por qué de la investigación feminista}

El trabajar desde la perspectiva feminista permite visibilizar el quehacer de las mujeres. Desde esta investigación, se problematizan críticamente las situaciones de opresión y discriminación femenina.

Interesa particularmente conocer, comprender, vincular y develar el quehacer de las mujeres articuladas en organizaciones políticas y culturales. De acuerdo con Castañeda (2008), desarrollar e incorporar la investigación feminista es un esfuerzo y un procedimiento que se propone empezar con y por las mujeres.

Seguidamente, el investigar los temas que las mujeres quieren y necesitan, es otro componente de esta corriente, el cual es aquí retomado a fin de evidenciar problemáticas femeninas específicas y que, una vez que se logran visibilizar, se convierten en denuncias. Por lo tanto, interensan las experiencias, las prácticas, las voces, las motivaciones silenciadas, los silencios estructurados de las mujeres en movimientos socioculturales en espacios mixtos. Conocer sus situaciones dispares, tanto de índole personal como en relaciones de género, y en forma significativa según sus luchas y experiencias.

La historización es otro componente base de este procedimiento. La investigación en mención está enmarcada en un periodo histórico determinado, a partir del siglo XXI, como movimiento contemporáneo, porque obedece al carácter coyuntural de las demandas y denuncias donde se exigen cambios, transformaciones sociales, económicas, 
culturales, políticas. Se profundiza en la participación y dinámicas femeninas en esferas de poder tradicionalmente marcadas por jerarquías y relaciones de poder patriarcales.

Otro elemento señalado por Castañeda (2008), se refiere a la deconstrucción y el desmontaje. Se deconstruyen conceptos, hallazgos, experiencias; a través de la investigación se desmontan las relaciones de poder profundas y las desigualdades, presentes en grupos mixtos, que implican para las mujeres actos de renuncia, aceptación, violencia o emancipación.

El último elemento de este procedimiento es la elaboración conceptual y la teorización ya que interesa profundizar sobre las relaciones de género, sobre todo su incidencia política en la sociedad costarricense y en los movimientos sociales.

La investigación feminista procura que sus resultados apoyen el cambio social indispensable para erradicar la opresión de las mujeres. En este sentido Reinharz (1992, citado en Castañeda, 2008) apunta que las investigadoras feministas desarrollan una "doble mirada: la propiamente científica y la política. Mirada que lleva consigo también una doble responsabilidad: con la comunidad científica y con las mujeres" (p.48).

Las mujeres organizadas en los comités patrióticos (en adelante CP), participan en luchas sociopolíticas que implican cambios personales, familiares, institucionales, sociales, políticos, ambientales, culturales y comunales. Dichos cambios son llevados a cabo por medio de las relaciones y estrategias de confrontación y denuncia.

\section{Antecedentes socio-históricos de los comités patrióticos}

La firma del Tratado de Libre Comercio entre Centroamérica, República Dominicana y los Estados Unidos (TLC), es el detonante que da lugar a movilizaciones populares en el país, pues el órgano legislativo debió de ratificarlo y, ante el descontento de algunos sectores de la población, que no apoyaba y decía NO al TLC, se organizó el primer referéndum en Costa Rica para la consulta nacional (07 de octubre del 2007), a fin de determinar si se aprobaba o no dicho tratado.

Al respecto, Martínez (2008, p.36), señala que "Un estrecho margen de diferencia que le dio ventaja al Sí con apenas $51 \%$ de los votos sobre el NO que alcanzó $48,4 \%$, una distancia de 50 mil sufragios, se convirtió en un enconado debate nacional y la profundización de las movilizaciones sociales y sectoriales".

El debate sobre el TLC giró alrededor de preocupaciones nacionalistas y patrióticas por las posibles implicaciones derivadas de los contenidos del tratado, en aspectos como inversiones, acceso a mercados, derechos de propiedad intelectual, entre otros. En la conformación de los CP, los 
sectores sociales en oposición encontraron el espacio propicio para denunciar y expresar esas preocupaciones y movilizarse en contra del tratado.

De tal forma, Rayner argumenta como los CP:

[...] nacieron a la luz del primer referéndum en la historia de Costa Rica para decidir la entrada o no de este país al CAFTA. El debate público giró en torno a tres temas: 1) Las condiciones del acceso al mercado estadounidense; 2) la habilidad del Estado de manejar los recursos nacionales y la economía doméstica; 3) la viabilidad de las instituciones públicas de bienestar encargadas de la salud (CCSS), la electricidad y las telecomunicaciones (ICE), y los seguros (INS) (2008, pp. 73-74).

La oposición al tratado visibilizada en el movimiento del NO, constituye una expresión de alcances nacionales que se expresa mediante un discurso de defensa de la soberanía nacional y del patrimonio institucional y natural. Ello da lugar a diversas formas de movilización y manifestación pública.

Para Vargas (2008), este movimiento puede ser caracterizado con base en los siguientes rasgos:

[...] el Movimiento del No al TLC enfrentó el poder concentrado de las oligarquías y, en el proceso, construyó contrapoderes, es decir, otros espacios de poder, cualitativamente distintos, gracias a lo cual estuvimos a centímetros de derrotar el TLC. Las resistencias y la protesta surgen justo porque existen espacios de poder que las oligarquías no controlan. En parte, es una resistencia muda, carente de expresión orgánica. Ese es el caso de esa amplia masa del pueblo que no se organiza, no se moviliza ni manifiesta y, a lo sumo, protesta por omisión, es decir, desentendiéndose de la política $\mathrm{y}$, en especial, negándose a votar. Pero también existe la resistencia y la protesta que sí desarrollan expresiones orgánicas. Esta segunda forma de resistencia tiende a crecer. En particular el TLC actuó como detonante que estimuló un despertar cívico (p. 2).

Algunos antecedentes que conviene tener en cuenta por su importancia y significación en la participación ciudadana, son la huelga del Magisterio Nacional en 1995, donde la población educadora se movilizó en contra de algunas reformas a su régimen de pensiones; así como la movilización nacional realizada en marzo-abril de 2000 contra la propuesta gubernamental conocida como "Combo ICE", que pretendía privatizar la energía y las telecomunicaciones; lesionando así al Instituto Costarricense de Electricidad (ICE). 
En estas expresiones sociales de organización y participación ciudadana participaron otros sectores sociales del país, entre ellos la población universitaria y los estudiantes de secundaria, los funcionarios de Estado, los agricultores y agricultoras, los educadores y las educadoras, las amas de casa.

La fortaleza de este movimiento social se alimentó en buena medida de una propuesta nacionalista, alrededor de la cual se organizaron las expresiones dirigentes y desde la que se logró una considerable recepción positiva en sectores de la población.

\section{La historia social de la vida cotidiana de un comité patriótico en una sociedad globalizante}

Los CP son organizaciones informales que nacieron en Costa Rica como respuesta crítica a la discusión del Tratado de Libre Comercio con los Estados Unidos, Centroamérica y el Caribe, se organizaron en barrios, urbanizaciones, caseríos, cantones y provincias, con impacto nacional. Su objetivo fue informar y formar sobre temas relevantes de interés nacional relacionados con el tratado a fin de impulsar un movimiento nacional de oposición.

Así, fueron el resultado de la búsqueda, por parte de la ciudadanía, de una nueva cultura política que permitiera a la organización vincular y articular los intereses por un país democrático y con justicia social. Se presentaron múltiples formas de manifestación que en algunos casos condujo a acciones de "desobediencia civil".

Los CP en lo fundamental son anti-neoliberales. En otras palabras se oponen a la doctrina política que antepone las leyes del mercado al Estado social de derecho, y que promueve un Estado con nula o muy poca participación en la administración de la economía.

Las personas integrantes de los CP asumieron la función de denuncia y fiscalización, pero también se involucraron en luchas y proyectos para contrarrestar factores que inciden negativamente en el desarrollo de una sociedad democrática.

Rayner (2008) indica:

Los CP se formaron autónomamente y por procesos distintos según la comunidad en que se dieron, en el contexto de un creciente movimiento en contra del TLC y un amplio despertar de compromisos fervorosos que posibilitaron una multitud de iniciativas de base. La formación de CP como tal ocurrió entre mayo y julio de 2007, después de la aprobación del referéndum en abril del mismo año. Pero la oposición al TLC ya llevaba varios años de organización y crecimiento, incluyendo, notablemente, el 
rápido surgimiento del Partido Acción Ciudadana (PAC) como una segunda fuerza electoral con una plataforma antiTLC y, una marcha de decenas de miles de personas en febrero. Este movimiento tenía sus propias raíces en un marcado aumento de oposición a la neoliberalización desde mediados de los noventa, incluyendo una huelga importante del magisterio en 1995 y una ola de protesta nacional en el 2000 contra la ley del "Combo ICE", que privatizaría la energía y las telecomunicaciones (p.74).

Esta década de movimientos permitió un tejido social entre opositores al neoliberalismo, tanto como cambios en ideologías y subjetividades que contribuyeron a la formación de los comités patrióticos y, por ende, a la organización ciudadana y la educación política.

En el conversatorio organizado por la Asociación de Estudiantes de Filosofía de la Universidad de Costa Rica, el 2 de noviembre del 2007, a un mes del referendo, dos mujeres ponentes y activistas resumieron:

[...]Los comités patrióticos se centraron, en informar a la gente, motivarla para ir a votar y, donde se pudo, transportarla el día de los sufragios. Ahora hay que hacer un trabajo más político de ciudadanía republicana y democrática. Para que se active bajo las formas de la reivindicación particular y de la resistencia, de la crítica, de la desobediencia civil (cuando se pueda organizar), de la acción no-violenta, buscando articular las reivindicaciones particulares con la existencia política básica, porque en esa articulación es que le va a la gente su existencia.

Entonces hay que reanimar los comités patrióticos, tornar los espacios de encuentro (convocatoria) y de organización y de incidencia. Y luchas para obtener victorias puntuales y también manifestaciones públicas, hacerse presentes, no dejar descansar a quienes creen van ganando o creen haberlo ganado todo. Alimentar objetivamente subjetividades para la resistencia y la lucha y para un emprendimiento colectivo nacional que logre una gran votación el 2010 es el sentido que vincula el trabajo de los comités patrióticos. Esto sólo puede hacerse desde la gente, poniendo a las ideologías propias en tensión con las necesidades de ciudadanos y pobladores. Nada fácil, pero

Las mujeres han destacado como protagonistas en los CP. Por ejemplo el $\mathrm{CP}$ de Hatillo, Ilamado "Clemencia Valerín", lleva el nombre de una educadora pensionada, militante de izquierda desde su juventud, quien históricamente ha estado en las luchas reivindicativas por una educación política que permita la liberación de las personas y la problematización crítica de su entorno.

Una integrante del CP de Hatillo, opina que: 
Hay varios comités patrióticos y gente patriota de todos los rincones de nuestro país, que no dejamos de latir y nos seguimos reuniendo semana a semana creando, discutiendo, reflexionando y trabajando en nuestras comunidades, aún después del 7 de octubre del 2007. Mediante esta experiencia buscamos la gran fuerza social; realizamos muchas reuniones y comisiones; ha sido un arduo camino, donde es difícil no cometer los mismos errores pero continuamos trabajando.

\section{El Comité Patriótico Nacional}

El 10 de abril de 2010, integrantes de comités patrióticos de San José se unen a similares de las provincias de Heredia, Alajuela y Cartago, así también con representantes de organizaciones y personas independientes, con el objetivo de continuar fortaleciendo la capacidad de movilización social y ciudadana. En la misma fecha nació el Comité Patriótico Nacional (CPN), de la conjunción de organizaciones y personas dispuestas a unir esfuerzos para alcanzar objetivos comunes.

El objetivo esencial del CPN, así como el de todos los CP es fiscalizar el quehacer de las instituciones del Estado costarricense; denunciar actuaciones y omisiones del gobierno central y de los gobiernos locales de turno que atenten contra valores de justicia social y de equidad, o que impliquen el retroceso de las conquistas sociales y el patrimonio natural y cultural de Costa Rica. Por otro lado, se persigue también resistir los embates del neoliberalismo y promover la información y la educación ciudadana permanente, para alcanzar una participación política activa y crítica (Boletín, 2011).

\section{Expresiones locales en los comités patrióticos}

Durante la investigación, el primer contacto con los CP investigados fue en la convocatoria para organizar el CPN en abril del 2010; seguidamente se contactó a las mujeres asistentes y organizadas en los CP. Sin embargo, sólo se lograron entrevistas con las mujeres de los CP de Hatillo, Paso Ancho y Barva de Heredia, así como de los CP de Curridabat y Occidente, gracias a contactos y referencias personales.

Se estudiaron cinco CP: Curridabat (provincia de San José, cantón de Curridabat); Barva de Heredia (provincia de Heredia, cantón de Barva); Paso Ancho (provincia San José, cantón Central); Hatillo (provincia San José, cantón Central) y Occidente (provincia de Alajuela, cantón San Ramón).

Se tomará el ejemplo del CP de Curridabat para explicar la génesis de un comité: 
1. La identidad de las entrevistadas se resguardará, por esta razón los nombres utilizados son pseudónimos.
La mayoría de las personas integrantes de este comité, en los años 70 y 80 fueron militantes de izquierda, son profesionales y aún mantienen la esperanza de cambiar tantas injusticias en el país. Por medio de la red por internet e invitaciones boca a boca, una persona amiga que fue dirigente en los sindicatos bananeros en los años 70 y 80 , convocó a un foro para discutir sobre el TLC, el lugar fue en las instalaciones de la Municipalidad de Curridabat. Llegaron alrededor de 25 personas, hubo gente que estaba a favor y en contra del TLC. No sabían que era un Comité Patriótico. El primer objetivo fue intercambiar información entre la gente de la comunidad. Lo primero era una mejor información uniforme, que la mayoría tuviera acceso a la información.

En este Comité eran casi todos y todas profesionales: funcionarios de las universidades, sociólogas (os), psicólogos (as), ingenieros en sistema, de oficios habían electricistas, amas de casa, una señora de 80 años, estuvo siempre activa y dinámic Nombraron personas líderes, había muchas mujeres, hombres y jóvenes también. La gente colaboró con la comida, sobraban los alimentos, todo era alegría y camaradería. Se creó un Comité de divulgación y llegaban hasta 60 personas, se comunicaban por boletines los pegaban en los lugares visibles de Curridabat, por correo electrónico y de voz a voz. Familias enteras se reunían, padres, madres, hijos, tíos, así formaron y se integraron familias, también hubo reencuentros de generaciones, por ejemplo (Natalia, entrevista personal, 27 de mayo de 2010) ${ }^{1}$.

Seguidamente, se muestran algunos testimonios de mujeres organizadas en los CP, los cuales demuestran la incidencia política lograda por medio de sus acciones, prácticas políticas y luchas comunales, con carácter local. Por ejemplo, un joven de 15 años del CP de Paso Ancho, durante el 2010, realizó una convocatoria por correo electrónico para protestar frente a los Tribunales de Justicia por el problema social de la inseguridad ciudadana a la cual asistió una cantidad considerable de personas.

El siguiente testimonio en el CP de Barva de Heredia, reafirma el carácter local de lucha y el fortalecimiento del ejercicio de la ciudadanía:

Las más gratificantes fue haber ganado el NO al TLC en Barva y un regidor en la Municipalidad de Barva, como partido Barva Unida; nuestro mayor reto es ganar la Municipalidad (Guiselle, entrevista personal, 21 de mayo de 2010).

Autores como Párraguez (2010), hacen un llamado a la participación global-local, en términos de que son luchas con compromiso que impactan tanto el hogar como la comunidad y muestran alcance global y local.

El proceso de construcción de luchas con alcance global [...] puede conservar su orientación local y particular, es decir, pueden 
permanecer comprometidos con las causas de sus hogares y sus comunidades al mismo tiempo que participan de una política global emergente [...] puede ayudar a los actores locales a adquirir cierta sensación de participación en causas que, si bien no necesariamente son globales, tienen una distribución global por su recurrencia en numerosas localidades (p. 244).

\section{Mujeres en procesos de transformación en los comités patrióticos}

Se entrevistaron 28 mujeres, con edades entre 17 y 80 años, profesionales, algunas laboralmente activas y otras jubiladas. Solo una de las entrevistadas es ama de casa y se dedica a la economía campesina. Todas ellas con múltiples responsabilidades personales, familiares, de estudio, laborales, comunales, organizativas, institucionales, locales y nacionales.

La mayoría de las entrevistadas ha tenido una trayectoria de militancia en partidos políticos de izquierda. De las mujeres entrevistadas sólo una no tiene grado profesional, el resto posee un perfil académico alto. en las disciplinas de: Educación, Derecho, Sociología, Ingeniería Agroalimentaria, Ingeniería Tecnología de Alimentos, Trabajo Social, Historia, Literatura, Informática Educativa, Filología, algunas, con estudios especializados en Género y Derechos Humanos y, otra se encuentra estudiando en el nivel de secundaria. Según su estilo de vida, es posible situarlas como clase media con estatus socioeconómico medio y alto.

Desde los $\mathrm{CP}$, las mujeres mantienen percepciones de la realidad a partir de lo que trabajan y lideran desde las múltiples expresiones territoriales, económicas, culturales, educativas, sociales, políticas. Percepciones que se construyen en los procesos de interacción y en las relaciones sociales con un carácter socio-histórico. En este sentido Lerner (1990) manifiesta: "Las mujeres, cuando piensan fuera del patriarcado, añaden ideas que transforman el proceso de redefinición" (p.79).

Pero, ¿Cómo se visualizan esas transformaciones ocurridas en las mujeres en los espacios mixtos, en contextos de lucha política y de relaciones de género, excluyentes y desiguales? Puede argumentarse que en los espacios en los que estas mujeres están participando -los CPes importante su presencia, no sólo por el significado que tiene la lucha o luchas, sino también por los aportes a su vida.

Las mujeres que están dando la lucha actualmente encuentran un factor de motivación en lo histórico, en relación con diversas luchas, por ejemplo la del Combo ICE en el año 2000. Ellas sienten que además de 
aportar a la lucha, ellas se benefician, en términos de mayor confianza en sí mismas, logro de reconocimiento, experiencias compartidas, nuevos conocimientos $y$, en algunos casos, mediante el desarrollo de procesos de crítica y autocrítica.

Lo anterior se ilustra por medio de los siguientes testimonios:

Se está forjando una ciudadanía, planteando propuestas, hay capacidad de protesta. Es importante rescatar que los partidos políticos han sido históricamente excluyentes y los comités patrióticos incluyentes (Alina, entrevista personal, 21 de mayo de 2010).

Las mujeres durante toda la historia han sido promotoras de cambio social, cultural, etc.; no obstante la sociedad ha invisibilizado su accionar. Dentro de los comités patrióticos las mujeres, desde sus diferentes percepciones de la realidad, han contribuido al cambio social de una u otra manera, su participación contribuyó a elevar el nivel de conciencia social y a vencer los miedos a denunciar y manifestarse en contra de los atropellos por parte de los gobernantes y políticos (Guiselle, entrevista personal, 21 de mayo de 2010).

Las mujeres organizadas en los $\mathrm{CP}$, de este modo están en la búsqueda de nuevas formas de pensar, de participar, de hacer política desde sus intereses particulares y grupales, dentro de procesos de construcción de nuevas identidades.

\section{¿Por qué las mujeres se organizan?}

Dentro del orden cultural dominante, las virtudes y capacidades de racionalidad, fortaleza y voluntad se consideran propias del hombre. Cuando las posee una mujer o un grupo de mujeres se les masculiniza en la percepción social y se les señala como féminas que reniegan de su presunta naturaleza.

El mundo globalizado, dominado por el sistema económico neoliberal, no solo obedece a una estructuración económica mundial injusta, también a otra estructura de dominación, igualmente mundial, que es el patriarcado. La dominación patriarcal puede tomar diversas manifestaciones y cambiar a lo largo del espacio y el tiempo, no obstante, la dominación y la subordinación de las mujeres son universales.

Al respecto, Zabala se refiere a los procesos de naturalización de las estructuras de dominación del género en los términos siguientes:

Una sociedad asimétrica, en la que el poder, el prestigio, la fuerza y la riqueza se conjugaban en masculino, y dejaba a las mujeres los ámbitos considerados complementarios, tales como el cuidado, la 
ternura, el servicio, el don de sí, la docilidad, la obediencia (2008, p.46).

Se logra así detectar procesos de maduración que cuestionan esa naturalización de las relaciones de poder entre géneros por parte de las mujeres que participan de estos espacios organizativos mixtos. Al respecto una entrevistada expresó lo siguiente:

[...] son espacios ciegos para las mujeres, se ocultan las diversidades, han crecido los movimientos de mujeres con esas visiones, se han debilitado, pero también hay demandas democráticas de mujeres, cada vez se acercan más a espacios feministas y en este caso los comités patrióticos no son amigables para las mujeres con espacios propios (Tania, entrevista personal, 22 de noviembre de 2009).

Hay un cuestionamiento que, a su vez, reclama una reflexión adicional cuando una informante clave propone: "No se logra casi nada desde los espacios de organización político ideológico, porque se refuerzan espacios conservadores con visión de mujeres cuota, sin identidad, se alimenta la fantasía que negociamos con equidad, las mujeres no aportamos y nada pasa" (Tania, entrevista personal, 22 de noviembre de 2009).

Otra informante clave cuestiona esa relación de desigualdad entre los hombres y las mujeres: "No nos podemos saltar procesos históricos, las mujeres han logrado llegar a liderazgos locales porque es más cercano a su cotidianidad, llegar a otros espacios está limitado por los patrones patriarcales que demandan otros valores" (Cecilia, entrevista personal, 19 de abril de 2010).

Pero, otra entrevistada vislumbra esperanza más allá de esa realidad de desigualdad, porque, hay "Nuevas maneras de interpretar y organizar nuestra realidad. Pasar de la dominación a la asociación con esperanza global" (Guiselle, entrevista personal, 21 de mayo de 2010).

De forma similar, las mujeres organizadas en el CP de Occidente, reclaman y al mismo tiempo ofrecen opciones para superar esas visiones y prácticas patriarcales:

La formación de las mujeres es relevante, si tenemos una posición política para vincularnos, es más fácil ahora porque se ve aquello que se está movilizando y otras personas que no hacen nada. Si hablamos desde nuestras mamás, ¿Quiénes construyeron las escuelas? [...] Somos las mujeres, a pesar que estamos invisibilizadas tenemos espacios importantes para hacernos visibles (Entrevista realizada en San Ramón en el año 2011). 
En la dinámica y organización de los $\mathrm{CP}$, otro cambio observado es la incorporación de la familia en las responsabilidades del comité y sus luchas. El componente familiar en algunos casos no es un obstáculo para decidir, participar, involucrarse en todas las actividades que amerita el trabajo comunal, político, ambiental, entre otros. Al igual que las relaciones familiares, las prácticas sociales y comunitarias les motivan para su crecimiento y bienestar personal.

Los datos y los testimonios presentados en la investigación ponen de manifiesto las posibilidades y los espacios que algunos comités han brindado a las mujeres participantes en términos de participación y gestión política, del aporte de sus conocimientos, capacidades y experiencias.

Una mujer integrante del CP de Paso Ancho, manifiesta que "El comité sí ha tenido transformaciones después del TLC, se maneja más articulado y la incorporación de la juventud refresca la organización" (Marielos, Entrevista personal, 12 de setiembre de 2010).

Sin embargo, desde el punto de vista de las relaciones de género, un elemento que obstaculiza la inserción de las mujeres en los comités se encuentra todavía en el imaginario, se perciben como "vagas, que deben estar en la casa y no en la calle", lo cual evidencia la doble discriminación que afrontan, por ser mujeres desarrollándose en espacios políticos socialmente aceptados solo para los hombres. El siguiente testimonio evidencia lo anterior, además con contenido homofóbico:

[...] les dicen marimachas, la gente inventó este término porque son mujeres valientes, hablan la verdad. Para que la mujer pierda el miedo tiene que hacer muchas cosas que hacen los hombres, debe ser muy fuerte. Los hombres y las mujeres desprecian a esa mujer que los descalifica, a ella misma le pasó, su propia familia la marginó por ser comunista (Alejandra, entrevista personal, 21 de enero de 2011).

Las investigadoras Farah y Salazar (2009) tratan de hacer un llamado contra las injusticias que recaen sobre las mujeres, cuando procuran invadir los espacios propios del poder patriarcal:

[...] la persistencia de sistemas culturales de género que no reconocen a las mujeres como proveedoras pone bajo sospecha la participación política de las mujeres, al vulnerar el poder y supremacía masculina en la representación política, y las culpa por salir de los hogares a trabajar a causa de la compulsión económica de generar ingresos en los mercados nacionales e internacionales (p. 14).

Asimismo, los testimonios dados por mujeres demuestran la desigualdad y la deslegitimación desde la cuales las mujeres deben llevar adelante su participación política. 


\begin{abstract}
¿Qué hace falta? Flexibilidad en los partidos políticos con estructuras viejas y tradicionales, con procesos mentales ya desfasados y adquirir nuevas formas de pensamiento, ya todos los CP realizaron un planteamiento, dar un pronunciamiento de NO a la Violencia, tienen que darse acciones de desobediencia civil (Teresita, entrevista personal, 01 de marzo de 2011).

Siempre son ellos los que dirigen las reuniones aunque seamos nosotras las que aportemos las ideas (Karen, Entrevista personal, 04 de setiembre de 2010).
\end{abstract}

Las mujeres organizadas en los comités están asumiendo posiciones políticas, ponen de manifiesto la lucha y los avances significativos en el proceso de superación de esas identidades socialmente construidas desde lo patriarcal y hegemónico. Sus argumentos, asentados en un análisis que incorpora elementos críticos, aportan elementos que contribuyen a develar los contextos próximos de desigualdad, las asimetrías de género, y los diversos estereotipos que impactan en sus vidas, en el querer vivir entre otros y otras, sin discriminación de género y exclusión en la participación política. Despliegan así una lucha contra una doble discriminación: por ser mujeres y mujeres desarrollándose en espacios políticos.

\title{
El peso de la mirada patriarcal
}

El patriarcado como estructura social, cultural, política, se reproduce igualmente en lo organizacional. Coloca al hombre como sujeto único de la sociedad, de la historia, como medida y referente del accionar cotidiano, así como en el desarrollo a largo plazo e incluso en el origen de las sociedades.

Cuando las mujeres descubren y develan lo que ellas realizan, aportan, construyen y proponen en ese accionar cotidiano, ocurre entonces, según Femenías (2009), el "mirar la historia con ojos de mujer que ha permitido visualizar cuál ha sido su papel en lo social, económico, político y cultural" (Seminario CIICLA-UCR, 2009, párr.2).

La mirada con ojos de mujer de acuerdo con Femenías produce en las mujeres reacomodos o descontentos, que les permiten comprender acciones que anteriormente las aceptaban como normales; por ejemplo, a) la jerarquía en las asociaciones, comités, luchas, convocatorias; b) las salidas a las comunidades, los nombramientos de coordinadoras 0 coordinadores, la fijación de horarios para reuniones, convocatorias, elección y priorización de temas de agenda, lugar o lugares de encuentros, reuniones; c) el peso familiar en el cuido de la prole, del oficio doméstico; d) la figura de la mujer política en la sociedad patriarcal, invadida de mitos y estereotipos, cuando les llaman vaga, puta, comunista, mala madre, buscadora de hombres. 
Femenías enfatiza en que "Hay que tratar de evitar el riesgo de adherirse al discurso patriarcal masculino, haciendo gala de todas aquellas características consideradas como femeninas (tolerancia, sensibilidad, humanidad, solidaridad). Sin embargo, ahora hay que tener presente que muchas veces esto no se logra alcanzar" (Seminario CIICLA-UCR, 2009, párr. 6).

Lo anterior es una llamada de atención en relación con el riesgo de caer en el juego de poder que reproduce el discurso patriarcal y abre espacios a la culpabilidad o la autojustificación, según los estereotipos de mujeres sensibles y tolerantes. Es el riesgo de asumir pasiva y acríticamente los cargos y papeles impuestos socialmente por y para los hombres.

Estos comportamientos también se reproducen en los comités. Un caso que los ilustra es el del CP de Barva de Heredia, -posteriormente transformado en el Partido Barva Unida- durante la participación en las elecciones municipales. El candidato para la alcaldía del gobierno local de Barva de Heredia es un hombre y una de las mujeres es la candidata a vicealcaldesa, quien manifiesta "Eso lo negociamos, porque los hombres pueden arriesgarse más... mi mamá me lo dijo, si llego a quedar de vicealcaldesa no me cuidará a mi hijo, tengo que ver qué hago entonces".

Así, las desigualdades manifiestas en las relaciones de género se expresan como construcciones identitarias (Lerner, 1990), que a su vez hacen manifiesta la existencia de las relaciones de poder asimétricas $\mathrm{y}$, respectivamente, visiones de mundo y construcciones simbólicas donde las mujeres están en condiciones de desventaja abierta en el ejercicio del quehacer político diario.

Los siguientes comentarios ilustran cómo se desarrollan y evidencian las desigualdades.

En las sesiones municipales hay luchas de poder en las sesiones, porque el machismo en las sesiones municipales es evidente, por ejemplo, cuando hay actividades, ¿quiénes cocinan? Son las mujeres. En la agrupación Coalición son los hombres los que visitan a las comunidades, las mujeres son muy pocas. (Mireya, entrevista personal, 15 de diciembre de 2010).

Todas las organizaciones donde hay mujeres estamos en proceso de algo, estamos trabajando en algo, cuando se haga conciencia de esto vamos a avanzar mucho, por ejemplo el tema de violencia doméstica no tiene incidencia productiva en el país, pero es algo por lo que hay que luchar bastante. (Grace, entrevista personal, 15 de diciembre de 2010).

El hecho de que estas mujeres reflexionen sobre las circunstancias en que se desarrollan dichas inequidades, es importante para que no se continúe en la opresión y discriminación cotidiana entre los géneros. 


\section{Implicaciones para las mujeres al asumir responsabilidades políticas}

Ante todo, es importante aclarar que cuando las mujeres deciden incursionar en política no significa que se encuentran liberadas de los roles tradicionales de su género, más bien se suman los nuevos a los ya existentes.

Asumir nuevos roles más los que ya tiene "cargados", porque debe demostrar que el entrar al ejercicio público de la política es capaz y valiente de asumirlos, es doble o más el desgaste de sus tareas por cumplir en el tiempo y sus resultados (Betty, entrevista personal, 15 de diciembre de 2010).

La participación de las mujeres en el ámbito laboral y social las obliga a ubicarse en los procesos sociales y políticos que ha vivido y vive el país en torno a la movilización y organización, con las implicaciones en términos de aporte, de modificación de estructuras organizativas e institucionales (incluidas las gubernamentales), y de las formas de concebir e implementar los procesos mismos. Las condiciones generadas por estos procesos han movilizado a la mujer de un contexto privado hacia uno público.

Se observa que la muestra de mujeres entrevistadas en esta investigación, ha logrado realizar cambios que significan reivindicar, por parte de sus familias y su pareja, el respeto hacia sus actividades en el $\mathrm{CP}$, en la comunidad y con otras organizaciones sociales. En cuanto a las relaciones entre hombres y mujeres dentro de los $\mathrm{CP}$, las órdenes ya no son verticales hacia el sector femenino; se presenta una distribución equitativa de las tareas; se discuten las decisiones para no perjudicar a nadie; por ejemplo, al definir las horas de reunión se toman en cuenta las responsabilidades familiares.

Para que la participación de las mujeres sea más representativa en los ámbitos políticos y en otros espacios de toma de decisión, se deben superar diversos obstáculos, tales como:

- Aquellos de carácter subjetivo que impiden el ejercicio activo de la ciudadanía por parte de las mujeres. Estos traen como consecuencia la inseguridad de las mujeres respecto a su capacidad para una participación activa en espacios políticos o ciudadanos.

- La resistencia de algunos políticos al acceso de las mujeres a su mundo, por considerarlo una invasión al espacio tradicionalmente masculino.

- La difícil compatibilidad para muchas mujeres entre su vida familiar y el trabajo político. 
- Aquellos que tienen que ver con las barreras impuestas por el poder político y social patriarcal, generalmente de carácter formal: los partidos políticos, los sindicatos, los ministerios, las empresas, las organizaciones y asociaciones gremiales; las leyes, los procedimientos y las instituciones, a menudo deniegan el acceso a las mujeres.

Son asuntos importantes para comprender cuándo y qué es necesario transformar. Es la idea de la acción política como vivencia de transgresión para el desarrollo de las capacidades y el aprendizaje desde su experiencia. También se relacionan con la capacidad para resignificar esos procesos, desde los cuales desarrollar sus posibilidades para construir espacios sin imposiciones ni dominación.

\section{Explorar cómo la identidad y la capacidad de acción de las mujeres provoca cambios subjetivos y colectivos}

En la construcción de los rasgos identitarios ¿de dónde vienen los miedos? ¿Cómo replantear la identidad? ¿Existe una crisis de la subjetividad? Durante el proceso se plantean luchas por el reconocimiento, la apropiación y la legitimidad. Surge entonces la imagen de mujeres involucradas en procesos de transformación social, cultural, económica y política, lo que implica, a su vez, la transformación de las condiciones de su propia existencia y de sus contextos más cercanos. También emergen nuevas problemáticas alrededor de la contradicción que suponen los avances en la conquista del espacio público y la ausencia de una transformación cultural y social para asumirla.

Diversidad de estructuras y lógicas circulan en torno a la segmentación, los roles y la división del trabajo entre los sexos y afectan al desarrollo de la cotidianidad, la cual se configura como un producto que refleja la asignación "sexuada y generizada" de hombres y mujeres. Siguen adquiriendo dimensiones difícilmente compatibles con el discurso de la equidad: la separación entre espacios domésticos y públicos, la proyección social del trabajo masculino frente a la invisibilización del femenino y la escasa conciliación entre vida familiar y profesional.

A pesar de las diversas manifestaciones, actuaciones y denuncias aún permanecen vigentes dichas asimetrías entre lo público masculino y lo privado femenino, entre lo familiar y lo profesional, entre hombres y mujeres. Los siguientes testimonios exponen esas realidades:

Consideran que actualmente hay un nuevo posicionamiento en la comunidad. Existe un mito: el que se mete en política es deshonesto, en las municipalidades son los hombres los que hablan, los hombres odian a la organización Mujeres Unidas en Salud y Desarrollo (MUSADE), ellas no saben el porqué, porque todos los hombres son los que tienen el poder, creen que tenemos que hacernos valer, diciendo soy la esposa de... 
(Felicia, entrevista personal, 15 de diciembre de 2010).

Actualmente las mujeres no nos hemos decidido a liderar esas organizaciones, ellos son siempre los que las dirigen (Cristina, entrevista personal, 04 de setiembre de 2010).

Ha sido dura la lucha de género, porque hasta hay gente mayor que no acepta a las mujeres en la lucha político-organizativa, es un proceso, pero ha habido bajas, por ejemplo dos hombres que se fueron del $\mathrm{CP}$, porque no pudieron con ella, no permitían que ella les diera directrices por seguir (Alejandra, entrevista personal, 21 de enero de 2011).

La subjetividad como proceso de dar sentido a determinadas situaciones contribuye a distinguir criterios de identificación y de pertenencia a grupos. Implica a su vez lo que se produce y reproduce históricamente, que requiere de experiencia y vivencias, de memoria histórica para responder a preguntas como ¿qué quieren las mujeres?, ¿qué pueden ser?, ¿qué necesitan?, ¿con quiénes se están relacionando?

Asimismo, la subjetividad dispone de los sentidos ¿qué ver? ¿qué buscar? También, para desmontar contextos próximos ¿cómo hacen las personas para asumir responsabilidades?, ¿cómo se construyen las capacidades y potencialidades de las personas que participan en la organización política?

Crear discursos y formas de entender el mundo, alejadas del punto de vista patriarcal, implica romper con estereotipos que subordinan a las mujeres y las reducen a un papel de cuidadoras, madres exclusivas, mujeres objeto. Por tanto, equivale a construir nuevos modelos que critiquen personajes femeninos en conflicto consigo mismas o con el mundo.

Jelin (1987) propone que "la identidad es el elemento clave para entender el movimiento social de las mujeres" (p.54), elemento que se constituye alrededor de la identidad de género, la cual es la síntesis explícita de los distintos roles tradicionales que las mujeres asumen: ser madre, ama de casa, esposa, acompañante, servidora. Sin embargo, es importante reconocer el carácter sociocultural e histórico de la denominación de géneros, sus nociones legitimadas por la sociedad para excluir y discriminar a las personas que no responden a esa identidad impuesta.

En esta investigación, sin embargo, se encontró mujeres que transgreden esos patrones tradicionales. En lo político, encontramos como ejemplo de ello mujeres del CP de Curridabat que participaron en las elecciones municipales para elegir a otros representantes de la comunidad, organizaron otro partido político alternativo y se lanzaron a las calles para que la comunidad votara por esta nueva representación. 
Se presentan así procesos de transgresión que ponen en cuestionamiento los atributos culturalmente asignados a las mujeres, al confrontarse con las condiciones que genera el ser parte de un órgano social como un CP local. Lo anterior da lugar a la reestructuración simple, conflictiva y compleja, en su identidad de género; reconocen la elaboración de un proyecto político alternativo y encuentran la fortaleza para realizarlo. Estas mujeres comparten experiencias, vivencias, conocimientos y espacios de interacción social que les permiten definir sus intereses y el despliegue de prácticas políticas y organizativas.

Los puestos que ocupan los hombres dentro del sistema de cargos provoca la permanente vivencia de la contradicción marcada por la existencia de las relaciones de poder desiguales. Dichas desventajas les impide tener la movilidad institucional (dentro de la estructura patriarcal), social y política que les permitiría participar en las esferas públicas de toma de decisiones, como sí ocurre en el caso de la vinculación entre los hombres, en el sistema de cargos y el gobierno local. Por consiguiente, es relevante visibilizar dichas desventajas en lo cotidiano. Sobre este tema una entrevistada manifiesta:

[...] sí, hay un vicio patriarcal, se notó en la selección a candidatos, los hombres quisieron disimular, aguantaron todo el proceso pero con el afán de sobresalir, en tener puestos de poder, en cambio las mujeres sólo piensan en la unidad (Ivonne, entrevista personal, 4 de setiembre de 2010).

En el proceso, las mujeres avanzan hacia la elaboración de una autoimagen positiva no obstante el contexto de subordinación es generalizado. Cuando se trata de la participación política de la mujer, la situación se torna más compleja, pues a pesar de que la organización de la sociedad parte del principio que mujeres y hombres están en igualdad de condiciones, esto no opera en la realidad. Las mujeres tienen menos oportunidades que los hombres para ser tomadas en cuenta a la hora de asumir decisiones e intervenir en lo político.

\section{Posibilidades y obstáculos de las mujeres políticas. Perfiles y estrategias}

Entre las diversas motivaciones que declaran como germen de sus decisiones, la mayoría de las entrevistadas defienden el compromiso político, social y el servicio personal a la comunidad:

[...] la aceptación de que la democracia y los movimientos políticos de las mujeres van de la mano, ha empezado a surgir lenta pero persistentemente en todos los países de la región...está abriendo brecha en la conciencia histórica de las sociedades latinoamericanas. La acción política de las mujeres, en la segunda mitad del siglo XXI, deberá enmarcarse en el actual contexto 
político de los países... (Escalante, 2010, p.97).

La ilusión por trabajar, por conseguir logros para beneficio colectivo, se demuestra en estos hechos sociales:

A nivel comunal: En forma permanente las y los integrantes del CP de Hatillo, tienen mesas de diálogo con la comunidad. Ellos crearon un boletín como medio de comunicación, donde la población de Hatillo hace las denuncias, y es de tipo divulgativo y formativo. Están con el proyecto de crear un Hospital para los barrios del Sur, se unen con el CP de Alajuelita. En abril de 2009, en el mismo CP de Hatillo, realizaron un foro juvenil para dar participación a la juventud. Realizan denuncias a los órganos competentes, por ejemplo, a los medios de transporte; han denunciado el maltrato que dan los choferes a las personas de la tercera edad. (Alejandra, entrevista personal, 21 de enero de 2011).

En las mujeres políticas este reconocimiento de su contexto próximo y la necesidad consciente de transformarlo se convierten en los detonantes de su acción. Humanizar la política como esquema de acción, en el que cada mujer singular es una persona que se articula en el nosotras/nosotros colectivo, es otro reto por asumir.

La conciencia de que las mujeres enfrentan problemas que tienen que ver con un modelo dominante de construcción social, hace necesaria la acción política que trasciende lo legal. Se logra así avanzar hacia una conciencia más clara que permite evaluar en colectivo y no sólo desde lo personal. Se hace claro entonces que sus problemas son asuntos de género, de relaciones desiguales y de discriminación. Lo anterior se evidencia en la siguiente entrevista:

Las mujeres como promotoras de cambio, claro que somos capaces, pero por ejemplo, las mujeres que integran los CP para reunirnos los fines de semana, en las noches, nos está vedado en los espacios para el voluntariado. Porque, si a todos y todas se nos educara no como diferentes, tendríamos esos espacios para la labor comunitaria y se daría el apoyo comunal, por ejemplo para el cuido de hijos, hijas, ancianos, ancianas y somos las mujeres las que siempre tenemos que renunciar a esta labor del voluntariado, porque no tenemos esas redes de apoyo comunal. (Alejandra, entrevista personal, 21 de enero de 2011).

La falta de tiempo tiene efectos en el mundo social de las mujeres, quienes deben de atender relaciones personales de distinto orden al político. Las amistades se resienten, según dicen, cuando aparecen el cansancio o los enfados que no se han podido saldar en el tiempo de trabajo político. 
Muchas de las mujeres políticas en la actualidad aspiran a ser identificadas y a sentirse seguras de su rol político, de su vida, de su sexualidad, de su comunidad. Frente a esta situación, es impostergable establecer alianzas que puedan sustentar el quehacer político para las mujeres.

Pero en su mayoría el poder político sigue estando en manos masculinas y siguen respondiendo a una lógica masculina, lo que debe conducir a no olvidar quiénes están en el poder, en qué consiste y cuáles son las bases y el discurso de ese sistema. Con base en este saber se podrán proponer nuevas formas de ejercicio del poder. Son lógicas de construcción del orden social, que se producen en contextos de socialización en desigualdad. Lógicas que se expresan en el plano de lo simbólico pero también en los juegos de poder instalados como dominantes.

Para Irigaray (1992) se debe establecer que:

La justicia, en el derecho a la vida, no se puede ejercer sin una cultura capaz de considerar que el género humano está compuesto de hombres y mujeres, y sin que se recojan por escrito los derechos y deberes civiles correspondientes a sus respectivas identidades (p. 78).

\section{Punto de partida de la ruptura del orden simbólico patriarcal: hacia la visibilización de las mujeres}

Mostrar problemáticas privadas equivale a recordar los enunciados feministas de los años 70: lo personal es político. Se debilita la idea de que lo que ocurre en el espacio doméstico son problemas personales y no sociales o políticos. No sólo se pone el foco en las problemáticas, sino que se revelan los sueños y las aspiraciones de las mujeres.

Una temática más es la denuncia de violaciones a los derechos humanos básicos de las mujeres que provocan exclusión por su condición de raza, de orientación sexual, identidad de género, clase social, credo religioso, nacionalidad. La situación de inferioridad y desigualdad estructural que sufren las mujeres en todos los lugares del planeta hace que sus derechos más básicos sean vulnerados y que sea necesario exigirlos.

En una sociedad desigual, la estructura sociocultural hegemónica establece diferencias y discrimina a las mujeres a la vez que naturaliza la desigualdad, la cual se explicita en las organizaciones mixtas de los CP mediante voces femeninas.

El problema es que Curridabat sigue siendo muy pueblerino y castigan a las líderes que se lanzan de la vida privada a la vida pública (Eva, entrevista personal, 27 de mayo de 2010).

Las mujeres al incursionar en espacios prohibidos, lo que se nos viene es pensar en las nuevas generaciones, en los 
hijos, hijas, nietos, nietas. Otro asunto es la lucha por el medio ambiente y sus problemas, eso la moviliza (Natalia, entrevista personal, 26 de mayo de 2010).

A las mujeres, se les ha enseñado a través de variados espacios que ellas poseen una "docilidad" natural y que dependen de los otros para sobrevivir.

\section{Los estereotipos}

Los estereotipos los construimos en la práctica, se desarrollan, evolucionan, incluso mutan en las relaciones sociales y sus interacciones. Constituyen construcciones simbólicas que sintetizan relaciones de poder y prejuicios culturales arraigados. Generalmente, contribuyen a fortalecer el orden hegemónico vigente $y$, en ese tanto, son reflejo de la ideología dominante. Los mismos operan como justificación social de una distribución asimétrica del poder y permiten seguir manteniéndola.

Es necesario visibilizar y llamar la atención sobre las formas, los estilos, las palabras, los mensajes y hechos que acontecen en la realidad inmediata sobre y en las mujeres que se atreven a transgredir los modelos tradicionales de mujer. De acuerdo con Hidalgo (2010):

[...] lo femenino relacionado con la abnegación, el sacrificio, la atención al otro, vivir en función del otro, con la capacidad de empatía, de solidaridad, de cuidado del otro, las mujeres fuimos socializadas para eso; no nacimos para eso. Entonces, ¿qué pasa ahí con el instinto maternal?, pues que no existe. ¿Qué es lo que existe? La capacidad de vincularme con el otro que yo puedo adquirir a partir del vínculo con el otro (p.161).

Algunos de estos estereotipos que diariamente están ejerciendo ese poder mediático en las mujeres son, según nuestras entrevistadas:

En los años ochenta, a las mujeres que se organizaban les llamaban lesbianas, comunistas, actualmente son amenaza. Claro, se ha avanzado porque pueden hablar, han tomado poder, aunque hay una doble moral y podemos gozar de los mismos derechos, pero siempre hay algo que no es comprendido. A pesar que tengo un esposo comprensivo, si me viera limitada seguro estaría divorciada. (Rina, entrevista personal, 12 de diciembre de 2010).

Los movimientos feministas se rechazan porque hay un peligro que las mujeres tomen posiciones en la sociedad, somos las mismas mujeres las que hemos aportado, hay leyes y políticas que apoyan ahora a las mujeres, pero esos 
cambios los hemos dado otras mujeres. (Sonia, entrevista personal, 02 de febrero de 2011).

Su padre, su madre, sus hermanas y hermanos, la han criticado como vieja vaga, mala madre, hasta los compañeros de trabajo. (Alejandra, entrevista personal, 21 de enero de 2011).

A los jóvenes los ven como locos, porque cuando son jóvenes es difícil ser y luchar por estas luchas, para los adultos tal vez no. A ella le pasó, la profesora de físicomatemáticas del colegio donde estudiaba bachillerato le puso el ojo porque ella se mantenía firme en su convicción y cree que es peor cuando se es mujer. La veían como bicho raro, cuando se piensa diferente le dicen que es una "rara", pero no hay que olvidarse de la realidad nacional. Por otro lado, si se está en movimientos feministas, te dicen que eres lesbiana, si estás a favor del aborto, te dicen que eres hereje, si andas en marchas te dicen que eres marimacha, lo dice la gente de derecha, la gente que no entiende, ataca en vez de analizar, los menos irrespetuosos son los viejitos, no dicen nada, pero no agreden. (Laura, entrevista personal, 23 de febrero de 2011).

La pregunta que brota es si con el tiempo estas mujeres que luchan y logran acuerdos, proyectos, acciones comunales y nacionales, los mantendrán o si desplegarán trayectorias más abiertas y ambiciosas o serán las mujeres organizadas en lo político quienes se atreverán a desafiar lo establecido social e institucionalmente.

\section{Conclusiones}

Asumir los desafíos en el campo de lo social, lo político, lo económico, lo cultural y la subjetividad, caracteriza los movimientos socioculturales a los cuales se integran y por los que luchan las mujeres. Los motivos de lucha y de integración son diversos: a) necesidad de verse, sentir pertenencia a un grupo; b) las que han formado parte de un partido político de izquierda y necesitan mantener "vivo" al partido o al menos el compromiso que este expresaba; c) algunas que no están en partidos políticos quieren trabajar y luchar por los problemas del país, de su comunidad, de su barrio y continuar en un CP, el cual pasa a ser su referente, un espacio para compartir y solidarizarse; d) personas para quienes asistir a las reuniones les proporciona sentido como parte de un grupo social y afectivo.

Articular lo político con lo personal para comprender cómo el poder es mediado, resistido y reproducido en la vida cotidiana lleva a definir una pregunta política ¿cómo desarrollar un movimiento social donde las mujeres asuman un rol crítico y se coloquen en una posición significativa de respeto a la vez que avanzan hacia su efectiva emancipación? 
Es un reto que adquiere mayor significación en el contexto de sociedades cada vez más complejas y diversas, en las cuales se configuran movimientos sociales novedosos y se cuestionan los roles y relaciones de género. Hay procesos de cambio en curso y, con ello, la pugna se plantea entre la emergencia de relaciones intergénero más equitativas, frente a las estructuras del poder patriarcal tradicional, esencialmente excluyentes y opresivas.

En esta investigación se han analizado y tratado de comprender los espacios nuevos de lucha en que se visibilizan las mujeres desde su propia individualidad. En el proceso se ha constatado la práctica y el discurso de estas mujeres en su cuestionamiento sobre las estructuras económicas, sociales, culturales y políticas que mantienen las relaciones de inequidad entre los géneros.

Los cuestionamientos analizados conducen a la siguientes interrogantes: ¿desde la perspectiva de género, cómo se construye socialmente la responsabilidad de ser mujer?, en la moral costarricense contemporánea ¿sobre cuál concepción de mujer prevalecen los derechos y deberes en la formación de una nueva ciudadanía?

Se destaca también el interés de las mujeres por ocupar espacios visibles en una sociedad caracterizada por las desigualdades y las relaciones de poder asimétricas y de comprometerse en construir y desarrollar redes solidarias con el objetivo de visibilizar y viabilizar su transición desde la esfera privada (doméstica) a la esfera pública (la vida en sociedad).

En los grupos mixtos, es fácil reproducir explícita e implícitamente la desigualdad, la dominación, la opresión, la discriminación y la violencia. La sociedad ha ejercido una presión constante para evitar que en el patriarcado se sensibilicen valores cuyo origen se percibe como femenino.

El proceso investigativo mostró una doble significación para la autora:

1. El investigar temáticas de género, desde el ámbito de las mujeres organizadas en lo artístico, lo político y lo social, permite acercar y relacionar sus vidas, la de mujer investigadora y profesional, pero también madre, jefa de familia, ciudadana. Son espacios que permiten visualizar las dinámicas internas y externas de las mujeres, quienes cotidianamente vinculan lo privado con lo público. Somos producto de una socialización y construcción cultural, segmentada por la familia, la historia, los intereses políticos, ideológicos, económicos y sociales, que sujetan y estructuran comportamientos, actitudes, manifestaciones, que la sociedad espera y demanda.

Pero qué ocurre cuando se rompen esos patrones esperados, cuando las mujeres transgreden los límites establecidos, por la familia, la pareja, la organización, la institucionalidad; acontece lo que se demuestra en la investigación, los estereotipos y los mitos 
emergen para descalificar las acciones que estas mujeres luchadoras y activistas están haciendo y construyendo para sí mismas y para la sociedad costarricense.

La investigación permite visualizar a mujeres que están movilizándose en espacios políticos y artísticos por el mejoramiento del agua, la salud, la seguridad ciudadana, el ejercicio público, por la definición y ejecución de políticas públicas sanas, democráticas y, sobre todo, porque sean equitativas y justas.

2. En la Universidad Estatal a Distancia (UNED), la investigación con perspectiva de género se encuentra en punto de partida. No obstante, la perspectiva de género es un eje transversal en la institución, es un compromiso integrarlo en las prácticas cotidianas que se ejerce en las tutorías, en los múltiples departamentos y oficinas a cargo de la administración, en las escuelas, en las esferas donde se planifican y toman las decisiones, es decir donde estén presentes las relaciones entre géneros.

El objetivo es también potencializar la construcción de prácticas culturales en género, tomando en cuenta el conocimiento generado en las investigaciones.

\section{Bibliografía}

Boletín 18 de mayo 2011 del Movimiento Patriótico Juanito Mora, año 4, N ${ }^{\circ} .47$ /Julio 2011/ En: Ferlini, H. Periódico digital Surcos en Movimiento. (2011). año 4, №.47. San José, Costa Rica.

Castañeda, S. (2008). Metodología de la investigación feminista. Antigua Guatemala. Guatemala: Fundación Guatemala. Centro de Investigaciones Interdisciplinarias en Ciencias y Humanidades.

Conversatorio Asociación de Estudiantes de Filosofía, Universidad de Costa Rica. (2007). Costa Rica escenario político postreferéndum. Obtenido de http:www. heliogallardoamericalatina.info

Escalante, AC. (2010). Gobernabilidad y convivencia democrática en América Latina: el papel de las mujeres. San José, Costa Rica: FLACSO.

Farah, I. y Salazar, C. (2009). Neoliberalismo y desigualdad entre mujeres: elementos para replantear el debate en Bolivia. En: Género y globalización. Buenos Aires, Argentina: CLACSO.

Femenías, M. (2009). Seminario el feminismo en América Latina. En: Centro de Investigación Identidades Latinoamericanas. (CIICLA). 
Facultad de Letras. Universidad de Costa Rica.

Hidalgo, R. (2010). La Medea de Eurípides. Hacia un psicoanálisis de la agresión femenina y la autonomía. San José, Costa Rica: Editorial UCR.

Irigaray, L. (1992). La cultura de la diferencia. En: Yo, tú, nosotras. Madrid, España: Ediciones Cátedra.

Jelin, E. (1987). Ciudadanía e identidad. Las mujeres en los movimientos sociales latinoamericanos. Ginebra: UNRISD.

Lerner, G. (1990). La creación del patriarcado. Barcelona: Editorial Crítica.

Martínez, M. (2008). El estado actual de los movimientos sociales latinoamericanos. En: Los movimientos sociales del siglo XXI. Diálogos sobre el poder. Caracas, Venezuela: Fundación Editorial el perro y la rana.

Párraguez, L. (2010). La reconfiguración de los movimientos sociales en el proceso global de urbanización capitalista. Revista Internacional de Sociología, 68 (3), 705-730.

Rayner, J. (2008). Neighbors, Citizens and Patriots. The Spatiotemporality of Resistance to Neoliberalism in Costa Rica. Ponencia presentada en las Jornadas de Investigación del Instituto de Investigaciones Sociales. San José, Universidad de Costa Rica.

Vargas, L. (2008). Construcción de alternativas más allá del TLC (2). El punto de partida. San José: EUNED.

Vargas, L. (2009). Programa Globalización Cultura y Desarrollo. Vicerrectoría de Investigación. UNED.

Young, I. (1990). La justicia y la política de la diferencia. Cap.II. Las cinco caras de la opresión. Madrid: Ediciones Cátedra.

Zabala, B. (2008). Movimientos de mujeres. Mujeres en movimiento. Nafarroa: Tzalaparta. 


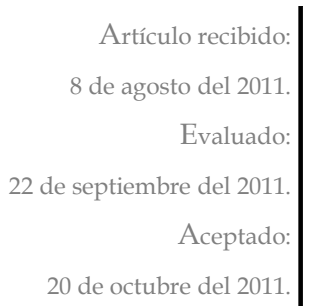

de octubre del 2011
La creación de respuestas con The Creation of Answers with
sectores sociales rurales: Retos Rural Social Sectors: The
desde la investigación
Challenges of Research

RESUMEN

El artículo presenta el Programa Gestión de Alternativas de Organizaciones Indígenas y Campesinas Mesoamericanas (PROICAM), integrado en el Centro de Investigación en Cultura y Desarrollo (CICDE) de la Universidad Estatal a Distancia (UNED). Desde la propuesta de investigación acción de este programa se cuestiona la construcción de alternativas de desarrollo para sectores excluidos de la sociedad; en especial en el agro. La pregunta que este texto formula gira alrededor de los elementos metodológicos implicados en la construcción de alternativas para sectores excluidos en el actual modelo de desarrollo aperturista. El texto brinda posibles orientaciones metodológicas sobre el tema.

Palabras Clave

Construcción de alternativas, investigación acción, foro economía solidaria, sectores excluidos
ABSTRACT

The text presents the PROICAM research programme integrated into the CICDE at UNED. Since its proposal of action research and initial experiences, it wondered on the construction of alternative development for excluded sectors of society in particular in the agricultural sector. With the experience carried out in connection with the National Forum Solidarity Economy (2010), the question was asked is about the methodological elements involving the construction of alternatives for disadvantaged sectors in the development model do, which has widened the gaps and inequities in the region and the country.

\section{KEY WORDS}

Construction of alternatives, researchaction, solidarity economy forum, excluded sectors

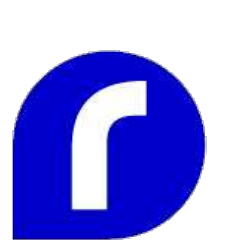

Jorge Luis Hernández Cascante
Máster en Sociología. Integrante de redes de organizaciones campesinas en Costa Rica y Mesoamérica. Coordinador del Programa Gestión de Alternativas de Organizaciones Indígenas y Campesinas Mesoamericanas (PROICAM) del Centro de Investigación en Cultura y Desarrollo (CICDE). Correo electrónico: jorgedezca@gmail.com 


\section{La creación de respuestas con sectores sociales rurales: retos desde la investigación}

\section{Introducción}

En este texto se discuten las posibilidades de la ciencia social para brindar respuestas a los retos y circunstancias limitantes que envuelven a los sectores excluidos del desarrollo, especialmente en el agro. En específico se plantea el caso del Programa Gestión de Alternativas de Organizaciones Indígenas y Campesinas Mesoamericanas (PROICAM), incorporado en el Centro de Investigación en Cultura y Desarrollo (CICDE).

Bajo la misma orientación, se analizan las implicaciones de crear estas respuestas o alternativas. Por tanto, el texto se centra en la exploración de algunos criterios metodológicos que desde este programa se plantean para la construcción de alternativas de desarrollo para los sectores subordinados o excluidos ${ }^{1}$.

La construcción de propuestas alternativas es una premisa orientadora de este artículo. La misma nos remite al problema de la construcción de conocimiento social en un marco igualmente social, en el cual hay un importante tránsito de intereses y significaciones por parte de los sectores involucrados. La complejidad de intereses surge desde los diversos actores e instituciones sociales, y se expresa conforme a los objetivos e intereses grupales, territoriales o culturales.

Para la presentación y discusión del problema en mención, interesa incorporar algunos aportes sobre el PROICAM en el ambiente institucional de la Universidad Estatal a Distancia (UNED). Se enfatiza la orientación del PROICAM hacia la gestión de propuestas, fundamentadas desde la constatación teórica y empírica que surge del diálogo con los actores directos. Este punto se desarrollará bajo el título: Construir investigación con sectores agrarios.

1. Para ese fin se retoma, con criterios ilustrativos, la realización del pasado Foro Nacional de Economía Solidaria, celebrado en noviembre de 2010 en las instalaciones de la Universidad Estatal a Distancia (UNED), así como los elementos utilizados para su puesta en práctica. 
La estrategia del PROICAM plantea el problema de la construcción de propuestas o respuestas, como ejercicio intelectual y como compromiso institucional, en relación con los sectores a los que se orienta. Para ello se incluye el punto El proceso de construcción desde la investigación acción. Como derivación del mismo tema se incorpora la pregunta sobre lo que es alternativo en el apartado Crear respuestas o alternativas al modelo vigente. De igual forma, interesa delinear brevemente algunos elementos metodológicos sobre el concepto de sectores excluidos o vulnerables en la coyuntura de desarrollo del país. Para ello se plantea el siguiente punto: Los sectores excluidos.

A partir de esos temas desarrollados, el texto revisa, a modo de ilustración y práctica, el caso del Foro Nacional de Economía Solidaria realizado a finales del año 2010. Este ejercicio fue un recurso de método para ayudar a identificar y confrontar, con pertinencia histórica, algunos elementos o factores que podrían ser incorporados en la construcción de respuestas o alternativas. El documento cierra con un apartado de conclusiones.

\section{Construir investigación con sectores agrarios}

EI PROICAM se propone como un esfuerzo de investigación acción universitaria. El programa está organizado en varios proyectos orientados hacia la búsqueda de respuestas, institucionalmente organizadas, de apoyo a los sectores rurales excluidos del desarrollo actual. De igual manera, busca atender y responder a la pérdida de patrimonios culturales y formas de vida agrarias que van reduciéndose o desapareciendo ante la modernidad vivida en la región.

Los proyectos por desarrollar se apoyan en las corrientes de nueva ruralidad, impulsadas principalmente desde las instituciones internacionales que operan en apoyo al sector agropecuario, tales como el Centro Latinoamericano de Ciencias Agrícolas y el Instituto Interamericano de Cooperación para la Agricultura (IICA).

En el contexto de la coyuntura que vive la región, el PROICAM se justifica ante todo como un apoyo a los esfuerzos de la sociedad civil en los territorios rurales, en un reiterado intento por encontrar opciones o posibilidades para afrontar, y en lo posible superar, los efectos no deseados que conlleva la propuesta neoliberal vigente en la región.

Este programa propone generar respuestas, "institucionalmente más orgánicas (más cercanas y oportunas para las expectativas de los sectores rurales), que atenúen la drástica reducción estructural de los espacios de reproducción y producción cultural de las familias indígenas y campesinas" (PROICAM, 2009, p. 3). 
Con esa intención, en el PROICAM se plantea una orientación metodológica de investigación acción cuyo objetivo es: "Concebir espacios de investigación científica que articulen el quehacer de la Universidad con las organizaciones campesinas e indígenas de la región mesoamericana, con el fin de generar respuestas rigurosamente fundamentadas que promuevan y apoyen el desarrollo autónomo de estos actores sociales" (UNED, CU, 2010, p. 4).

Se nota, a través de este objetivo, el interés del PROICAM en la generación de alternativas o respuestas históricamente válidas para los sectores a los que dirige su gestión.

Conforme con lo refrendado oficialmente por la UNED (acuerdo CU-2010352 , art. 5, reglamento anexo, p. 4), ese objetivo general del programa se reafirma mediante tres de cinco objetivos programáticos que orientan los proyectos involucrados en el programa (CICDE, 2010, p. 146):

- Construir un programa de trabajo donde investigadores/as y productores/as agrarias, se orienten en la búsqueda y sistematización de opciones o alternativas de desarrollo para los sectores indígenas y campesinos en el país o la región Mesoamérica.

- Diseñar y compartir un conjunto de investigaciones que aporten recursos de análisis e interpretación, sobre la realidad indígena campesina en el contexto actual.

- Acompañar y profundizar en alternativas o propuestas/ experiencias exitosas de las organizaciones, con las que se establezcan acuerdos de trabajo.

EI PROICAM, en tanto programa, es parte constitutiva del CICDE, el cual opera desde la Vicerrectoría de Investigación de la UNED. La vinculación del programa a este centro obedece a los intereses compartidos, así como al enfoque de trabajo investigativo en función de sectores vulnerables 0 excluidos de la sociedad costarricense. Consecuentemente, comparte con el resto del centro universitario la necesidad de generar alternativas de desarrollo en beneficio de estos sectores.

El objetivo general del CICDE ilustra su direccionalidad y coincidencia con lo antes anotado:

Desarrollar investigación científica orientada a la indagación sistemática y rigurosa sobre la cultura y los problemas del desarrollo, desde una perspectiva de construcción de alternativas democráticas, participativas, ecológicas y socialmente inclusivas (UNED, CU, 2010, p. 4). 
Igualmente, se delinean algunos criterios sobre el enfoque epistemológico del Centro que resaltan características tales como su perspectiva crítica, pluralista y propositiva. De esta última cabe retomar que el CICDE:

[...] se asienta en una concepción del quehacer científico que combina la exigencia de rigor y excelencia, con el esfuerzo sistemático en procura de democratizar el conocimiento mediante el acercamiento a las realidades y vivencias de los actores sociales así como la interrelación viva y el diálogo abierto con tales actores (CICDE, 2010, p. 14).

En los siguientes términos lo propuso el rector de la Universidad Estatal a Distancia, en ocasión de la clausura del Foro de Economía Solidaria:

Cuando hablamos de hermandad casualmente ahí es donde hacemos las cosas diferentes. Esta [el foro] es una actividad abierta, solidaria y ahí es cuando tenemos que hacer énfasis que lo que falta es reactivar esa solidaridad. No puede ser posible que la gente, que sufre las consecuencias de las políticas, nos quedemos con los brazos cruzados, y en actividades como estas vemos el potencial que tenemos, no necesitamos a los políticos para hacer el cambio, lo que se necesita es voluntad, y aquí es cuando entramos las universidades públicas como la UNED, que nació para darle voz a quien no lo tiene y dar el conocimiento donde otros no llegan, así deberían ser todas la universidades públicas (PROICAM, 2010b, p. 30).

Esta opinión expresada en la clausura del citado foro es congruente con la misión de la UNED. En similares términos se expresa esta orientación, en el acuerdo del Consejo Universitario relativo al modelo pedagógico de la UNED, donde se señala:

La UNED conserva su vocación de ser conciencia crítica de la sociedad costarricense (Segundo Congreso Universitario, moción 009; Lineamientos de Política Institucional, Numeral I), en particular, mantener los valores y promover las acciones y el cambio social que ayuden a enfrentar las amenazas de deterioro del ambiente, de las armas de destrucción masiva, de la globalización de la economía, de la injusta distribución de los bienes y la cultura y de las discriminaciones sociales, para orientarse hacia la construcción de una sociedad más justa (UNED, CU, 2004, p. 7).

La propuesta de una universidad orgánica y necesaria para las mayorías excluidas es un imperativo que se lanza frecuentemente a la corriente de opinión en toda la región. Como lo señala el siguiente autor: 
La universidad, en tanto producción cultural de la sociedad, se encuentra situada en un contexto histórico y en una sociedad particular, de la cual no puede permanecer aislada. La universidad debe tener la capacidad de responder a las necesidades de su entorno con propuestas adecuadas a sus valores y su cultura. Además debe ser capaz de ver al futuro, de identificar los nichos y los cauces apropiados para una transformación de la sociedad hacia un estadio donde el hombre pueda lograr un desarrollo más justo y pleno (Ibarra,

Se cierra este punto sobre la gestión del programa y el CICDE en el marco de una universidad que se plantea la tarea de comprometerse orgánicamente con los sectores excluidos.

\section{El proceso de construcción desde la investigación acción}

Acorde con las orientaciones del PROICAM, se opta por asumir estrategias metodológicas que propician la investigación acción. Cabe recordar que esta forma de investigación es una orientación metodológica de largo historial en la región latinoamericana.

Algunos autores, cuyas ponencias reúne Fals Borda (1998), señalan la investigación acción como una corriente de pensamiento que tiene raíces desde los años 40 del pasado siglo, aunque tiene su despliegue más amplio en los años 70. En esa década es importante recordar la celebración del Simposio Mundial sobre la Investigación Acción de Cartagena, Colombia, en abril de 1977. Este encuentro mundial, orientado por el sociólogo y educador popular Orlando Fals Borda, y otro realizado 20 años después, dieron relevancia a una gama de tendencias y estrategias metodológicas. De hecho, en la actualidad se proponen diversas denominaciones: "investigación acción, investigación para la acción, investigación en la acción, investigación participativa, investigación militante, e investigación acción participativa (IAP)" (Pulido, Ballén y Zúñiga, 2007, p. 41).

Desde esa perspectiva, en el PROICAM, la investigación acción se visualiza como un proceso metodológico de integración de esfuerzos, donde confluyen el aporte académico y el aporte experiencial vital de los actores sociales, en este caso agrarios.

En el PROICAM la producción de conocimientos surge desde la confrontación teórico conceptual con la realidad y los procesos históricos que viven los actores sociales agrarios. En esa confluencia se suman voluntades académico institucionales y comunales organizativas, surgiendo así la necesidad de incorporar la contribución del o la investigadora con su reflexión crítica, el ordenamiento de datos y la sistematización. 
Bajo esos marcos de diálogo, la investigación acción desde el PROICAM tiende a concebirse como una estrategia que acerca y complementa el conocimiento de sentido común cotidiano y el conocimiento científico, generado a partir de un esfuerzo consciente y metódico conforme con el planeamiento que se construye entre el sujeto investigador y el sujeto investigado.

La investigación acción en ese marco dialógico, se proyecta entonces como una estrategia de investigación en la cual aplican diversas técnicas y metodologías, hacia resultados vinculados con las acciones de los actores sociales en su contexto histórico particular. Es una estrategia investigativa orientada a precisar o producir conocimientos sobre problemas sociales y aumentar la participación y empoderamiento de los actores sociales involucrados. Lo anterior con el fin de generar conocimiento factible de ser utilizado en la superación de las situaciones estudiadas. El Congreso Mundial de Cartagena ya citado, concluye señalando que la investigación acción es una investigación participativa que puede definirse como:

Un método de estudio y acción que va al paso con una filosofía altruista de la vida para obtener resultados útiles y confiables en el mejoramiento de situaciones colectivas, sobre todo para las clases populares. Reclama que el investigador o investigadora base sus observaciones en la convivencia con las comunidades de las que también obtiene conocimientos válidos. Es inter o multidisciplinaria y aplicable en continuos que van de lo micro a lo macro de universos estudiados, pero siempre sin perder el compromiso existencial con la filosofía vital del cambio que la caracteriza (Fals, 1998, p. 182).

Como se indica en el documento del proyecto sobre economía solidaria del PROICAM, la investigación acción:

[...] se orienta a través de una metodología centrada en un análisis participativo, donde los actores sociales implicados se convierten junto y con el equipo de investigadores, en los protagonistas del proceso de construcción del conocimiento del objeto que problematiza el proyecto. El proceso investigativo se orienta hacia la detección o identificación de las demandas reales relacionadas con el problema, que luego se concretan en propuestas de acción ajustadas a las necesidades de los sectores con los que se trabaja (PROICAM, 2010, p. 12).

Esta estrategia se asienta en algunos criterios orientadores:

3. Se orienta hacia el estudio de aspectos sentidos como relevantes para los actores sociales y definidos mediante apoyo, involucramiento y consulta a los mismos.

4. Es una forma de investigación cualitativa.

5. Incorpora la recuperación del saber local y la recuperación de 
otros saberes, dando protagonismo a las comunidades $u$ organizaciones.

6. Se plantea la relación dialógica y horizontal con los grupos o afectados.

7. Implica la sistematización y devolución del conocimiento reconstruido.

8. La propuesta de investigación incluye acciones educativas o de organización en la etapa de devolución de resultados.

Entre otros documentos, pueden consultarse también las 160 ponencias del congreso de Cartagena de 1997. Igualmente se sugiere revisar el aporte de autores como Ander Egg (2003) y Fals (2008).

\section{Crear respuestas o alternativas al modelo vigente}

Los puntos anteriores permiten señalar algunos criterios para las tareas de construcción que propone el PROICAM. Asimismo, le aportan algunas premisas teórico metodológicas que animan la búsqueda del enfoque de trabajo para ejecutar sus tareas, a partir de la estrategia de investigación acción. En este apartado se retoman las implicaciones que conlleva la construcción de alternativas desde un centro de investigación, para lo cual se valoran algunos de los elementos que surgen como puntos de encuentro en las diversas fuentes consultadas.

Los aportes de los autores consultados se incorporan a la discusión como elementos constitutivos, como base para la edificación de discursos alternativos. Por ello en renglones siguientes se enumeran los elementos o factores que se plantean como necesarios de tener en cuenta en la construcción de una alternativa de desarrollo.

En esto es pertinente recordar que la doctrina neoliberal, implementada mediante las políticas recientes de apertura en todos los países del área, e impulsada por los instrumentos de política comercial, también se aplica en Costa Rica a partir de la segunda mitad de 1980, por medio de los acuerdos con el Fondo Monetario Internacional (FMI) y los Programas de Ajuste Estructural (PAE). Uno de esos instrumentos, el más reciente, son los tratados de libre comercio.

Se trata de un modelo de desarrollo diseñado mediante una estrategia de liberalización y ajuste que:

[...] ha aportado una disminución de la participación estatal en los mecanismos del mercado, una mayor apertura externa, una orientación claramente definida hacia las exportaciones, una desordenada y casi anárquica proliferación de tratados de libre comercio. Pero no ha creado elementos de base para el desarrollo nacional (Vargas, 2002, p. 312). 
Estas políticas de inserción al mercado mundial desde los criterios del Consenso de Washington vienen a reforzar y ampliar la pobreza e inequidad que históricamente caracteriza al país y a toda la región. Con ellas se amplían las brechas socioeconómicas ya existentes. La crítica de ese modelo de orientación neoliberal, sentada sobre las bases históricas del intervencionismo estatal de los años 70 y 80 del siglo anterior, condujo a muchos analistas y pensadores al planteamiento y diseño de diversas propuestas de desarrollo alternativo.

Sobre este punto, se anota que hay una diversa producción bibliográfica que aborda y desarrolla esa crítica, la cual surge desde instituciones internacionales, organismos no gubernamentales (ONG) locales e internacionales (con vocación de servicio a las poblaciones menos tomadas en cuenta en la orientación de esas políticas de apertura), y en iglesias con prácticas históricas ligadas a comunidades. A manera de crítica a este modelo de desarrollo, las propuestas que se plantean como alternativas regularmente recurren a varios elementos que en su ejecución pretenden viabilizar su carácter alternativo, propositivo y, ante todo, de respuesta en beneficio de los sectores sociales desfavorecidos.

Por esta razón es necesario distanciarse del uso abusivo de lo alternativo propositivo por parte de fuentes oficiales gubernamentales, pues produce la cooptación de las estrategias participativas de desarrollo con fines de legitimación e imposición del poder sobre los sectores sociales agrarios. Propiciar una alternativa de desarrollo es una acción que desde la UNED es posible y necesaria. En este caso, es la tarea que asume el CICDE como una forma de responder a las aspiraciones de la población rural en general.

Un proyecto o modelo alternativo:

[...] debería basarse en ciertas premisas básicas: retomar y sintetizar las aspiraciones fundamentales del pueblo y la sociedad costarricense, tratar de potenciar esas aspiraciones como principios impulsores para el desarrollo futuro [...] enriquecer aquellas aspiraciones así como las formas culturales básicas que modelan esta comunidad nacional mediante la más amplia y rica interacción con el mundo pero donde dicha interacción este fundada en la solidez misma de la cultura y la identidad nacionales (Vargas, 2002, p. 283).

Un listado de aspectos para ser considerados en la elaboración de propuestas alternativas, surge desde la experiencia de la ejecución de los proyectos ejecutados desde el PROICAM, valorados como importantes de tomar en cuenta como práctica investigativa ya transitada. Los aspectos se proponen como líneas metodológicas y tienen un carácter instrumental; por supuesto, no se indican como rutas de obligada aplicación, sino como líneas de orientación general, por ejemplo: 
- La obligada lectura del contexto, en particular desde la posición o situación sociopolítica de los sectores subordinados o excluidos, que permita fundamentar posiciones críticas, sustentadas en el análisis de la información recogida.

- La perspectiva de género como visión alternativa histórico-cultural.

- La perspectiva de diálogo entre diversos sectores sociales y culturales que permite asumir el paradigma de la interculturalidad como base de análisis y proyección de acciones.

- El apoyo teórico o la construcción de conceptos orientadores para la sustentación y la comprensión más integrada de los acontecimientos e información que requieren los actores sociales.

- La redimensión de lo económico como variable importante, pero no central o determinante, en la organización de los planteamientos o construcciones.

- La valoración de lo local territorial como espacio de acción y tejido social.

- La consideración de los actores impulsores de estrategias cuando sea pertinente remarcar la atención del papel protagónico de los actores sociales, lo que implica entre otras estrategias el empoderamiento de los mismos.

- El impulso de propuestas locales y diferenciadas, enmarcadas o en consonancia con propuestas de modelo país o nacionales, bajo esquemas de complementación de lo local y lo nacional.

- La autocrítica, la retroalimentación y los mecanismos de revisión interna para los actores sociales.

- La apelación a los procesos pedagógicos participativos como recurso central para la asimilación de las propuestas por parte de los actores sociales excluidos.

- La participación protagónica como eje y constante en todas las fases del proceso investigativo, a partir de la identificación de problemas de investigación, el diseño de las estrategias metodológicas, la recolección y análisis de la información recolectada y la misma elaboración de resultados y propuestas.

\section{Los sectores excluidos}

El objeto de atención del CICDE, y del PROICAM como uno de sus programas, según el anterior recuento de sus objetivos, va orientado hacia sectores no beneficiados por la estructura de relaciones generadas en el modelo de desarrollo actual.

Su trabajo se enmarca en ese espacio de ruptura o "fallamiento social", de donde pende la vida de diversos sectores vulnerables ante la acometida de políticas de corte neoliberal que han impulsado las administraciones de gobierno recientes. 
EI CICDE aspira a ser un centro que desarrolle investigación de frontera, es decir, situada en las áreas punteras de la investigación en relación con los complejos proceso de cambio socio-cultural, económico y político que viven nuestras sociedades (CICDE, 2011,p 3).

El actual estado de desarrollo del país acusa un agresivo proceso de crecimiento esquizofrénico, donde algunos sectores empresariales y de finanzas avanzan, a la vez que otros sectores productivos quedan debilitados. En otras palabras, el crecimiento económico experimentado por el país en la práctica se expresa en incrementos en la desigualdad socioeconómica en términos absolutos. La situación se traduce en la ampliación casi exponencial de las asimetrías sociales y la exclusión como rasgo central de la dinámica que cruza toda la sociedad costarricense actual.

Sobre la exclusión social existen diversidad de planteamientos y estudios, entre los cuales se hallan las definiciones incluidas en la ponencia presentada en el XIII Informe del Proyecto Estado de la Nación titulado Exclusión social y pobreza irreductible. Reflexiones desde el caso costarricense. Con respecto a la exclusión social los autores de la citada ponencia señalan que: “... el núcleo central de este concepto no es el de las necesidades básicas insatisfechas (que plantea el enfoque de la pobreza), sino el de la marginación social, entendida como privación de ciudadanía social y afuncionalidad laboral" (Pérez, Mora y Morales, 2007, p. 3).

Asimismo, sobre este mismo tema los autores citados vinculan de manera directa la exclusión con el ejercicio del poder. En efecto "un grupo es excluido porque otro lo excluye mediante ejercicio de poder. $\mathrm{Y}$, en este sentido, estamos ante un proceso de producción de desigualdades sociales. Más aún, diríamos que la exclusión es la manifestación más extrema de la desigualdad social" (Pérez, Mora y Morales, 2007, p. 5).

Para la realidad nacional estos autores proponen cinco elementos que ayudan a comprender el fenómeno de la exclusión, a saber:

Primero, al origen de la exclusión reside en el ejercicio de poder de un grupo social contra otro(s). Segundo, como corolario de lo anterior, la exclusión es una manifestación de producción de desigualdades sociales; de hecho, es su expresión más extrema. Tercero, este ejercicio de poder genera procesos de clausura social que, si bien no se consuman como cualquier proceso social, sí generan situaciones cualitativamente diferentes. Cuarto, la exclusión es un fenómeno multidimensional, o sea hay distintos tipos de exclusiones que pueden interactuar entre ellas reforzando las dinámicas excluyentes. Y quinto, exclusión sería sinónimo de 
negación de ciudadanía social pudiendo cuestionar así su función arquitectónica de legitimación de desigualdades (Pérez, Mora y Morales, 2007, p. 6).

Por último al plantear la superación de la exclusión, en relación con la pobreza los autores citados señalan que "La reducción de la pobreza se basa en un voluntarismo moral mientras que la superación de la exclusión implica redefinición de las relaciones de poder, lo que interpela el contrato social existente" (Pérez, Mora y Morales, 2007, p. 11). En este sentido es importante señalar que:

En el país, las políticas públicas implementadas por el Estado que afectan al sector campesino, han tenido un efecto tendencialmente excluyente hacia el mismo. Como resultado, se ha profundizado la pobreza rural, la expulsión del campo y la pérdida de seguridad y soberanía alimentaria. Se ha configurado, en los últimos 25 años, un panorama rural que muestra un desequilibrio en el acceso a oportunidades y beneficios del crecimiento económico experimentado en el mismo periodo (Hernández, 2007, p 11).

Esta tendencia de exclusión se acentúa en los últimos años. En esa orientación, en un texto reciente se señala que "la exclusión campesina por efecto del mercado, ha merecido un amplio conjunto de investigaciones a nivel nacional e internacional. La primacía de la eficiencia de mercado capitalista, que se ha erigido como valor fundamental en la economía global de signo neoliberal, rige dichos procesos de exclusión" (PROICAM, 2010c, p. 10).

\section{El caso del Foro Nacional de Economía Solidaria}

En la conclusión parcial del punto anterior se realizó una enumeración de aspectos primordiales para la construcción de propuestas, a partir de la experiencia del PROICAM. En este nuevo apartado se fija la atención en algunos detalles expuestos en el Foro de Economía Solidaria, realizado como parte de los esfuerzos de trabajo conjunto del PROICAM con los sectores sociales, y por tanto se constituye en una experiencia que aunque inicial podría servir para retomar la propuesta metodológica participativa. El foro se ejecutó el mes de noviembre de 2010 luego de un proceso logístico e investigativo de aproximadamente ocho meses.

Las acciones previas a la realización de este foro iniciaron con la presentación de la propuesta, en febrero de 2010, a las contrapartes del Programa de Economía Solidaria (PECOSOL). Luego se logró crear una coordinación nacional del foro, desde junio 2010, con apoyo de los sectores indígenas, campesinos, cooperativos, de cooperación solidaria en el país, y los representantes de la Universidad Nacional (UNA) y la UNED. 
El foro inicia desde el 23 de noviembre 2010, con la instalación de la feria en la cual participan organizaciones de todo el país, fue inaugurado por don Luis Guillermo Carpio Malavassi, Rector de la UNED. Inicia con una primera jornada de exposiciones de organismos como la Unión Nacional de Pequeños y Medianos Productores Agropecuarios (Upanacional), el Foro Ecuménico para el Desarrollo Alternativo de Guanacaste (FEDEAGUA) y la Federación Nacional de Cooperativas Agropecuarias y de Autogestión (FECOOPA R.L).

Posteriormente se abren cuatro foros temáticos:

- Rasgos centrales identitarios de la economía solidaria.

- Servicios y apoyos.

- Redes y alianzas.

- Oportunidades y desafíos.

Estos foros temáticos fueron presenciados por los 130 asistentes al evento. Finalmente, se realizó una jornada de clausura y un espacio de revisión de acuerdos para su seguimiento.

El proceso, en general, intentó asentarse sobre la mayor participación posible de los diversos sectores sociales involucrados; unos en la organización directa del foro, otros en el acompañamiento y seguimiento de las acciones del mismo.

La diversidad de actores institucionales y sociales participantes fue muy amplia: trece cooperativas, dieciséis organizaciones indígenas y campesinas, nueve dependencias de la UNED y de otras universidades del país, dos instituciones del Estado, dos iglesias, además de dos delegaciones provenientes de El Salvador.

En la puesta en ejecución del proceso cabe resaltar algunos elementos. Los mismos se toman en cuenta en el afán de delinear componentes que perfilan una gestión propositiva y a la vez de respuesta a las necesidades de los sectores sociales convocados como participantes en el foro.

Se presentan tres momentos fundamentales, con sus respectivos comentarios puntuales, en términos de valoración de su contribución o apoyo a la gestión alternativa.

\section{Cuadro 1}

Elementos involucrados en la propuesta de gestión alternativa para la ejecución del Foro de Economía Solidaria, noviembre 2010

\begin{tabular}{|l|l|}
\hline Elementos que se retoman & $\begin{array}{l}\text { Valoración sobre su contribución al lo- } \\
\text { gro del proceso de respuesta a los sec- } \\
\text { tores sociales participantes }\end{array}$ \\
\hline Primer momento: hacia el foro \\
\hline $\begin{array}{l}\text { Consulta con actores involucrados sobre } \\
\text { la pertinencia o no de ejecución del foro y } \\
\text { la forma de realizarlo en términos de los }\end{array}$ & $\begin{array}{l}\text { Los ejercicios de consulta a los actores } \\
\text { sociales en algunos casos se subordinan } \\
\text { a otras preocupaciones de la agenda dia- }\end{array}$ \\
\hline
\end{tabular}


aspectos prioritarios y el carácter de la actividad, ya fuese como foro, asamblea, feria o intercambio nacional.

Organización de la propuesta del foro en lenguaje accesible para todas las personas representantes de los grupos y organizaciones sociales interesadas. Se trata de facilitar el análisis por parte de los interlocutores de sectores sociales como condición para poder asimilar la propuesta y posteriormente rebatirla, replantearla o ajustarla según los intereses. ria de los grupos y organizaciones, por lo que se pierde efectividad en la respuesta esperada de parte de los actores involucrados.

Aunque se hacen esfuerzos por integrar, resumir y adecuar los procesos en lenguajes entendibles, no en todos los casos se supera la distancia sociocultural que implica el diálogo entre la academia universitaria y los sectores sociales.

Este punto es relevante de enfatizar dado que en esta actividad se concreta el diálogo de saberes, entendido como la relación, confrontación y complemento de saberes propios de sectores socioculturales ubicados en contextos diferentes. En este caso el contexto público universitario que orienta la política de la UNED y el contexto que surge desde la dinámica de las comunidades mayoritariamente rurales, caracterizadas desde la diversidad de regiones y culturas locales involucradas en este proceso de foro.

Desde cada saber local, el participante aprehende y asimila la propuesta de foro y la incorpora a su propio universo cultural desde el cual "lee", interpreta y valoriza la propuesta. De igual manera, desde el contexto institucional y en particular desde el contexto de programa de investigación universitaria se proyecta la propuesta de foro.

Apelación a diversos mecanismos de consulta acorde con las características socioculturales de los grupos involucrados. Esos mecanismos incluyen:

f. Documento síntesis de la propuesta

g. Explicación oral de la propuesta

h. Identificación de los elementos constitutivos de la misma, mediante esquemas proyectados en power point (incluye pasos del proceso, actores, requerimientos de participación, gestión de recursos y otros)

i. Tiempos programados para la revisión en cada organización o comunidad

Recuperación de criterios culturales según cada actor en función de mejorar la propuesta.

Distribución de tareas, descentralización de la gestión hacia la realización del foro.
El contexto de limitación socioeconómica y el marco de exclusión social que envuelve a los sectores sociales, no se cambian o varían con la sola apelación a una comunicación planeada de forma incluyente. La comunicación requiere ser acompañada con otros signos visibles de involucramiento y empoderamiento de los sectores sociales.
El aporte de criterios culturales por parte de cada sector involucrado tiende a convertirse, en este caso, en aportes puntuales en una actividad ya estructurada en un patrón cultural ajeno, al cual se le hacen los aportes.

La descentralización no anula la centralización de tareas, en este caso, desde la academia. 


\begin{tabular}{|c|c|}
\hline $\begin{array}{l}\text { Identificación conjunta o colegiada de las } \\
\text { dirigencias o liderazgos más recomenda- } \\
\text { bles para orientar la ejecución de las di- } \\
\text { versas acciones del foro, según los obje- } \\
\text { tivos consensuados. }\end{array}$ & $\begin{array}{l}\text { De nuevo la estructuración de la actividad } \\
\text { bajo un patrón cultural ajeno provoca que } \\
\text { los aportes en la conducción de activida- } \\
\text { des particulares en el foro, se presente } \\
\text { conforme lo dado y no según los criterios } \\
\text { y formas de trabajo de los actores socia- } \\
\text { les participantes. }\end{array}$ \\
\hline \multicolumn{2}{|l|}{ Segundo momento: en el foro } \\
\hline $\begin{array}{l}\text { Respeto y respaldo a las decisiones asu- } \\
\text { midas por los responsable de cada parte } \\
\text { del programa y de las actividades previs- } \\
\text { tas en el foro y la feria. }\end{array}$ & $\begin{array}{l}\text { Se toman decisiones en un rango que no } \\
\text { cuestiona o varía el montaje general de } \\
\text { las actividades. En ese sentido es una } \\
\text { toma de decisiones restringida. }\end{array}$ \\
\hline $\begin{array}{l}\text { Incorporación de las capacidades indivi- } \\
\text { duales y puesta en común de manera so- } \\
\text { lidaria en función del mejor avance posi- } \\
\text { ble de la actividad. }\end{array}$ & $\begin{array}{l}\text { La puesta en común se vuelve un acto de } \\
\text { juego de roles en un esquema predis- } \\
\text { puesto. }\end{array}$ \\
\hline \multicolumn{2}{|l|}{ Tercer momento: después del foro } \\
\hline $\begin{array}{l}\text { Consulta en el corto plazo para aprove- } \\
\text { char el entusiasmo y buen ánimo gene- } \\
\text { rado por la realización del foro y la feria. }\end{array}$ & $\begin{array}{l}\text { La información que se transmite esta pre- } \\
\text { viamente revisada y resumida. En esa } \\
\text { orientación la consulta es direccionada. }\end{array}$ \\
\hline $\begin{array}{l}\text { Comunicación a participantes para el se- } \\
\text { guimiento de acciones. }\end{array}$ & Presenta la misma valoración anterior. \\
\hline $\begin{array}{l}\text { Conformación de equipo de trabajo para } \\
\text { el seguimiento. }\end{array}$ & $\begin{array}{l}\text { El proceso es asumido por pocas perso- } \\
\text { nas dado que la mayoría de los participan- } \\
\text { tes se refugia de nuevo en su propia diná- } \\
\text { mica local territorial y organizativa. }\end{array}$ \\
\hline
\end{tabular}

Fuente: elaboración propia.

Como se puede deducir de la segunda columna del cuadro 1, resaltan las dificultades que acompañan y matizan los procesos de construcción de conocimientos bajo modalidades participativas de investigación acción.

Más allá de los acuerdos que los equipos de investigación logran con actores sociales vulnerables, como el caso del PROICAM, se mantienen las dinámicas que caracterizan la vida cotidiana de esos actores. En esta perspectiva, los avances en la producción de conocimiento a partir del diálogo de saberes entre investigadores y comunidades/organizaciones, está matizado por el contexto de limitaciones socioeconómicas que caracteriza la condición de exclusión y vulnerabilidad de los mismos. Así el contexto es parte activa de la metodología de investigación y condiciona, por lo tanto, los posibles resultados.

\section{Conclusiones}

EI CICDE plantea una propuesta de trabajo que integra de forma directa a organizaciones y comunidades con equipos de investigación como el PROICAM.

Para ello el PROICAM plantea esfuerzos de integración en el marco de la investigación acción, corriente de pensamiento de larga data en Latinoamérica y otras regiones del mundo, caracterizada por la retroalimentación y el diálogo de saberes. Bajo este enfoque es plausible construir propuestas que ayuden en el esclarecimiento y eventual 
superación de los problemas abordados mediante esta forma de investigación.

A la vez, en la línea del CICDE las propuestas se orientan hacia la generación de alternativas al modelo vigente. Una argumentación central al respecto es la de que los sectores que el CICDE privilegia en su gestión investigativa se ubican bajo esa categoría de exclusión o vulnerabilidad generada por el modelo en grandes sectores de la población.

En este marco de análisis, se retoma la ejecución del Foro de Economía Solidaria expuesto en el apartado anterior. El mismo se convierte en un laboratorio concreto para la propuesta de investigación acción a que aspira el PROICAM, en tanto permite avanzar en la comprensión de las prácticas comunitarias y organizativas de los actores participantes.

Al respecto, y retomando esa experiencia, cabe anotar que la construcción de conocimientos sociales se ejecuta en un entorno de conciliación y confrontación de los diversos intereses de los grupos involucrados en cada caso. Esa característica del objeto de estudio de lo social permea, de manera directa, los resultados posibles al elaborar aportes válidos y útiles para los sectores involucrados o afectados por la problemática en estudio.

Esta premisa se complejiza si además se toma nota de que hay un acceso diferencial al conocimiento y a la información por parte de los diversos sectores sociales, según el contexto o lugar desde donde desarrollan su práctica vital. Con base en los dos elementos, intereses sociales en confrontación y acceso diferenciado a la información y conocimiento, en el PROICAM se plantea la pertinencia de construir propuestas a los problemas de desarrollo que aquejan a los sectores rurales excluidos.

Construir alternativas es diseccionar el argumento vigente incorporándole otros puntos de vista y otra dirección, no la dominante, es un ejercicio de reordenar o dar una nueva explicación a la realidad.

Lo anterior implica rearmar un pensamiento que integre los criterios de diversos sectores que logran conciliar distintos puntos de vista en un nuevo bloque de pensamientos, en una perspectiva de diálogo de saberes que permita incorporar precisamente lo que no ha sido tomado en cuenta en el pensamiento oficial, centralista y vertical.

Surge así, como posibilidad, la construcción de un conocimiento que no solo apela a la academia, sino que se centra en el diálogo horizontal que esta puede propiciar directamente con los actores sociales. 


\section{Bibliografía}

Ander Egg, E. (2003). Repensando la Investigación Acción Participativa. Buenos Aires: Lumen Hvmanitas.

Centro de Investigación en Cultura y Desarrollo. (2011). Plan de Trabajo. UNED.

Fals, O. (Comp.) (1998). Participación Popular: Retos de Futuro. Bogotá: ICFES, IEPRI, COLCIENCIAS.

Fals, O. (2008). Orígenes universales y retos actuales de la IAP. En: Peripecias , (110). Recuperado en http://www.peripecias.com/mundo/598FalsBordaOrigenesRetosIAP .html

Hernández, J. (2007). Organizaciones Rurales de Costa Rica. Retos y Propuestas. San José: EUNED.

Ibarra, J. (2002). Conferencia presentada en la Mesa de Expertos del Tercer Congreso Internacional y Segundo Nacional "Retos y Expectativas de la Universidad". México: Universidad del Estado de México.

Pérez, J., Salas, M., Morales, N. (2007). Exclusion social y pobreza irreducible. Reflexiones desde el caso costarricense. Ponencia preparada para el Decimotercer Informe Estado de la Nación. San José: FLACSO-Costa Rica y Estado de la Nación. Recuperada en http://www.estadonacion.or.cr/images/stories/informes/013/docs/E quidad/Perez-Mora-Morales-2007.pdf

PROICAM. (2009). Presentación original. UNED.

PROICAM. (2010). Fortalecimiento organizativo de organizaciones campesinas en Costa Rica (Proyecto investigación). UNED.

PROICAM. (2010b). Foro Nacional sobre Economía Solidaria, Construyendo desde las Experiencias (Borrador de memoria). San José, 24 noviembre del 2010: UNED.

PROICAM. (2010c). Apoyo teórico-práctico a experiencias de economía solidaria y propuestas de enfoques pedagógicos para su fortalecimiento nacional, propuesta proyecto investigación. UNED.

Pulido, R., Ballén, M., Zúñiga, F. (2007). Abordaje hermenéutico de la investigación cualitativa: teorías, proceso, técnicas. Bogotá: Universidad Cooperativa de Colombia.

UNED, Consejo Universitario, CU-2004-1714, 9 julio 2004, p. 31. 
UNED, Consejo Universitario, CU-2010-352, 31 mayo 2010, p 9.

Vargas, L., Zúñiga, X., Hernández, J. (2010). CICDE. Estudio de Estructura del Centro de Investigación en Cultura y Desarrollo de la UNED. UNED.

Vargas, L. (2002). Costa Rica. 1985-1997. Liberalización y Ajuste Estructural o la Autodestrucción del Neoliberalismo. San José: EUNED. 



\section{Documentos}




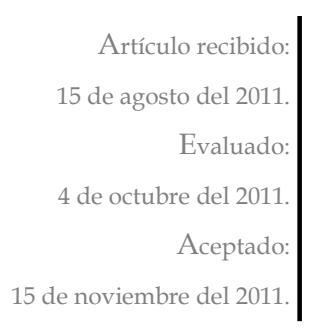

15 de noviembre del 2011

\section{Óscar Wilde y Reinaldo Arenas. Oscar Wilde and Reinaldo Enigmas de pasión \\ Arenas. Enigmas of passion.}

RESUMEN

Este no es en realidad un ensayo sobre literatura comparada. Utilizando como excusa el arte del escritor irlandés Oscar Wilde y el del cubano Reinaldo Arenas, intentamos proponer algunas ideas y análisis sobre la libertad y el impacto que han tenido sus creaciones sobre el medio social. El artículo aspira a demostrar cómo los esquemas sociales, políticos e ideológicos están estrechamente relacionados con nuestra noción de libertad en la sociedad contemporánea. La Poesía y la Libertad, la Poesía y la Existencia son algunos de los temas abordados en un trabajo que ya es parte de un texto mayor, en el cual se intenta también establecer posibles relaciones entre la escritora brasileña Clarice Lispector y la inglesa Virginia Woolf.

Palabras Clave

Poesía, literatura, libertad, Cuba, Inglaterra
ABSTRACT

This is not really an essay on comparative literature. By using the artcraft of both the Irish writer Oscar Wilde and the Cuban Reinaldo Arenas we tried to advance some ideas and analysis on freedom and the impact of social environment on their creations. The article is aimed to prove how our notion of freedom is always behind, social, political and ideological frames and how they are tightly intertwined in contemporary society. Freedom and Poetry, Freedon and Existence and other issues are discussed in a piece of work which is now a part of a major project dealing also with possible evocations between the Brazilian writer Clarice Lispector and the British writer Virginia Woolf.

KEY WORDS

Poetry, literature, freedom, Cuba, England

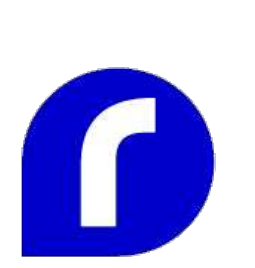

Rodrigo Quesada Monge

Historiador costarricense. Catedrático jubilado de la Universidad Nacional, Heredia, Costa Rica. Con estudios doctorales en la Universidad de Londres, Inglaterra. Ha publicado varios libros sobre historia económica y social de América Central y del Caribe. Premio Nacional de Historia de la Academia Costarricense de Geografia e Historia (1998). Ha sido merecedor de becas de la Fundación Ford, de la Fundación Fulbright y del DAAD de la República Federal Alemana. Fue profesor invitado para impartir cursos de historia económica de América Latina en las Universidades de Wisconsin, USA, y en la Universidad Libre de Berlín. Jurado Internacional en el prestigioso premio Casa de la Américas (2001), sus artículos se publican en revistas de Chile, España, Inglaterra, Suecia, Perú, y México. Correo electrónico: quemoro2004@yahoo.com 


\section{Óscar Wilde y Reinaldo Arenas. Enigmas de pasión*}

"La libertad no se define, se ejerce". Octavio Paz.

\section{Introducción}

Este es un ensayo sobre la pasión por la libertad y el goce de expresarla abiertamente. Aunque requiere un esfuerzo considerable encontrar a escritores, poetas, músicos o pintores que logren, de manera armoniosa y fructífera, enlazar ambas dimensiones del arte, es conveniente y útil hacer el intento. Más aún cuando se trata de escritores como Óscar Wilde (1854-1900) y Reinaldo Arenas (1943-1990), uno irlandés y el otro cubano, para quienes la libertad y la belleza son las dos caras de un mismo asunto: la vida.

El movimiento pendular que caracteriza a la obra de estos dos grandes escritores, entre la sutileza más excelsa y el desenfado más escabroso imaginable, es el eje vertebral que hace vibrar la riqueza sin límites de sus distintos medios de expresión estética e intelectual. No es posible concebir a un Óscar Wilde que reflexiona sobre la belleza, el arte, la buena conversación, y el buen comer, sin que sus valoraciones tengan algún grado de incidencia política, trabajada con la laboriosidad de orfebre del buen ironista y el sarcasmo penetrante de quien conoce las fisuras y debilidades de su objeto de crítica. Lo mismo sucede con Reinaldo Arenas, también un "escritor en las orillas" como diría Beatriz Sarlo refiriéndose a Borges, sólo que en este caso, las riberas en las que se despliega el arte y el pensamiento de Arenas son aquellas que la revolución cubana, en su etapa más dura, le permitió avizorar.

A Wilde la justicia victoriana lo silenció, o quiso silenciarlo, porque él les puso el espejo al frente, sin empacho alguno. Elías Canetti (1905-1994) decía que la era victoriana tenía una grandeza nutrida sobre todo de sus fracasos y omisiones. Esos defectos y problemas precisamente hicieron intolerable el espectáculo que Wilde quería obligarlos a ver. La supuesta justicia revolucionaria, en un primer momento, silenció a Reinaldo Arenas exactamente por lo mismo. Para estos dos autores, y así lo probaron en la práctica, la vivencia de la libertad no es un asunto puramente teórico. Existe una relación muy estrecha entre nuestras nociones de la belleza y sus eventuales resultados políticos, entendida ésta, la política, como la

* Artículo publicado en agosto del 2011 en la revista Escáner Cultural, no. 139 http://revista.escaner.cl/node 15576 
forma más efectiva para que los seres humanos, en grupos e individualmente, disfrutemos la riqueza que la sociedad y la naturaleza son capaces de ofrecernos. Si no toda la cultura occidental rodaría por los suelos. Porque la política no es sólo el ejercicio, habilidoso o torpe, del poder.

Con este ensayo aspiramos a orientar al lector, para que, según sugería Octavio Paz (1914-1998), aprenda a escuchar lo que los poetas tienen que decir sobre temas tan diversos como el arte, la belleza, la pasión y la política. La sordera del lector contemporáneo es insigne en muchos aspectos, como veremos. Por lo tanto, llegó el momento en que es posible retomar lo que estos dos grandes maestros de las letras nos tienen que decir, sobre una sociedad en la que el anonimato les ha borrado completamente el rostro a las personas. Se trata, por desgracia, de un anonimato muy bien trabajado, donde no interesa lo que uno piense, sienta o haga, en el tanto en cuanto ejerza su creativa labor de consumidor. Se trata de un anonimato rentable, que deglute mercancías y genera ganancias. Las opciones para ser persona se han reducido en un universo repleto de posibilidades, y eso es un enigma. Es un enigma también que hoy la belleza y el talento, la inteligencia y la sensibilidad se hayan elaborado a tal extremo que se confunden con productividad, rentabilidad y rendimiento. De todo esto trata este ensayo.

Aclarémosle a nuestro posible lector que para el caso de Óscar Wilde, cuya obra ya trabajamos en otros momentos (Quesada, 2004), hemos utilizado esencialmente sus cartas. En nuestro ensayo anterior las utilizamos pero el propósito era otro, retratar al hombre contra el escenario de la sociedad victoriana. Con este trabajo, más íntimo y personal, las cartas son un recurso vital y bibliográfico inigualable. Reinaldo Arenas es un insuperable novelista, un mago extraordinario con el lenguaje. Sus experimentos literarios y novelísticos solo encuentran semejanzas en otros escritores cubanos del mismo fuste como Severo Sarduy (1937-1993) y José Lezama Lima (1910-1976) o el argentino Julio Cortázar (1914-1984). Por eso nos serviremos de sus novelas, donde el lector encontrará unos frescos y murales de la historia cubana y latinoamericana del último cuarto del siglo $\mathrm{XX}$, raramente igualados hasta ahora. Los ensayos de Arenas, por otro parte, constituyen un descarnado retrato de sus emociones y sentimientos más profundos, sobre el impacto que tuvo para él la revolución cubana, en su dimensión más existencial y articulada al problema de la civilización.

\section{Poesía y libertad}

Para ambos poetas, existía una relación desconcertantemente estrecha entre estas dos nociones. $Y$ es también desconcertante la forma en que ambos vivieron sus existencias; al filo de la navaja; siempre al borde del precipicio. Esa práctica existencial de vida la vuelve un reto constante, porque se trata de vaciarla del anodino transcurrir de la cotidianidad. Con esta clase de artistas la cuestión de la libertad va más allá de ser un 
asunto de naturaleza puramente lírica, y se cubre de piel y se llena de sangre, tanto así, como para que se apueste la vida en ello. Deja de ser, además, un problema que le pertenezca a las esferas teóricas del análisis del poder, para convertirse también en materia poética, pero una que se adhiere a la existencia cotidiana, de forma tal que nos resulta imposible, más bien inimaginable, desligar el quehacer poético de Wilde o Arenas, de sus vivencias más entrañablemente sentidas, aquellas que están a pura flor de piel.

Con Wilde y Arenas no hay dobleces, no hay distorsiones ni gestos cumplidos para atender el buen decir de los "conocedores". Con ellos se hace poesía en las calles, en los bares, en los burdeles y en las cárceles, o no se hace del todo. Esa separación, retórica y banal, elaborada por algunos, entre poesía y bohemia, para explicar, a medias, los logros en el lenguaje pero no en la vida, también los avances existenciales, aunque no los grandes logros artísticos, tiene que ver más con los alcances de una supuesta filosofía del arte, que con el ejercicio de la poesía como expresión supina de la libertad individual.

Estamos hablando de la cotidianidad, de la temporalidad, de la transitoriedad y profundidad de la poesía de verdad, aquella en la cual cada poema destila el perfume, los agravios y desagravios, así como el sabor y los sinsabores de los esfuerzos del poeta. Para Wilde y Arenas, la poesía es cuestión de fuego, de aprender a consumirse a sí mismo en las hogueras de la locura y de la lírica. Esto no pasaría de ser más que un buen epigrama, sino supiéramos que en la poesía de Wilde está retratada con sangre y rutina, toda la escenografía cotidiana de la era victoriana. Así como en la obra de Reinaldo Arenas, se encuentran posiblemente, los guiños y retruécanos más duros y mordaces que se puedan registrar en la literatura latinoamericana contemporánea, con relación a los excesos del poder desplegados por grupos políticos y sociales, interesados con pobreza en el quehacer artístico e intelectual de nuestros países.

Si los mejores testigos de su tiempo son los poetas y los artistas, cuando se trata de procesos revolucionarios, como la revolución industrial en el caso de Wilde o de la revolución cubana, en el de Arenas, las dudas y preguntas que nos sobrecogen, tienen más que ver con su protagonismo en tales procesos, antes que con la calidad y riqueza de su producción artística, pues ésta no se somete a juicio en ese preciso momento, en virtud de que el mismo le pertenece a la posteridad. Sin embargo, a pesar de las pocas coincidencias, o de las muchas resonancias que podamos hallar en los proyectos vitales de uno sobre el otro, así como del grado de influencia que pudieran haber ejercido los momentos históricos y sociales, en que les tocó vivir, ambos acertaron en diseñar trayectos, caminos distintos pero igualmente efectivos, para ejercer su propia concepción de la libertad.

Para Tzvetan Todorov, Wilde, junto a Rainer María Rilke (1875-1926), y Marina Tsvetaeva (1892-1941), es uno más de los aspirantes a ser parte de los "aventureros del absoluto", con lo cual podríamos estar diciendo 
mucho o nada, da lo mismo (Todorov, 2007). Prácticamente toda la cultura occidental desde los griegos, y particularmente después del Renacimiento, reposa sobre la búsqueda del absoluto, de tal manera que escoger a estos tres poetas para sostener una tautología, nos resultó al final de cuentas poco alentador. Sin embargo, el ensayo de Todorov, maravillosamente bien escrito, es un buen principio para quienes andan detrás de poetas que han resuelto, de manera trágica, el enigma de la pasión, la terrible disonancia entre vida y poesía.

Con Reinaldo Arenas, la poesía no es cuestión de niños, o un asunto que pueda ser asumido con frivolidad y displicencia. Pero no tanto la poesía en abstracto, es decir su dimensión teórica o epistemológica, sino su ejercicio, su práctica cotidiana, cuando el poeta se suda la camisa en un combate cuerpo a cuerpo con las palabras, luchando por arrancarles una melodía, un tono, una organicidad que no siempre logra los niveles de perfección esperados. Uno de estos grandes luchadores, para Arenas, fue precisamente el gran escritor cubano José Lezama Lima, su maestro en muchos aspectos, tanto estéticos como existenciales.

En uno de sus más valiosos ensayos, publicado en La Habana en 1969, antes de salir de Cuba, Reinaldo Arenas nos regala algunas de sus más lúcidas consideraciones teóricas, estéticas, políticas y vitalistas sobre el quehacer de la poesía, utilizando como ejemplo superior el caso de Lezama Lima (Arenas, 2001a):

¿Y quién es el que cree sino el que crea?, se pregunta Arenas. ¿Y quién es el que crea sino el poeta? Es decir, un ser misterioso y terrible, un elegido. Poeta es una condición fatal que se convierte en dicha sólo cuando logra expresarse cabalmente. Para el poeta, expresar su condición es ser. Los poemas que son están por encima de todo tiempo y de todo terror ocasional (sin ser ajenos a los mismos), instalados en el gran tiempo y en el gran terror permanentes (Arenas, 2001a, p. 119).

El poeta que ha tenido la desdicha o la bendición de haber presenciado el transcurrir abrasador de un proceso revolucionario como el cubano, se enfrenta a tener que darle respuesta a un conjunto imprevisto de preguntas, para las cuales sólo la historia, tal vez, tendría soluciones razonables. Fue el caso también de otros grandes poetas como Boris Pasternak (1890-1960), o Vladimiro Maiakovski (1893-1930), en su momento. Son preguntas muy relacionadas con el manejo que haga el poeta, el artista, el intelectual, de los perímetros concedidos por el poder político establecido. "En eso ha consistido siempre la labor del poeta: hacer una obra perdurable a pesar de su época", nos añade Arenas (2001a, p. 120). Esa perdurabilidad es un asunto que, para el poder político, se decide en el escritorio, o el gabinete, de un valet al servicio de un rey o de una reina, o, en último caso, de un burócrata de partido.

Existe, además, una sustancial diferencia entre un "fabricante de poemas", según el buen decir de Arenas, y un creador de poesía como 
Lezama Lima. El supuesto hermetismo de las creaciones de este último, es ante todo un mal digerido sambenito, en boca de periodistas, radiodifusores, y críticos mal enquistados en las estructuras del poder, desde donde se dedican, tiempo completo, a cazar poetas, supuestamente "muy difíciles", quienes, dicen ellos, han sido capaces de elaborar una especie de lenguaje críptico, con el cual escamotear las buenas costumbres y la supuesta moral revolucionaria, brillantemente administrada desde las sacrosantas altas esferas del poder.

Arenas critica el supuesto hermetismo del que hablan algunos lectores poco avezados, así como la escasa penetración analítica de críticos profesionales quienes, cuando no entienden lo que están estudiando, hablan "de que el principal personaje de la joven novelística cubana es la palabra", para discutir sobre la validez de argumentos y construcción de novelas tales como Paradiso de Lezama. En estos casos, el pecado original con que nace el escritor, el novelista, es su productiva obsesión por la palabra, la cual no encaja en teorías literarias pre-concebidas, o pergeñadas al calor de la temporalidad o de la inmanencia de procesos sociales y políticos, que nada tienen que ver con las preocupaciones estéticas de quien quiere hacer poesía de la forma más libre posible.

Es muy raro, lo decían con cristalina claridad Oscar Wilde y Walter Benjamin, encontrar a un crítico que conciba, respetándose a sí mismo, su labor como una obra de arte. El crítico artista, de que nos habla Wilde, es tan excepcional, como es artístico el producto de su trabajo:

(...) Más aún: yo diría que la crítica más elevada, siendo la forma más pura de la impresión personal, es, a su modo, más creadora que la creación, ya que tiene menor relación con todo patrón externo a sí misma, y es, en rigor, su propia razón de existir, y-como dirían los griegos-es un fin en sí misma y para sí misma. Ciertamente, jamás se ve trabada por cualesquiera cadenas de verosimilitud. Sobre ella jamás influyen innobles consideraciones de probabilidad, esa cobarde concesión a las tediosas repeticiones de la vida doméstica y pública. Se puede apelar de la ficción ante el hecho, pero no se puede apelar del alma (Wilde, 2000, p.755).

Walter Benjamin hace un análisis similar, varios años después, respecto a la producción artística de Goethe (Witte, 2002). Sin compartir plenamente el optimismo de la ilustración de que el mundo será redimido por el arte, es fácil encontrar, tanto en Oscar Wilde como en Reinaldo Arenas, una nostalgia profunda y casi instrumental sobre la ausencia de críticos imaginativos, creativos y dignos de sus propias creaciones; reclamo de los más sentidos por los grandes analistas anglosajones del siglo XX, al estilo de René Wellek, Edmund Wilson, Northrop Frye, Michael Dirda, Cyril Connolly y otros. 
En la "era del olvido" como la llama Tony Judt (2008), hacemos a un lado el pasado más inmediato antes de comprenderlo en su justa dimensión, con lo cual nos desmemoriamos y nos desvinculamos de todo aquello que nos haga responsables del presente que tenemos entre manos. En estos casos, es el poeta el que constantemente nos conmina a establecer una articulación más efectiva con la realidad que tenemos al frente, pero que queremos escamotear debido a su fealdad o a su siniestra capacidad opresiva.

Con Oscar Wilde nos enfrentamos a un dilema: hizo todos los esfuerzos posibles para que su vida fuera una elongación de su arte. Un esfuerzo así tiene muchas posibilidades de fracasar, pero le deja al poeta, así como a todos aquellos que lo lean y lo sigan, la satisfacción de haber emprendido un programa de apreciación estética y de vivencia de la cotidianidad, que le da sentido a la espontaneidad y redondea nuestras limitaciones para comprender la profunda distancia que media entre ética y arte. La tardía manifestación pública de la homosexualidad de Wilde, tiene poco que ver con un claro programa de defensa de su sexualidad, como lo hiciera abiertamente Arenas en su momento (Cabrera, 1998. pp. 181-188). Para éste, su identidad sexual era un asunto político, y estaba en relación directa con los niveles de participación civil que pudiera desarrollar, ya fuera en Cuba o lejos de ella (Ocasio, 2007). Su capacidad de arriesgar la vida con el fin de lograr mayores y más efectivos espacios de expresión artística, política y sexual, no estaba estrujada por su ambigüedad con respecto al poder político, como le sucedía a Wilde.

Los victorianos estaban educados para reverenciar a los héroes, algo que para Wilde resultaba muy asfixiante, pues vivir una existencia en la cual el reto, el desafío y el heroísmo fueran artilugios cuasi religiosos, obligaba a los individuos con cierta sensibilidad, a callarse cuando con más fuerza y vigor debían hablar (Newsome, 2001, p. 177). Arenas, por el contrario, pudo vociferar su inconformidad contra la revolución cubana, hasta el momento en que para ésta, la figura del escritor resultaba una sombra que había que conjurar. Reinaldo hizo todo lo posible por no encajar. Wilde intentó lo contrario. Hay que recordar, como bien lo apunta Cabrera Infante, que Arenas no era realmente un revolucionario, era un rebelde. Esto le cambia, completamente, la óptica que podamos tener de su quehacer artístico e intelectual, porque de ser apreciado como el anticastrista vociferante y lacrimoso, nos surge una imagen diferente, la del tipo duro (como un romano, diría Cabrera Infante), sin tapujos para defender su profunda reticencia contra las aspiraciones y objetivos de la revolución cubana.

Encajar, y encajar bien, era para Oscar Wilde algo esencialmente estético, pues, según él, la moral y las buenas costumbres pertenecían al limbo de la privacidad. Pero los victorianos hacía rato habían descubierto que entre la moral pública y la moral privada, prácticamente, no había frontera. Wilde comprendió muy tarde la eficacia de este descubrimiento. Lo sorprendió en el estrado del juez que lo condenaría a dos años de trabajos forzados por sodomía. 
Con Arenas el asunto es un poco más claro: su noción de libertad no se negocia. Arenas no apuesta por nada ni con nadie las desproporciones que su idea de la libertad pudiera alcanzar. Es vibrante, y las palpitaciones que pudieran producirle cualquier atentado en dirección contraria, solo pueden ser atribuibles a un terror feroz contra toda expresión totalitaria. La pasión y la fuerza que conducen los razonamientos y emociones de Arenas, en lo que compete a su tratamiento de la libertad, no están vinculados ni bajo la influencia de ningún acercamiento teórico al asunto. La libertad es una cuestión carnal y no tiene nada que ver con los libros de texto:

¿Acaso ya olvidaron que vivir bajo una tiranía no sólo es una vergüenza y una maldición, sino que es también una acción abyecta que nos contamina, pues, quieras o no, hay que cooperar con el tirano si se vive bajo sus leyes? (Arenas, 1999, p. 357).

En efecto, todo intento por "administrar" la libertad, ya sea por aquellos que se llaman a sí mismos depositarios de la verdad espiritual, o por los que constantemente hipostasían su concepción de la historia, como los burócratas de partido, está condenado al fracaso desde el momento mismo en que la libertad no es un objeto, o ente, cuya ubicuidad nosotros podamos establecer con antelación:

Catolicismo ramplón y comunismo (fanatismo y dogmatismo) son términos equivalentes en lo que podría llamarse una particular ética de la hipocresía. No exponen la vida a la realidad, sino a una teoría de la realidad. Ambos se rigen no por la experimentación, sino por la adoración del dogma. La vida no cuenta. Cuenta la obediencia, los preceptos, y naturalmente las jerarquías. Un beato obediente (Cristo cada vez más lejano) tiene que aceptar y apoyar cualquier humillación impuesta a su vida, ya que precisamente su religión no es más que una cadena de limitaciones e imposiciones antinaturales. El comunista militante (Marx casi prohibido) debe de antemano renunciar a toda autenticidad, a toda vitalidad, y obedecer incondicionalmente las orientaciones que "bajan" del partido. Bajar, esa es la palabra. Indiscutiblemente "la Divinidad" (Dios o el dictador vitalicio) está muy alta. La libertad (creación, amor, rebeldía, renovación, vida) es ajena a ambas teorías (y prácticas), o más que ajenas, ambas teorías (y prácticas) son enemigas irreconciliables de la libertad (vida) (Arenas, 2001a. p. 178).

Las reflexiones que, en ese sentido, hacía Arenas tienen resonancias sumamente sugerentes de otras hechas por un autor soviético del calibre de Mijail Bulgákov (1841-1940) a quien el régimen estalinista no pudo aniquilar, en razón de su prestigio internacional y de la contradictoria 
admiración que le profesaba el dictador, pero cuya profundidad y vigencia están en relación directa con las dimensiones estéticas reales de su quehacer artístico.

Para escritores como Arenas, Wilde o Bulgákov, o algunos otros de los que hasta aquí hemos mencionado, en vista de que la libertad no es un objeto, ni un ente omnipotente, sino una vivencia, una emoción, o si se quiere una condición, un estar ahí, la sociedad, la estructura de poder o el régimen político que no la facilite o la garantice, corre el riesgo de caer podrido al menor intento de ejercer su administración. Esa putrefacción sería el resultado de su incapacidad para crear los instrumentos que hagan posible su ejercicio irrestricto e incondicional. En este tipo de situaciones el costo personal puede ser enorme. El tirano o la tiranía pocas veces corren el riesgo de establecer excepciones, que puedan convertirse rápidamente en vehículos de demandas generalizadas a favor de la libertad, la democracia y el libre ejercicio del pensamiento, la creatividad y la sensibilidad. Por eso el campo artístico es y ha sido siempre un tremendo dolor de cabeza para los dictadores de todos los pelajes.

Las relaciones sostenidas por los artistas, los académicos, los científicos y los humanistas con los procesos revolucionarios de cierta profundidad, a lo largo de la historia, siempre han sido difíciles y muy complejas. El haz de alternativas políticas en dichas relaciones, se teje en función de que el libre ejercicio de la creatividad no encuentre obstáculos de ninguna textura. Desde Cromwell, en el siglo XVII inglés, pasando por los jacobinos en la Francia revolucionaria del siglo XVIII, y los bolcheviques en el siglo $X X$, los procesos revolucionarios se han visto sacudidos por esta clase de desacuerdos con la comunidad académica, científica y artística.

La historia de las revoluciones de los últimos quinientos años está plagada de arbitrios, violencia y brutalidad contra los intelectuales que no lograron adaptarse rápidamente a los ajustes institucionales, políticos e ideológicos que trajeron consigo dichas revoluciones. Su arremetida contra la independencia y la creatividad, estuvo más en relación directa con los resultados políticos de las mismas, que con la oferta ética y estética hecha dentro de los canales revolucionarios mismos. Es decir, rara vez una tiranía que dice apoyarse en una revolución o en cierta herencia de esta naturaleza, aceptará el hecho incontrovertible de que es incapaz de producir a sus propios intelectuales, en el momento inicial del proceso revolucionario mismo. Siempre tuvieron que servirse de los intelectuales del régimen despojado del poder, al menos mientras la institucionalidad revolucionaria se va construyendo lentamente. Así, los que no encajan, inician una etapa de precariedad sumamente dolorosa, que los deja prácticamente sin alternativas dentro del proyecto social que recién despega: 
En fin, para 1971 ya creíamos que ninguna nueva calamidad podría azotarnos, por estar absolutamente rebosantes de ellas. Pero precisamente ese año cayó sobre todos los escritores cubanos lo que bien podría llamarse la noche oscura del alma y, desde luego, de la creación artística. Lo que significó la estalinización absoluta de la cultura cubana (su destrucción) y comenzó con el ya conocido caso Padilla". "Se sabía ya que todas las conversaciones de sobremesa sostenidas por escritores como Lezama Lima y Virgilio Piñera habían sido minuciosamente registradas (grabadas) por la policía secreta, y que los menores detalles de nuestra vida privada engrosaban enormes expedientes. Dejamos finalmente de ser seres humanos para convertirnos en un número. Nos quitaron no solamente la libertad de escribir y publicar, sino la de pensar en voz alta y hasta la de conversar íntimamente con algún amigo. $Y$ sobre todo nos quitaron-y en eso Padilla fue el vehículo o chivo expiatorio-lo poco que aún nos quedaba: la dignidad (Arenas, 2001a, pp. 16-17).

Cuando se revisa con algo de cuidado la obra ensayística de Reinaldo Arenas, o se escuchan y se leen sus entrevistas, se puede establecer con cierta solvencia que las baterías críticas de Arenas no están dirigidas tanto contra el socialismo, el sovietismo, o lo que él llama la "superestalinización" de la revolución cubana, sino contra la versión que esa revolución tenía de todo ello:

Ese proceso de superestalinización, llevado a cabo por un equipo militar que decía, entre otras cosas, que el escritor era un obrero; "porque escribía con la mano" y que "lo mágico, lo real maravilloso es la visión caduca y pintoresca que va quedando atrás sobrepasada por la conciencia socialista, científica y revolucionaria"; fue precisamente por eso, no sólo siniestro en su implantación burocrática, sino hasta en los mínimos matices de sus métodos" (Arenas, 2001a).

En realidad Arenas no alcanzó a sistematizar su visión del proceso de burocratización de la cultura en Cuba (en realidad no le interesaba), pero sí nos heredó, posiblemente, el más acabado libelo, henchido de amargura y resentimiento en contra de lo que pretendía la revolución contra la libertad artística y sexual en la isla, para Arenas, dos conceptos estrechamente ligados.

A ese respecto, el lector que busca informarse, debe tener cuidado de no dejarse abrumar por la andanada de improperios, chismes, sarcasmo y vulgaridad (chapucero, dice Cabrera Infante) que a veces parecieran penetrar las críticas y los análisis hechos por Arenas sobre la cultura cubana en particular, y latinoamericana en general. Estos son datos que otros autores han señalado con lujo de detalles, pero es que el dolor del exilio y la humillación que sobrecogen a Reinaldo Arenas, pudieran 
influenciar nuestra búsqueda sobre su noción o nociones de la libertad en determinados momentos de su crecimiento como novelista y como intelectual. Hay ocasiones en que su obsesión por denunciar al régimen de Castro en Cuba, bordea los abismos de un nihilismo mal entendido, y se acerca más a la apología retrospectiva de la dictadura de Batista que a una preocupación auténtica por el futuro político, social y cultural de la isla: "Es bueno recordar que nunca, durante las pasadas y no menos aborrecibles dictaduras, Cuba sufrió una incomunicación y una censura como la que ahora padece" (Arenas, 2001a, p. 310).

La libertad por la que luchó y sufrió hasta el agobio Reinaldo Arenas, como muchos otros de sus colegas contemporáneos, no podía diseñarse en el escritorio de un burócrata o en las buenas intenciones financieras de alguna embajada imperial en Cuba, o en cualquier otra parte de América Latina. Aquí se trata de cuestiones básicas: libertad para escribir lo que se me antoje y como se me antoje, para ejercer mi sexualidad libremente, para trasladarme adonde quiera y para criticar sin tener que mirar por el encima del hombro, con temor y suspicacia. Si un régimen político, del signo que sea, niega, bloquea o manipula estos ingredientes esenciales, la particular sensibilidad de un intelectual, un artista o un poeta, se pondrá en movimiento para denunciarlo. Pero también existe la posibilidad de transar, de negociar de terminar adaptándose al régimen oprobioso, con lo cual la actividad intelectual, académica o artística se desnaturaliza de manera brutal, inaceptable para un hombre como Reinaldo Arenas:

Ante tal burla (ante tal atropello) a los intelectuales cubanos-y los intelectuales dignos del mundo entero-, ante tal terror policial, ante tal miedo absolutamente justificado, a nosotros los escritores cubanos nos quedaban muy poco caminos a escoger: la traición a nosotros mismos, el cinismo, la cárcel o el suicidio-el exilio nos estaba prohibido absolutamente-. Algunos se suicidaron, como fue el caso entre otros de la poetisa Marta Vignier y del novelista José Hernández; otros se traicionaron completamente, transformándose en altos funcionarios del Estado y naturalmente de sus aparatos represivos, como Nicolás Guillén, Roberto Fernández Retamar y Lisandro Otero entre muchos más; otros, los menos conocidos, asumieron una actitud heroica y perdieron sus vidas-o gran parte de sus vidas-en las cárceles, como Jorge Valls, Ángel Cuadra y Armando Valladares; los demás pasamos al campo del cinismo, del silencio o de la cobardía, derivando silenciosamente a una suerte de compás de espera que podía prolongarse (y en algunos casos se prolongó) toda una vida (Arenas, 2001a).

Es en vista de esta actitud rebelde, intransigente y frontal, nihilista a veces del novelista cubano contra el régimen de Castro, que las afirmaciones de un autor reciente nos parecen algo excesivas, cuando sostiene que mucho de la producción novelística de Arenas, responde a las exigencias de un marxismo-leninismo más o menos elaborado:

El portero, una novela escrita en los Estados Unidos, es una parábola 
de la lucha de clases y el desarrollo de la conciencia revolucionaria y la obra más explícitamente marxista de Arenas, aunque su radicalismo político lo ocultan al principio su contenido y su estructura narrativa (Cacheiro, 2000, p. 85).

Tratar de descubrir un Arenas marxista, bajo los arabescos estilísticos de sus obras, puede ser una pretensión interesante, pero debería renunciar por completo a la explicación de sus viscerales diatribas contra la revolución cubana. Por eso decimos, más bien, que la actitud del novelista es de naturaleza nihilista, entendido el nihilismo dentro de la tradición clásica rusa, para la cual la franqueza, el sentido crítico y la total libertad de expresión son fundamentales. En Occidente siempre se cometió el error de confundir nihilismo con terrorismo, o nihilismo con la absoluta falta de convicciones políticas y morales, una conducta que pertenece más al mundo del psicoanálisis, pero que tiene poco que ver con el ejercicio de la libertad:

El nihilista lleva su amor por la sinceridad hasta los detalles más insignificantes de su vida diaria, desechando las formas convencionales del lenguaje en sociedad y expresando sus opiniones de un modo directo y lacónico no desprovisto de cierta afectación de brusquedad externa (Kropotkin, 2005, p. 600).

Con relación a Wilde, al que jamás podríamos acusar de nihilista, sus duros y fríos comentarios críticos de la moral victoriana y sus convencionalismos, se mueven más bien en el terreno del dandysmo, de la ironía elegante y contenida, pero jamás aspiró a cambiar nada de eso. Para Wilde, quien vivió de hacerles notar a la aristocracia y a la alta burguesía imperial inglesa sus dobleces y quebrantos, nunca pretendió hablar de revolución, y jamás utilizó sus piezas teatrales como plataformas subversivas contra el orden de cosas establecido. Por eso es sencillo sostener que el utopismo de Wilde está más cerca del anarquismo, que el nihilismo de Arenas. Wilde sólo quería un mundo más bello. Arenas uno más libre. Pero cuesta establecer, con algún grado de certeza, si ambos tuvieron preocupaciones revolucionarias, entendidas éstas como aquellas aspiraciones que posee un individuo, o un grupo humano, por transformar radicalmente el mundo en el que vive, con su participación activa y beligerante. Wilde creía en el poder de la conversación, la amistad y el amor. Arenas en el poder de la sensualidad y la fabulación:

Esta es la historia de una isla dominada por un tirano absoluto llamado Fifo. El tirano llevaba en el poder cuarenta años, y desde luego, ejercía un control total sobre todos los habitantes de la isla. La gente se moría de hambre pero tenían que elogiar incesantemente la abundancia en que vivían gracia a las técnicas productivas introducidas por el tirano. La gente no 
podía salir de la isla ni podía hacer el más leve comentario contra el tirano, pero tenían que pasarse día y noche entonando himnos a la libertad maravillosa y al porvenir luminoso que les había concedido el tirano. En aquella isla todo el mundo vivía por lo menos una doble vida: públicamente no dejaban ni un instante de alabar al tirano, secretamente lo aborrecían y ansiaban desesperadamente que reventase. (Arenas, 1999, p. 136)

Por eso es fácil sostener que la mayoría de sus novelas son fábulas, en las que algunos de sus personajes devienen arquetipos de la libertad, la independencia, el antiautoritarismo y la espiritualidad. Es fácil, también, descubrir en la poesía y la narrativa de Reinaldo Arenas un ingrediente religioso, un sostenido retorno a las raíces, como sucede con Celestino antes del alba (Arenas, 2000). A Oscar Wilde, por el contrario, lo seduce la parafernalia principesca del papado, aunque su moral de catecismo nunca le produjo ningún efecto moral o espiritual duradero.

La crítica socio-política y cultural de Reinaldo Arenas no es, por lo tanto, ni revolucionaria, ni tiene tampoco aspiraciones apologéticas del liderazgo de la revolución cubana. Con él, en su quehacer cotidiano, en el compromiso con que asume la creación artística y cultural, en la pasión con que aborda los problemas sociales y políticos de Cuba, no existe ninguna consideración para aquellos que han osado asaltar el poder, manipularlo y prostituir, de esta manera, todo lo que tenía que ver con la libertad en la isla. Su "dadaísmo", presente en varias de sus novelas, así como en su poesía (entendido el dadaísmo como el síndrome del rechazo - del rechazado), está en relación directa con la intolerancia que desarrolló el novelista hacia las ingerencias extra-literarias en su labor como artesano de la literatura. Tales ingerencias las entendió como una irrupción violenta contra su sexualidad. Porque, como nos dice el profesor Cacheiro:

Arenas evalúa la existencia desde la perspectiva de la sexualidad. Su existencia está centrada en el placer. Tres pasiones rigieron la vida y la muerte de Reinaldo Arenas: la literatura no como juego sino como fuego que consume, el sexo pasivo y la política activa. De las tres, la pasión dominante era, es evidente, el sexo. No sólo en su vida sino en su obra. Fue el cronista de un país regido no por Fidel Castro, ya impotente, sino por el sexo (2000, p. 119).

Sin olvidar el placer, la sensualidad y el erotismo, Wilde, por su lado, nunca asumió una actitud de confrontación hacia el orden establecido. Sabía perfectamente que a la moral victoriana era imposible sitiarla, de tal manera que, se decidió por el sendero del menor esfuerzo, es decir, redujo las peculiaridades de sus pequeños gustos de alcoba a la esfera meramente individual y privada. El problema era que, para los victorianos, a su vez, la esfera de lo individual podía tornarse en un asunto público, mediante el truculento recurso de juzgar y enjuiciar a Wilde, por haber convertido sus vicios privados en una cuestión pública, sirviéndose del elusivo expediente de que su labor era puramente artística. Coincidir hoy, 
por esta razón, con los prejuicios ideológicos de los victorianos, podía tornarse, en cualquier momento, en una confrontación, cuando tales prejuicios hubieran sido vaciados de sus contenidos estéticos, y quedara expuesto, así, el cadáver maloliente de su hipocresía.

Utilizando el teatro, entonces, como plataforma, para dirimir sus pequeñas y cotidianas batallas contra la moral victoriana, pudo Wilde, a la larga, elaborar un mundo refractario donde la pastosa urdimbre de los diálogos, el frívolo sentido del humor y unos personajes atrapados en el atolladero de sus insulsas viditas, que apenas toleraría los embates de la realidad. El esfuerzo creativo de ese mundo de ficción, que para muchos autores es una tarea integral de la labor cotidiana, por lo tanto razonablemente vivencial, en el caso de Wilde supuso un esfuerzo descomunal-como sucedió con Reinaldo Arenas, también-, lo que apenas le permitió un respiro, para tomar consciencia de que estaba cruzando la línea fronteriza entre la ficción y la realidad. Para ambos casos, entre lo privado y lo público. El camino transitado por Reinaldo Arenas, sin embargo, estaba plagado de espinos, amargura y vejaciones, porque asumió que su labor pública, como intelectual, como artista, como escritor, estaba estrechamente relacionada con su vida privada; más explícitamente, con sus vivencias de alcoba, algo que no logra entreverse por completo en la obra de Oscar Wilde. En su novela El color del verano, Arenas dice que "los verdaderos intelectuales son demasiado inteligentes para creer, demasiado inteligentes para dudar y lo suficientemente sabios para negar. Por eso la gran inteligencia no va al poder sino a la cárcel” (1999, p.194).

Arenas descubrió muy temprano que las aspiraciones de la revolución cubana no satisfacían sus necesidades más sentidas y convirtió su lucha contra ésta en un proyecto de vida, estético y político. En sus novelas más elaboradas y complejas, de una extraordinaria riqueza verbal, dramática y argumental, no deja de sentirse la preocupación que lo atosiga por la libertad. Ha llegado a convertir sus ansias de libertad en un asunto de carne y hueso, tan vivencial y sostenido, que no alcanza a visualizar-tan enceguecido se encuentra por la desesperación de escapar-los lentos pero profundos cambios que está trayendo consigo la revolución cubana. Otra vez el mar reúne, con mucho, algunos de los mejores ejemplos de lo que estamos diciendo:

Constantemente, incesantemente, estamos ahora en guerra, dijo de los altos dirigentes. Estamos en guerra, óyelo bien, vivimos bajo la amenaza de que nos fulminarán; en una perpetua lucha que va más allá de los límites del campo de batalla, que a veces, siempre sobrepasa en horror a la misma batalla...A quién puede interesarle mi tragedia, si ahora mismo todos podemos perecer fulminados. Pero es terrible, dice Héctor, y yo lo escucho (ahora, rumbo al trabajo, esperando el cambio de luz), es terrible vivir siempre bajo la amenaza, la 
advertencia, de que este miserable día puede ser el último; aun dentro del horror es imprescindible que haya una estabilidad, detenerse en un punto, decir aquí me instalo, de aquí parto, de acuerdo a estas condiciones trataré de sobrevivir. Pero ni siquiera eso, dice ( $\mathrm{y}$ ya el auto echa a andar, pronto me apearé y entraré en el trabajo), ni siquiera eso tenemos aquí. Es preferible la guerra abierta, que lleguen las bombas de una vez: así, por lo menos, habría un fin, el caos no sería perpetuo. Quizás hasta se podría empezar otra vez... (Arenas, 2002, p. 31).

El "pesimismo histórico" de Arenas, para utilizar una expresión de Walter Benjamin, no se hallará nunca en la obra de Oscar Wilde, porque en la de éste la poesía cumple el propósito de una especie de argamasa para construir, progresivamente, un universo utópico a contrapelo de la fea realidad que ofrece la industrialización en la Inglaterra victoriana. Con Arenas, la ironía histórica consiste en que la utopía que construían los hombres de la revolución en Cuba, no impactó las frustradas ensoñaciones del novelista, y más bien le abrió el camino hacia una demolición, mordaz y puntillosa de esa utopía, la cual encontró en la historia las explicaciones y los argumentos para rebatirla. Entre el símbolo y la alegoría, el escritor cubano eligió la última, dispositivo estético a medio camino entre la realidad brutal y la utopía delirante. Arenas comprendió con agudeza y sentido común la enorme fuerza de la euforia generada por la revolución cubana, pero nunca le preocuparon los senderos escogidos por ésta para exhibir sus realizaciones:

Eso es lo más importante, huir, poder sostenerse en vilo mientras pasa el mediodía (así piensa, estoy segura) y todo afuera sucumbe, todo se despoja del poco misterio que lo justifica y perece en la claridad y el calor desgarradores. No mirar (ésas son sus palabras), mientras todo se despuebla y se convierte en una superficie lisa, candente, donde sólo quedan los deseos...Esos gestos, esas manos desvergonzadas, esa manera indolente de andar (Arenas, 2002, p. 55).

"¿(...)Qué puede hacer un escritor en un sitio donde no pueda disentir? dice Reinaldo Arenas en uno de sus ensayos (2001a, p. 211). La censura de la obra de arte, del libro, de la pieza arquitectónica y escultórica, del drama o de la música, del discurso, de la prensa o de los motivos de viaje, es una de las expresiones más aberrantes del despotismo y la tiranía. Enmudecer porque el otro se siente amenazado, es lo peor que le puede suceder a un individuo con ideas y emociones independientes. En principio, podría decirse que Oscar Wilde no experimentó esta clase de censura. Su obra fue sujeto de escrutinio, por parte de la justicia británica, durante el juicio por sodomía y poco después de haber sido puesto a languidecer en una celda de la cárcel de Reading. No sería censurado tampoco por su sexualidad, hasta el momento de su revelación. Lo cual quiere decir que en la Inglaterra victoriana, el simulacro constituía una forma de supervivencia. Y Oscar Wilde era un excelente simulador. 
Reinaldo Arenas no lo era. Su devastadora honestidad nunca le dejó espacio a la prudencia política. Por esa razón, el riesgo constante de aniquilación física era una presencia inocultable. Bajo la insistente presión del aparato represivo sobre el hombre político, el hombre artístico, el creador Reinaldo Arenas, estuvo a punto de malograrse, para salvar una sensualidad que ha sido intolerable siempre, en todos los momentos revolucionarios de la historia. Todas las revoluciones han combatido la sensualidad, porque ésta es siempre proclive a la sedición. Y nada es más revelador acerca de las limitaciones y posibilidades de una determinada sociedad que la actitud de sus grupos de poder, con relación a la sexualidad y la religión. A este respecto la lucidez de Reinaldo Arenas es atronadora:

Catolicismo ramplón y comunismo (fanatismo y dogmatismo) son términos equivalentes en lo que podría llamarse una particular ética de la hipocresía. No exponen la vida a la realidad, sino a una teoría de la realidad. Ambos se rigen no por la experimentación, sino por la adoración del dogma. La vida no cuenta. Cuenta la obediencia, los preceptos, y naturalmente las jerarquías. Un beato obediente (Cristo cada vez más lejano) tiene que aceptar y apoyar cualquier humillación impuesta a su vida, ya que precisamente su religión no es más que una cadena de limitaciones e imposiciones antinaturales. El comunista militante (Marx casi prohibido) debe de antemano renunciar a toda autenticidad, a toda vitalidad, y obedecer incondicionalmente las orientaciones que "bajan" del partido. Bajar, esa es la palabra. Indiscutiblemente "la Divinidad" (Dios o el dictador vitalicio) está muy alta. La libertad (creación, amor, rebeldía, renovación, vida) es ajena a ambas teorías (y prácticas), o más que ajenas, ambas teorías (y prácticas) son enemigas irreconciliables de la libertad (vida) (Arenas, 2001a, p. 178).

Como la libertad es una vivencia, una condición de vida, para intelectuales y creadores como Arenas, las jerarquías no cuentan y denotan su inutilidad y su transitoriedad cada vez que son burladas por aquellos a quienes quisieran regimentarles la existencia. Ese ataque constante al ejercicio de la autoridad, proveniente del partido o de la iglesia, evidencia un posicionamiento libertario que en Arenas siempre fue más allá del simple gesto burocrático o la pose militar, pues experimentó en carne propia las enseñanzas morales y políticas para el correcto comportamiento revolucionario. Las disquisiciones y refriegas sobre lo correcto y lo incorrecto en el movimiento revolucionario latinoamericano, después del triunfo de la revolución en Cuba, metieron a las personas, y a las organizaciones en contradicciones tan serias que algunas terminaron por destrozarse a sí mismas, como le sucedería al espléndido poeta salvadoreño Roque Dalton.

Reinaldo Arenas tenía absoluta claridad que, en casos como los mencionados, la homosexualidad se vuelve una cuestión política, pues el 
libre ejercicio de la sexualidad remonta los estrechos límites de una lucha por los derechos civiles, y se convierte en una cuestión en la que va implícita la noción que se maneje sobre la libertad y sus posibilidades reales de construirla y de vivirla:

Un homosexual es un ser aéreo, desasido, sin sitio fijo o propio, que anhela de alguna manera retornar a no se sabe exactamente qué lugar. Estamos siempre buscando un sitio que al parecer no existe, Estamos siempre como en el aire y atisbando. Nuestra condición de pájaro es perfecta y está muy bien que así nos hayan calificado. Somos pájaros porque estamos siempre en el aire, en un aire que tampoco es nuestro, porque nuestro no es nada, pero que al menos no tiene fronteras (Arenas, 1999, p. 403).

Contrariamente, en los juicios contra Oscar Wilde, son los jueces, más bien, quienes revelan una desoladora lucidez sobre las posibilidades políticas de acusarlo y declararlo culpable por sodomía (Anónimo, 1996). Lucidez que, también, los burócratas en los inicios de la revolución cubana, desplegaron generosamente para silenciar todo indicio de oposición, y para establecer cuáles serían los patrones culturales y morales con que sería conducida dicha revolución. La agudeza y la templanza que caracterizan la penetración con que Arenas analiza el escenario político e intelectual en Cuba, después del triunfo de la revolución, abren un espacio de reflexión que nada tiene que ver con el anti-castrismo. Acusar al novelista cubano simplemente de posiciones "anti" es reducir su quehacer a la mera frivolidad, cosa que encendía la alegría de algunos funcionarios de partido, más interesados en abrirse espacios a codazos que en defender o promover una determinada noción del desarrollo cultural revolucionario en la isla.

Con el gran Rodríguez Monegal, bien podríamos decir que Arenas es uno de esos escritores considerados "fundadores de América", pues mucha de su labor como intelectual y artista estuvo apuntalada por la lucha en favor de la forja de una conciencia americana (Rodríguez, 2003, p. 363). En su caso, desde la defensa a ultranza de la libertad como vivencia en todas sus dimensiones: "Creo como Jorge Luis Borges, que el hombre americano tiene derecho a todas las culturas, ya que no es deudor de ninguna, y las padece casi todas; por lo mismo, no debe conocer ni respetar limitación cultural alguna" (Arenas, 2001a, p. 92). No es posible imaginar al intelectual latinoamericano promedio, sin su movimiento bascular entre la más irracional entrega a los excesos de las dictaduras, y su feroz combate en beneficio de una noción de libertad que no siempre tiene muy clara:

Nada irrita tanto como la libertad: los que la tienen no la soportan y los que no la tienen se matan por ella. Un buen dictador exalta la libertad mientras la destruye, pero los 
demócratas la destruyen sin exaltarla. Sólo los esclavos conocen el valor de la libertad, por eso cuando la tienen imponen el cepo. (Arenas, 1999, p. 194).

Arenas buscó ubicarse entre estos últimos, pero su denso nihilismo le tornó incómoda incluso su convivencia con los norteamericanos, cuando tuvo que refugiarse en los Estados Unidos:

Ahora en los Estados Unidos no hay intelectuales, decía, sino chupatintas de tercera categoría que sólo piensan en el nivel de su cuenta bancaria. No se puede decir que sean progresistas o reaccionarios, son sencillamente idiotas y por lo mismo instrumentos de las fuerzas más siniestras (Arenas, 2001a, pp. 260-261).

Aquí (en Nueva York) soy una sombra, allá (en Cuba) por lo menos era un hecho real, aunque doloroso. ¿A quién carajo le va a importar mi dolor cuando lo que interesa aquí es el espectáculo ligero y sin complicaciones? $\mathrm{Y}$ sin embargo, es éste, mi amigo, el único lugar del mundo donde se puede sobrevivir; lo digo de corazón, porque lo digo sin ningún tipo de ilusión. Los norteamericanos caminan muy rápido y si no circulas te tumban de un empujón. Parece que tuvieran asuntos muy importantes que resolver; realmente trabajan como bestias. Pero todo ese apuro consiste en llegar a su casa, quitarse los zapatos y sentarse a ver la televisión, que es horrible (Arenas, 1999, pp. 180-182).

En esta misma línea de argumentación, en otra parte (Arenas, 2001b, pp. 21-22), continúa diciendo que los Estados Unidos son los principales responsables de la vocación autoritaria en América Latina, por la negligencia con que han tratado a los regímenes democráticos, legítimamente institucionalizados, y el cínico apoyo que han brindado a dictaduras de factura genocida, como las que han proliferado en América Central y el Caribe. Arenas hace críticas muy severas a la vida cotidiana en los Estados Unidos, a los usos y costumbres del pueblo norteamericano, "uno de los pueblos políticamente más torpes de la tierra" (Arenas, 2001b), no tanto porque su posición sea de naturaleza antiimperialista, sino porque le resulta repulsivo verse involucrado en las visiones maniqueas con que la guerra fría fragmentó el planeta. Buscó refugio en los Estados Unidos, pero nunca se sintió obligado a reconocer o tolerar una vida cotidiana que, desde el primer momento, le resultó muy difícil de soportar. Los diez años que permaneció ahí, fueron años depresivos, grises, con pocas y salteadas alegrías, que definen a un escritor crítico, reflexivo y profundo, muy difícil de convencer sobre las bondades de la gran democracia norteamericana (Arenas, 1996, p. 310). Junto a ello, el drama del exilio, los traumas del desarraigo y la tremenda soledad, al ver cómo cristaliza su aislamiento, corporizado en la muerte y la persecución de algunos de sus más entrañables amigos, hicieron que su estadía en los Estados Unidos fuera todo menos placentera. 
La literatura festiva, con la que se rescata el carnaval, y se denuncia el simulacro, a través de la chota, la jarana y el chascarrillo, tan propias de la literatura caribeña, hallaron en Reinaldo Arenas a uno de sus más logrados cultores (Valero, 1991). En El color del verano el lenguaje erótico, que brota de manera incontenible, alcanza cotas pocas veces visitadas por la literatura latinoamericana, y abrió senderos de expresión continuados apenas por una pequeña elite. Es definitivamente una novela gay, si hay algo que pueda llamarse así, pero es también el texto más consumado y completo sobre lo que consiste en abordar la historia y el desarrollo revolucionario cubano, desde una perspectiva carnavalesca pero a la vez triste y amarga. Mijail Bajtin se hubiera dado cuatro gustos con este maravilloso trabajo.

El desarraigo que produce en un escritor como Reinaldo Arenas, no sólo la posibilidad del exilio, sino su realidad viscosa y descarnada introduce en sus novelas y poemas, una sentida ansiedad por el sitio fijo, el lugar donde echar raíces. La geografía del desarraigo adquiere con él expresiones literarias irrepetibles, sólo igualadas, tal vez, en la poesía de Mario Benedetti:

Ahora, cuando ya corría, cuando ya casi no se podía sostener, comprendía (eso también) que cualquier sitio es preferible a no tener sitio, al estar siempre en poder de los otros, al no contar siquiera con un espacio, mínimo y ardiente, donde al menos poder extender su desgracia (Arenas, 2001c, p. 184).

Con frecuencia las nociones geográficas de Arenas están en relación directa con los sueños, esperanzas y aspiraciones fallidas. Es recurrente el ansia de huir pero sin saber adónde, ni por qué ni para qué. La idea de libertad en Arenas tiene mucho que ver con los espacios donde se encuentren los seres humanos, sus personajes.

La muerte, el tiempo y la memoria en la creación literaria de Arenas son los tres ápices de una lectura de la historia de América Latina, que no mantiene una relación dinámica con el quehacer de los historiadores en esta parte del mundo. Su percepción de la labor de los historiadores pertenece más al campo de la concepción artesanal de la misma, y no hace justicia a los tremendos esfuerzos de reconstrucción histórica realizada por los investigadores, cultivadores de diversos paradigmas analíticos, que han buscado por años nuevos caminos para comprender mejor a la América Latina. En la visión de Arenas, la historia debería ser el otro nombre de una poética, antes que una práctica de la investigación humanística:

Por eso siempre he desconfiado de lo "histórico", dice el novelista cubano, de ese dato "minucioso y preciso. Porque, ¿qué cosa es en fin la Historia? ¿Una fila de cartapacios ordenados más o menos cronológicamente? ¿Recoge acaso la Historia el instante crucial en que Fray Servando se encuentra con el agave mexicano o el sentimiento de Heredia al no ver ante el desconsolado horizonte de 
su alma el palmar amado? Los impulsos, los motivos, las secretas percepciones que instan (hacen) a un hombre no aparecen, no pueden aparecer, recogidos por la Historia, así como aun bajo quirófano no se captará jamás el sentimiento de dolor del hombre adolorido (Arenas, 2001a, p. 97).

Aunque la decisiva distinción entre investigación histórica y la recuperación de la memoria tenga una enorme utilidad para roturar los campos de acción de los historiadores, los biógrafos y los novelistas, este no es el lugar para enmendarle la plana al escritor cubano. En el párrafo anterior, Arenas parece desplegar una concepción sumamente clásica del quehacer del historiador y opta por inclinarse hacia una reconstrucción histórica en la que la imaginación del novelista, no la del historiador, se abra espacio sin reparar en los convencionalismos de la precisión, o la simple verosimilitud. Este abordaje de la historia, se encuentra expuesto, espléndidamente, en las primeras páginas de El mundo alucinante, con toda probabilidad, la novela más latinoamericana de Reinaldo Arenas, pues en ella, ajustado a la más rancia tradición del barroco cubano, el derroche de imaginación verbal convierte a Fray Servando Teresa de Mier, un personaje del siglo XVIII, en el vocero de las ansias de libertad del novelista, así como de sus críticas más ácidas contra toda expresión autoritaria.

\section{Dice Arenas:}

Por largo tiempo había tenido que trotar el fraile para, finalmente, arribar al sitio que lo identifica y refleja: la mínima planta, arrancada y transplantada a una tierra y a un cielo extraños. El ciclo casi mítico del hombre americano, víctima incesante de todos los tiempos, componedor de lo imposible, pasa también por ese breve y fulminante encuentro entre alma y paisaje, entre soledad e imagen perdida, entre el sentimiento desgarrado de inseguridad y ausencia y el de la evocación que irrumpe, cubriendo, imantando, idealizando lo que cuando fue (cuando lo tuvimos) no fue más que un lugar común al que la imposibilidad de volver prestigia (1997, p. 17).

De nuevo el tiempo, la muerte y la memoria hacen su aparición, encuadrados por una determinada noción del espacio geográfico que, para Arenas, debería tener una extraordinaria relevancia. La geografía es la eternidad, diría Cabrera Infante, recogiendo con sensibilidad ese profundo sentimiento del intelectual cubano desarraigado, y que se destila en casi toda la obra de Reinaldo Arenas.

Con Oscar Wilde la situación es muy diferente, como veremos en el apartado siguiente. 


\section{Poesía y poder político}

Como Reinaldo Arenas, Oscar Wilde fue también víctima de los desplantes y de las maquinaciones del poder político. Sin embargo, en el programa ético y estético de Wilde, la política, la denuncia, tienen un peso específico menor que en la literatura de Reinaldo Arenas. Ambos murieron en sus cuarentas, y ambos fueron censurados por sus ideas artísticas y sus inclinaciones sexuales. Pero el tratamiento político que Arenas le dio a esas expresiones del autoritarismo, están lejos del esteticismo de Wilde, para quien el mundo sería un lugar más decente donde vivir, si los hombres y las mujeres entendieran la importancia de la belleza en la vida de las personas. Con esto no estamos diciendo que Wilde fuera el colmo de la ingenuidad, todo lo contrario, pues con él, prácticamente, se inicia el movimiento gay a escala mundial. Sin embargo, las acciones y los escritos de Arenas tienen una condición programática que llegó a convertirse en la plataforma de varias alternativas de lucha contra el autoritarismo, y en pro de las libertades civiles, sexuales y políticas, no sólo de las personas en problemas con el poder político, por su sexualidad, sino también para todos aquellos que combaten las distintas manifestaciones del despotismo.

La "estética ética" (Prewitt, 1997) de Wilde constituye un conjunto de principios y postulados que aspira a facilitar la labor del creador y su inserción en el mundo que le tocó en suerte. Puede ser visto como una guía para tener una vida más placentera, llena de arte, placer y satisfacciones. Carece de sistema, porque Wilde consideraba que todos los sistemas conducían, tarde o temprano, hacia el mismo lugar: la frustración y la amargura. Y este mundo ya tenía suficiente fealdad, como para ajustarse a sistemas que sólo aspiraban a programarles la vida a las personas, con la consiguiente cuota de soledad y desconcierto. Es por estas razones que no encontramos en la obra de Wilde algo similar a lo que Walter Pater o John Ruskin pretendían, dos de sus antecesores más sublimes, es decir pontificarle a la sociedad victoriana, la clase de moral que debía elegir para vivir mejor.

La poética de Wilde deja sin posibilidades estéticas al discurso libelista, a la diatriba política en la que fue tan habilidoso el novelista cubano Reinaldo Arenas. Una rara habilidad que tal vez no deba ser atribuida únicamente a la sensación de marginalidad, experimentada por los creadores de la llamada "generación del Mariel" (Charvátová, 2001, pp. 30-49), sino, más que nada, al talento carnavalesco que despliega Arenas en sus obras, a su capacidad para la parodia, la autocrítica y, a veces, hasta para la autoflagelación. De aquí que los recursos estilísticos de corte dadaísta -las aliteraciones, el tratamiento hiperbólico y la fineza con que mete el estilete cuando hace burla de algunas figuras públicas latinoamericanas, demasiado sumisas, para su gusto, a los gestos faraónicos de algunos dirigentes de la revolución cubana-, cumplan el propósito de abrir senderos hacia el hallazgo ontológico de la otredad del que ha sido dejado al margen de la revolución. 
Oscar Wilde no hizo observaciones precisas acerca de la posibilidad de construir un orden social, o un sistema económico mejor que aquel en el que estaba viviendo. En realidad, nunca se dirigió de frente a los economistas, como lo haría John Ruskin, en una serie de cuatro ensayos críticos de la sociedad victoriana, jamás superados hasta hoy (Ruskin, 1997, pp. 155). Como las teorías del arte de Nietzche, Novalis, Schiller y Baudelaire, la de Wilde también tuvo consecuencias políticas imprevistas en el quehacer de la posteridad, pero, a este respecto, el poeta irlandés siempre tuvo cuidado de ser muy asistemático, pues evadió con sutileza las propuestas programáticas, esquemáticas o catequísticas. En su conocido ensayo El alma del hombre en el socialismo (Wilde, 1998, pp. 15-47), defendió las posibilidades reales de la individualidad artística genial en un mundo socialista, pero reflexionó también, de manera excepcionalmente premonitoria, la poca atención que se daría al arte en sí mismo, pues éste terminaría estando al servicio de un sistema político, con lo cual degeneraría en pura propaganda.

Tanto Wilde como Arenas tenían una concepción del poder político que lo limitaba a ser una simple maquinaria opresiva, para la cual las expresiones de la individualidad deberían ser arrinconadas en virtud de los privilegios de la multitud. Este sofocante tratamiento de la actividad política, hacía que el arte, en sus distintas variantes, no pudiera ir más allá del perímetro establecido por una determinada autoridad, casi siempre anónima y descolorida, con la cual los artistas debían lidiar, apostando su libertad en cuanto a métodos de trabajo, teorías estéticas, técnicas y recursos para desarrollarse en toda su plenitud como personas. En estas circunstancias, dice Wilde, todas las expresiones del arte son inmorales (Wilde, 2000, p. 785), porque no atienden a las necesidades decorativas del poder político en materia artística. Es el momento en que un puñado de artistas, críticos e intelectuales se apura a convertirse en corifeos de la autoridad de turno. Para Wilde, de nuevo, en este lance, la crítica se vuelve irrelevante. Porque, para él, el crítico requiere un universo donde la contemplación tenga sentido. Es decir, según Oscar Wilde, la verdadera crítica es contemplativa (Wilde, 2000, p.784). Y esta clase de puntos de vista, le resultan intolerables al poder despótico, para el cual el hombre de acción, el hombre práctico, es el eje del proceso revolucionario que está tratando de construir.

Las posiciones críticas de Arenas, por su lado, parten, también, de un tratamiento contemplativo acerca de lo que está sucediendo en Cuba, al momento en que él la abandona. Pero Arenas discute, vocifera y se enardece, porque en el nuevo orden de cosas que se está levantando en la isla, él no tiene, o tendrá, ninguna participación. Cosa muy distinta a la crítica contemplativa por la que aboga Oscar Wilde, para la cual, el ejercicio de la libertad artística, no conoce de fronteras, o de limitaciones de orden discursivo o espacial, porque la misma es el resultado de un proceso interno, y no de los moldes externos a los cuales logre adaptarse el artista para sobrevivir. Por eso, concluye Wilde: 
La estética es superior a la ética. Pertenece a una esfera más espiritual. Discernir la belleza de una cosa es el punto más sutil a que puede llegarse. Hasta un sentido del color es más importante, en el desarrollo del individuo, que un sentido del bien y del mal (Wilde, 2000, p. 814).

No cabe la menor duda, por otro lado, que la "crítica cosmopolita" de Wilde está desprovista de la beligerancia política de las acciones emprendidas por Arenas, para defender su derecho a practicar el arte que se le antojaba, así como a tener una vida personal en la que nadie se inmiscuyera. A partir de aquí, el puente estético que se pueda tender entre ambos, a pesar de las sustanciales diferencias de época y espacio que podamos establecer, está construido con una sensibilidad similar, sobre el ejercicio de la libertad en medios en los cuales la fatigosa lucha contra los opresores abiertos y solapados produce los mismos frutos para la humanidad como un todo. Por esta razón, entre muchas otras, no sorprende la coincidencia de tono y melodía cuando los postulados autoritarios son formulados desde trincheras distintas. "Dentro de la revolución todo, fuera de la revolución nada", se decía en los momentos iniciales de la revolución cubana. Asimismo, se podría decir con la Corona británica- parafraseando el veredicto final, durante el juicio contra Oscar Wilde (Kauffman, 1998, p. 143; Eagleton, 1989, p. 60)-: dentro de la moral burguesa todo es posible, fuera de ella nada. Que la era victoriana fue un conglomerado de prácticas autoritarias, imperiales y abusivas es una afirmación que a muy pocos sorprendería. En la cuna del capitalismo feroz, las diferencias sociales son abismales, y aún bien entrado el siglo XX, como constata Emma Goldman en su autobiografía, muchos de los supuestos logros de la revolución industrial siguen siendo para unos pocos, quienes se encuentran rodeados, atosigados, por una pobreza asfixiante.

La maquinaria burocrática creada por el Imperio Británico, durante esos años, fue realmente insuperable, y significó, para los Estados Unidos, entre otros países, un laboratorio de aprendizaje irrepetible. Como ha quedado ampliamente registrado en la historia moderna, los imperios funcionan a partir de aparatos estatales ampliados, mejorados y profundizados. Llega un momento en que se les vuelve imposible funcionar sin estructuras ideológicas debidamente articuladas. En la historia inglesa dos de esos grandes momentos de expansión imperial son, precisamente, el reinado de Isabel I, en el siglo XVI, y el reinado de Victoria, a finales del siglo XIX (Quesada, 2001). La sofisticación ideológica del imperio británico, podría haber sido superada, solamente en algunos tramos, por el imperio francés. Ese magma ideológico penetra hasta los más recónditos escondrijos de las convicciones morales de las personas en su vida cotidiana. De tal manera que, hablando imperialmente, la reina Victoria operaba con el principio aristotélico de que, el imperio británico, era algo así como el "primer motor inmóvil" de la historia moderna. Todo partía de él y confluía en él. 
Ahora bien, por definición, todo estado imperial es un estado autoritario. Burocratizado y jerarquizado hasta las médulas; el estado imperial busca organizar el funcionamiento y operatividad de las instituciones imperiales allende los mares, hasta donde el estirón de los tentáculos de la Corona ya no dé más. Ello incluye las consciencias de las personas. Entre esa supuesta democracia parlamentaria burguesa, y el socialismo autoritario, ¿habrá alguna diferencia? Con la excepción de las proporciones, las aspiraciones son las mismas: hacerle a las personas la vida un infierno. A no ser que nos pleguemos al autoritarismo, como una salida válida hacia la supervivencia. Oscar Wilde vivió personalmente, la aplicación de lo que se consideraba "moral correcta" en su época. Reinaldo Arenas también compartió ese honor, cuando le apretaron las clavijas de la "moral revolucionaria". Oscar Wilde tomó consciencia de que sus actos tendrían consecuencias políticas muy severas hasta el final de su juicio. Reinaldo Arenas tomó consciencia de lo mismo, pero desde el principio, cuando la supuesta moral revolucionaria lo dejó por fuera de todos sus posibles beneficios, y lo convirtió en un paria exiliado. Oscar Wilde, al menos, degustó algunas de las mieles repartidas por la moral imperial. Peor aún, primero fue ensalzado, luego escarnecido. Pero Reinaldo Arenas, como él mismo dice: solo recibió una patada en el trasero.

No importa el tamaño de la maquinaria estatal, sea ésta gigantesca, o liliputiense, la vocación del Estado siempre será controlar, manipular, distorsionar y aniquilar lo más noble de la vida de las personas. Indistintamente del volumen burocrático que posea, así como de la flexibilidad o inflexibilidad que muestre, el Estado tiene como destino ineludible impedir que las personas sean personas. $Y$ es su aspiración mayor, sin importar el signo ideológico que porte, bloquear el despliegue libre y creativo de la libertad y la independencia de los seres humanos. Lo más triste de todo esto es que haya individuos que se presten a servirle, y que entreguen sus vidas, fortunas, familias y vocación para saciar la voracidad de un ogro -como diría Octavio Paz (1990, p. 85)- que no siempre tiene algo de filantrópico.

Gracias a Dios existe la disidencia. Oscar Wilde y Reinaldo Arenas fueron dos ilustres disidentes, y mientras existan esta clase de personas todavía es posible la decencia en el mundo. El primero comprendió con justeza el funcionamiento del universo burgués victoriano. A esa fortaleza inexpugnable trató de desafiarla y le costó la vida. El segundo, como el burro pegado a la noria, insistió también en demoler la tapia que lo separaba de las personas de bien, es decir, de los ajustados, de los bienquistados al régimen revolucionario, e igualmente le costó la vida. Porque no hay nadie más implacable que el funcionario bien entrenado, ciegamente convencido de que solo cumple con su deber. Esta casta de personas se rige por un código infalible, la obediencia contumaz al monarca, al presidente $\mathrm{o}$ al autócrata de turno. ¡Y han estado con nosotros desde el nacimiento de las civilizaciones!

Nadie podía expresarlo mejor que Octavio Paz: 
La historia de la literatura moderna, desde los románticos alemanes e ingleses hasta nuestros días, es la historia de una larga pasión desdichada por la política. De Coleridge a Mayakovski, la Revolución ha sido la gran Diosa (sic), la Amada (sic) eterna y la gran Puta (sic) de poetas y novelistas. La política llenó de humo el cerebro de Malraux, envenenó los insomnios de César Vallejo, mató a García Lorca, abandonó al viejo Machado en un pueblo de los Pirineos, encerró a Pound en un manicomio, deshonró a Neruda y Aragón, ha puesto en ridículo a Sartre, le ha dado demasiado tarde la razón a Breton (sic)...Pero no podemos renegar de la política; sería peor que escupir contra el cielo: escupir contra nosotros mismos (1990, p. 303).

Como en la célebre película alemana Mephisto, basada en la novela de Klaus Mann, el poder es algo más que un baile de máscaras, y el costo que debe pagar el artista en sus relaciones con las esferas de la autoridad, se desembolsa en cuotas de humillación, maltrato y arrinconamiento. Le cuesta mucho, al artista, disociar su imagen de lo que hace, con lo cual los afeites, las vestiduras y los gestos se vuelven algo de suma relevancia. En Oscar Wilde y Reinaldo Arenas, el precio de la pose adquirió tonos insalvables, cuando ya se había vuelto imprescindible la locuacidad. El silencio del artista es una traición, así lo piensa, cuando las condiciones sociales y políticas no perdonan su mutismo, si la historia le demanda un precio exorbitante a los hombres y mujeres para quienes la política, el ejercicio del poder y la autoridad se reducen a lo que puedan desayunar el día siguiente. Sin embargo, no es privilegio de los artistas tener esa lucidez, la cual demandaría un nivel de entendimiento de su ubicación en el universo, difícil de conquistar sin el abandono de su torre de marfil. Cuando lo han hecho, casi siempre han fracasado. Si la poesía puede cambiar el mundo, es un asunto que le pertenece a la sección siguiente.

\section{Poesía y existencia}

La historia registra cientos de casos en que la vida y la existencia, condicionan el quehacer artístico de poetas, pintores, músicos y humanistas en general. No es la neurosis el entramado crítico requerido para que el poeta catapulte su consciencia artística. La bohemia, el malditismo puro, no hacen poesía; si acaso la motivan. Pero quien nunca ha disfrutado la dulzura de un beso, ¿cómo puede escribir un soneto sobre las reverberaciones que deja en el aliento? ¿Quién, con conocimiento de causa consciente, puede escribir sobre los espasmos de un orgasmo si jamás los ha vivido? A fin de cuentas, tampoco se puede escribir sobre la existencia si ésta ha sido plana, desabrida y anodina. Como la poesía, son pocos los géneros literarios que mantienen una relación tan estrecha con lo vivido. No son el navajazo en la mejilla, el pistoletazo en la cantina, o la fuga por el balcón, los requerimientos a partir de los cuales, la poesía adquiere sentido. Pero sin ellos, la poesía 
también corre el riesgo de revestir la textura acartonada del pergamino, la variedad acrisolada de la sola imaginación, y el hieratismo monocromático de la forma pura.

Poetas como Oscar Wilde, Reinaldo Arenas, Rubén Darío, Pablo Neruda, Octavio Paz, Arthur Rimbaud, Luis Cernuda o Jaime Gil de Biedma, son poetas todos de la estructura y la forma exquisitas, pero también lo fueron de la vivencia nutricia, la chispeante paradoja y la sonora metáfora, las cuales, solo las brinda la vida, y no únicamente el talento por sí solo. Para ello fue necesario vivir, intensamente, asumiendo todas las consecuencias de los triunfos y fracasos que va ofreciendo la vida, en un encabalgamiento sin soluciones de continuidad y sin trucos. El simulacro, en el proyecto existencial de estos poetas, no reemplaza la propia piel, y sólo tiene sentido cuando se trata de desafiar el poder, en el momento cuando la ironía tiene que hacerle espacio a la supervivencia. Porque al poder hay que tomarlo muy en serio, tal y como lo probó ampliamente la burocracia judicial en el caso de Oscar Wilde. La ironía para él, los juegos de palabras, las mil imágenes reflejadas en el espejo, no tienen la punzante penetración de una vindicta redactada por Reinaldo Arenas. Oscar Wilde es irónico, pero sin deshacerse nunca del guante blanco. Arenas también lo es, pero con un guante de acero. Alguien diría, se trata de estilos irónicos producidos por épocas y situaciones muy distintas. Eso es cierto, pero también lo es que la ironía estilística de Wilde no es tributaria de causa política alguna, aunque su ingenuidad le cobrará más tarde este desconocimiento. Arenas, por su parte, tiene la descarnada consciencia de que la ironía hace trizas personalidades políticas, sin piedad.

En el mundo gris y cenagoso del Londres victoriano, la ironía es el gesto compungido del que dice o insinúa lo que no piensa. En el brillante y soleado universo caribeño se piensa lo que se dice a medias. Mientras tanto, entre verdades y decires a contra luz, el poder se fortalece y le anuncia a los artistas y a los intelectuales-a los técnicos no los toma en serio, porque piensan poco según dicen-, que en el mundo y la sociedad del futuro, la cultura de la simulación será la nota predominante. Infelizmente ni Wilde ni Arenas eran simuladores consumados. Ambos "ejercían" la libertad, como dice Octavio Paz (1990, p. 13), no se preocupaban por definirla. $Y$ en este ejercitarse por ser libres, el rey no puede ocultar su desnudez, haciendo brotar la evidencia de su impotente transitoriedad. El ejercicio del poder es fugaz y todo cambio social, político y cultural acuerpado por la violencia o por la fuerza no tiene ningún futuro real. Su asidero reside en el miedo, un miedo a veces provocado por la incertidumbre, en otros momentos por la pérdida del halago y en otros por el retiro de los recursos para sobrevivir, con que viven apañándoselas la mayor parte de los artistas.

Son escasas las oportunidades en que vemos a Wilde, con serios problemas financieros, para sostener, no tanto sus caprichos a la mode, como por atender los requerimientos y los apremios de lujo y derroche interpuestos por su compañero, Lord Alfred Douglas (Bosie), quien 
carecía del más mínimo sentido de las proporciones y las medidas en los gastos. En este caso, el dandysmo de Wilde, no se agota en la exquisitez de las palabras, y se amplía, más bien, con su actitud general ante la vida. El suyo es un dandysmo que tiene que ver con el buen vestir, la buena comida, los vinos fantásticos, la música suprema y el teatro ligero que aliviane la cotidianidad. Bien lo decía también el gran poeta español Luis Cernuda:

Mas recuerdo ahora que cierto amigo pretendió una vez convencer a quien esto escribe, y casi le convenció, de que él se acicalaba y adornaba no para atraer sino para alejar a la gente de su lado. Había notado, o creído notar, que si bien la mujer elegante atrae, el hombre elegante repele. Según dicha teoría el dandismo no sería sino una forma entre otras de aspirar a la soledad ascética del yermo, lo cual puede ser cierto. Al menos los más escépticos deberán reconocer que de todas las formas que ha revestido esa vieja aspiración humana de la soledad, esta del dandismo aparece así como la más refinada de todas (Cernuda, 2002, p. 272).

La soledad del dandy, en declarada rebeldía contra todo lo que le parezca vacuo, superficial, feo y aburrido, era el utillaje extraído de una lucha, cuerpo a cuerpo, contra los convencionalismos de un realismo cerril y cuadrado, aquel que desplegaba como uno de sus mayores logros, no sólo el imperio británico, ahíto de efectividad y riqueza, sino también el pujante industrialismo norteamericano:

El crudo comercialismo de los Estados Unidos, su espíritu materializador (sic), su indiferencia ante el aspecto poético de las cosas y su falta de imaginación y de elevados ideales inalcanzables se deben totalmente a la circunstancia de que ese país adoptó como héroe nacional a un hombre que, según propia confesión, era incapaz de decir una mentira (Wilde, 2000, p. 838).

Porque uno de los ingredientes esenciales en la teoría del arte que promociona Wilde por aquellos años, y la cual se nutre, inevitablemente, de su pose de dandy, es el embuste, la simulación, la mascarada. En su reconocido ensayo La decadencia de la mentira, Wilde teorizaadelantándose a textos con similares aspiraciones de Mario Vargas Llosa, Ernesto Sábato, Jorge Luis Borges y Sergio Ramírez, sobre la verdadera potencia de la mentira en la creación literaria:

Los únicos seres reales son los seres que nunca existieron, y si un novelista es lo bastante ruin para ir a la vida en busca de personajes, debe simular al menos que se trata de creaciones y no jactarse de que constituyen copias. La justificación de un personaje en una novela no es que otras personas son como son, sino que el autor es como es. De no ser así, la novela no es una obra de arte(Wilde, 2000 , p. 828).

La fuerza de la imaginación en el artista, en el creador, es la única que provee la energía suficiente para combatir el miedo, la indiferencia y la 
incertidumbre que alimentan la existencia del poder. Oscar Wilde sabía de eso. Reinaldo Arenas también. Sin la imaginación, sin la capacidad de retorcer y moldear la realidad a su antojo, el poeta debe darse por satisfecho con una vida insulsa, mortecina, sin las emociones y las ilusiones que el trabajo creativo diario hace posible. Es la carestía de imaginación la que Wilde le reclama a su amigo Lord Alfred Douglas en De Profundis, la larga carta que le escribiera desde su celda en la cárcel de Reading. Esta epístola, con toda probabilidad, uno de los mayores logros líricos de la literatura inglesa del siglo XIX, es en realidad un programa estético, y un sostenido discurso ético, sobre las responsabilidades que le competen al artista en el siglo que se avecinaba. Sus profundas reflexiones, sus divagaciones históricas, y sus abrumadoras referencias eruditas acerca de las relaciones entre poesía y existencia, o entre arte y vida, como bien le gustaba decir a Wilde, sorprenden por el momento y las circunstancias en que fueron redactadas. Torturado diariamente por las largas jornadas de trabajo en la prisión, Wilde tiene todavía el alcance emocional y la concentración, para sentarse a escribir sobre la cultura griega, sobre el renacimiento, el industrialismo y la moral en cuestiones artísticas. Pasan también, por esta carta, en cada una de sus páginas, transidas de dolor, frustración, amargura y resentimiento, los pensamientos e ideas que anuncian la nueva sensibilidad, aquella que prepara la llegada de la modernidad.

Bosie Douglas es sólo un interlocutor opaco, al cual Wilde utiliza como aparente receptor de un conjunto de teorías, proclamas y propuestas estéticas que irían a marcar la evolución artística de casi todo el siglo XX. Pero al mismo tiempo, Wilde prepara también el sendero por el cual transitarían la nueva crítica de arte, las tensas relaciones entre ética y política, así como la fuerza del individualismo en la creación artística e intelectual del siglo. Partiendo del consabido poder evocativo del Cristianismo, como referente prefabricado en lo que compete a la enseñanza de la moral, como diría Benjamin, Wilde logra articular una propuesta sobre el individualismo, en la que tiene un peso muy específico la responsabilidad del artista en la sociedad contemporánea. Entre las grandes individualidades que menciona en su epístola, Wilde menciona al pensador anarquista ruso Peter Kropotkin, como ejemplo de una vida dedicada a la creación, no tanto artística o intelectual, como vivencial.

Para Wilde, lo que él llama la gran desgracia de las sociedades modernas, la frivolidad, la ligereza, tiene poco que ver con las potencias individuales de quien asumió su labor, su oficio, como una forma de transformar el mundo, transformando su vida personal. Si alguien escogió una vida de apariencias, de gestos y mascarada, dice Wilde, tiene todo el derecho de llevar esa opción hasta sus últimas consecuencias, pero que no pretenda convertirla en un programa para ser asumido por todos, sin discriminaciones de ninguna especie. Este es, en realidad, el verdadero dandysmo de Wilde, del que nos habla el poeta español Villena, en el artículo mencionado. Porque cualquiera podría pensar que dandy es 
sinónimo de superficialidad, de "ligereza" diría Wilde. Ese bien puede ser el significado externo de la palabra, pero en poetas como Wilde, Cernuda y otros-recordemos a la generación del 27 en España-, su sentido interno deviene en una cuestión estrictamente personal. Un verdadero dandy, nos dice Villena, defiende su derecho a la rebeldía, a través de un esfuerzo sostenido por ser él mismo, en todo momento y circunstancia.

Y para desplegar esta autenticidad radical, sin importar el medio social, político y cultural en el que se encuentre la persona, se requiere un coraje que no todo el mundo tiene. Se trata de un coraje que supone riesgos, en los que, incluso, va involucrada la vida, como bien lo prueban las experiencias de Oscar Wilde y Reinaldo Arenas. Porque uno de los riesgos más siniestros de esta clase de rebeldía-también, dicho sea de paso, muy ligada con el romanticismo y el surrealismo-, es la muerte artística. La burguesía victoriana, con plena consciencia, intentó destruir a Wilde, estrangulando aquellos aspectos de su personalidad que más incitaban a la revuelta; sobre todo de las personas jóvenes, como su afán por la libertad, la independencia y la búsqueda incesante del sí mismo, a través del arte y del pensamiento. Wilde, posiblemente, no envió el mensaje correcto, pero en el intento reside la gloria. Bastaba que tales intentos de autenticidad llegaran a los corazones de la gente joven, para que la burguesía imperial británica se dejara invadir por el pánico.

Con Reinaldo Arenas, dicha búsqueda de la autenticidad tenía como entramado más positivo, no tanto la sensualidad-un aspecto en el que algunos autores, posiblemente, se han detenido con exceso-, sino también la lucidez a la que invitaba la certeza de que la literatura, el arte en general, son inútiles. Cuando Wilde decía esto, lo entendía como una forma de blandir sus más ácidas críticas, contra un dominio burgués, para el cual la productividad era lo más importante en la vida. La inutilidad del arte le resultaba a esa misma burguesía, áspera, avara y calculadora, no sólo un insulto, sino, particularmente, una amenaza. Los artistas, los intelectuales y los pensadores eran tolerables hasta el punto en que no atentaran contra su forma de vida, encuadrada por la disciplina, el orden y el ahorro. Y como el arte era una carga que no representaba ningún beneficio, era criterio de los ideólogos del imperio, que al menos debería estar al servicio de las aspiraciones de una burguesía que pagaba sus desafueros, aunque no los compartía ni por asomo.

La leyenda del "poeta maldito", del artista aterido hasta los huesos, escondido en una buhardilla maloliente, muerto de hambre y desamparado, solo tiene sentido si partimos del principio de que su rebeldía no se sustenta en los signos exteriores de una pasión inocua, sino en las potencias interiores que lo capacitan para enfrentar las deprimentes tendencias hacia la homogeneidad y el desabrido gusto burgués por lo meramente decorativo. Por eso sus buenos ideólogos nunca lograron que la burguesía entendiera cabalmente al surrealismo. Algo similar le aconteció con el romanticismo, al cual siempre quiso tener de su lado. Pero resultó que los románticos no estaban hechos para plegarse a un conjunto de postulados, especialmente, diseñados para 
ejercer el poder, la intolerancia, la censura y el sometimiento. El hombre y la mujer románticos eran en esencia rebeldes; tal vez no revolucionarios, pero sí eran portadores y defensores de un programa individualista en el que no cabían el presentismo y el sentido de la inmediatez, tan propios de la burguesía adinerada, y ahíta de éxitos financieros. En estos casos, el artista evoca un raro e incómodo parecido con las mascotas.

Reinaldo Arenas combatió con fiereza y dedicación ese horrible sentimiento. Sentirse como un bicho raro, sin conexiones reales con los sabios que ejercen el poder, para quienes el artista y el intelectual deberían estar agradecidos por permitirles conservar la vida, fue siempre motivo de las más furibundas diatribas de Arenas contra el supuesto ejercicio del poder revolucionario, que no miraba hacia delante, y renegando de lo mejor del pasado, pretendía construir un presente en el que los desplantes de autoritarismo eran el tono con que se levantaba el nuevo proyecto de sociedad. Obsesionadas con el presente, las revoluciones saquean y merodean el pasado, en busca de un espejismo, difícil de descifrar en el futuro. Sustituyen este futuro con las nociones utópicas de una sociedad más productiva, poderosa y mejor organizada. En tal sentido, Wilde era más proclive a las ensoñaciones de lo que sería Arenas, porque sus delirios utópicos se inclinaban más hacia una sociedad donde predominara la belleza, antes que la producción o la eficiencia. El alma del hombre en el socialismo es en realidad todo un programa sobre cómo debería funcionar una sociedad, cuyas mayores aspiraciones serían la belleza, la sensibilidad y unas relaciones humanas en las que la tirantez provocada por los espasmos del poder, le ceden su lugar a la ética, antes que a la justicia. Con más frecuencia de la debida, este extraordinario ensayo ha sido considerado por algunos críticos, como el punto de despegue de una nueva plataforma de inspiración anarquista. Sin embargo, el texto nos parece más bien una brillante puesta a punto de las relaciones entre ética y estética, en una organización social donde la libertad tenga las dimensiones antropológicas que siempre le han sido negadas, tanto por parte del socialismo autoritario como del capitalismo feroz. A Wilde, entonces, no se le ocurre otra forma de llamar a esa utopía que con el nombre de socialismo.

Arenas estuvo exiliado. Wilde estuvo preso. Pocos analistas han reflexionado sobre las implicaciones morales y las consecuencias estéticas de tan excepcionales condiciones, en ambos autores. El exilio del escritor cubano sigue imprecándonos en lo que respecta a las posibilidades reales del socialismo; a pesar de que las motivaciones iniciales para atentar contra las libertades individuales en la isla, al momento de la eclosión revolucionaria, hayan evolucionado. Arenas fue muy claro y lúcido al respecto. El exilio en los Estados Unidos, para un intelectual de su talla y de su contextura estética e intelectual, era problemático. Porque tal exilio le resultó siempre opresivo y limitador. Volvemos con Wilde: en la sociedad de la eficiencia y la productividad, el arte es completamente inútil. Y el artista deviene en lo mismo: en un lujo caro pero ineludible. Al poeta irlandés se lo humilló y se lo redujo a la 
mínima expresión, casi en las mismas condiciones que a Reinaldo Arenas. Tal vez, podría argumentarse, que la prisión de Wilde fue más física que la de Arenas, pero el aprisionamiento de éste, a pesar de su distinta naturaleza, generó los mismos resultados y lecciones.

Durante dos años, Oscar Wilde, estuvo exiliado, aislado, materialmente hablando, de la sociedad de su tiempo. Durante unos pocos años más, Reinaldo Arenas, también sufrió el mismo aislamiento, haciendo válida la triste paradoja burguesa del ejercicio de la libertad en una sociedad que, exclusivamente, se limitó a tolerarlo. Según él, mientras que la burguesía se limitaba a patearle el trasero, por gritar contra su sombría indiferencia de lo que estaba aconteciendo en Cuba, el socialismo en la isla también le hubiera pateado el trasero, pero en esta ocasión hubiera tenido que aplaudir. En ambos escenarios, se exigía del artista un silencio, no necesariamente cómplice de los abusos del poder, pero que, conforme pasaron los años, en el caso de Arenas, terminó pareciéndose mucho al nihilismo. Una forma de romanticismo radical, el nihilismo dejó al poeta cubano, al final de sus días, prácticamente solo. El romanticismo de Wilde, por su parte, tiene mucho de la ética sacrificial del cristianismo. Aspirar a la redención del otro, por medio de la autoinmolación, dejó, igualmente, a Wilde, en total soledad, durante los dos años, en los que, según algunos críticos, pudo haber escrito dos de las obras capitales de la literatura inglesa del siglo XIX y principios del XX. El empaque moral de Arenas no se prestaba para esa clase de ritual auto-sacrificial, pero hizo factibles las enseñanzas de una crítica contra la revolución cubana, que tiene vigor no por sus libelos anti-castristas, sino por la penetración estructural y el desamparo en que dejó a la política cultural de dicha revolución. Las críticas de Arenas a las instituciones y procedimientos culturales en la isla jamás fueron epidérmicas, como han querido retratarlas las reconvenciones de los supuestos revolucionarios de barba cochambrosa y uniforme verde olivo.

Con poetas como Wilde, Arenas o Cernuda (según lo ha hecho ver, magistralmente, Luis Antonio de Villena en su libro ya citado), el exilio adquiere otras connotaciones, aparte de las políticas o ideológicas, cuando se les suma la cuestión de la homosexualidad de estos escritores. La disidencia del poeta homosexual, algo que no se puede "embellecer" -a pesar de los intentos de algunos críticos y lectores, cuando se ha tratado de los casos de Wilde o García Lorca-, porque siempre fueron creadores en los bordes de la sublevación, es una disidencia que va más allá de la simple rebeldía, pero que reniega, al mismo tiempo, de las trampas ideológicas, del juego revolucionario, para el cual solo cuenta el resultado. "Normalizar" a Wilde o a Reinaldo Arenas, para que nos sean más deglutibles, puede devenir en algo así como arrebatarles violentamente su identidad. Algunos críticos, incluso, intentaron convertir al poeta cubano en un epígono de la revolución, retorciéndole el brazo a la teoría, para que Arenas pudiera ser presentado como un ejemplo decente de tolerancia revolucionaria (Cacheiro,2000). 
Aparte de su belleza, la metáfora utilizada por Villena, cuando se refiere a la disidencia y al exilio de Luis Cernuda, es increíblemente valiosa por su potencia para explicar mucho de la conducta social y emocional de otros poetas como Wilde y Reinaldo Arenas. En su correspondencia, Wilde siempre reflejó un trato discreto, distante y un poco frío, no sólo con Bossie, sino también con varios de sus otros amigos, como Robbie Ross, su madre y sus representantes teatrales. Incluso en una carta tan celebrada mundialmente como De Profundis el estilo reposado, y a veces hasta muy académico-lo cual sorprende por haber sido concebida tras las rejas de una prisión-, le imprime ese sello de emociones contenidas, tan propio de la actitud racional y calculada de Wilde. Con Arenas, la situación es distinta. Más explosivo, barroco y locuaz, su estilo no deja espacio para las dudas: se está con el poder, o en su contra. La homosexualidad en tanto que forma de rebeldía, de disidencia, de exilio y huída interior no tuvo en Arenas las mismas dimensiones que tuvo en Oscar Wilde, o en el mismo Luis Cernuda. Formar parte del ejército de recusados, según dice Villena, citando a Cocteau, puede llegar a constituir una condición insuperable, la cual convertiría al aislamiento y a la sensación de anormalidad en atributos del hombre rebelde, quien sin la libertad más total y comprensiva no puede funcionar.

Las lecciones que hombres de letras del calibre de Oscar Wilde y Reinaldo Arenas nos siguen dando a la distancia, tienen el poder de evocar que, las situaciones históricas y los escenarios políticos en los que les tocó vivir, no tenían ningún respeto por las emociones, la independencia y la vulnerabilidad que los caracterizaba a ellos, como poetas, como artistas y como luchadores. Wilde y Arenas nos mostraron cómo la cotidianidad en manos de la poesía, se convierte en un grillete insufrible, pues los tiranos y toda clase de dictadores buscan, furibundamente, ese tesoro inapreciable, que es controlar la vida cotidiana de los seres humanos. Es curioso, pero existe una relación dialéctica entre la poesía y la tiranía de la vida cotidiana, la cual, llegado el momento en que el ejercicio total de la libertad desparezca, convierte al poeta en un cacharro descartable. El pequeño burgués, el tendero, el mercachifle para quien el mundo está comprendido entre las cuatro paredes de su tienda, lo sabe muy bien: la poesía y el arte en general no sirven para nada. El tirano, por su parte, maliciosamente, conoce de la enorme utilidad de la poesía, para sostener y reproducir su despotismo. Estas condiciones históricas e ideológicas no han cambiado.

\section{Conclusiones}

En ningún momento hemos pretendido, con este corto ensayo, realizar un estudio erudito de literatura comparada. Ésta requiere un conjunto de métodos, técnicas y teorías que habrían vuelto ilegible, un trabajo que buscaba solo motivar en el lector la mejor aproximación posible a escritores como Arenas y Wilde. Obviamente, la mejor aproximación para quien esto escribe, quien jamás ha pretendido dárselas de crítico literario. Nuestro ensayo ha sido impresionista. Con él hemos buscado hacerles 
llegar a los lectores, el universo de escritores complejos, pero simples y accesibles al mismo tiempo para cualquiera. Le hemos brindado atajos sobre cómo llegar hasta ellos, sin agotarse o aburrirse. Y, para lograrlo, hemos tomado tres ejes esenciales en el trabajo realizado por ellos a lo largo de toda una vida. La libertad, la política y la existencia, abordadas desde la poesía, nos hacen reflexionar sobre las posibilidades reales y los límites con que cuenta un escritor, cuando le corresponde enfrentarse a los vacíos de la vida cotidiana, así como a sus pequeñas alegrías. Sin libertad el arte no tiene sentido. El artista y el poder político no siempre coinciden, cuando los seres humanos desean que sus sueños se parezcan lo más posible a la realidad. Los sueños del político podrían ser las pesadillas del artista. Y los sueños de este último, podrían ser la dosis de frustración que al político le recetan los pueblos.

La delicada añoranza del artista, del poeta, quien desea escribir, crear, sin que un funcionario ignorante y pendenciero, le esté vertiendo su fétido aliento en la nuca, indicándole cómo hacerlo, es una de las más profundas y queridas ensoñaciones de cualquier creador, en cualquier parte del mundo. Porque la creación apuesta siempre por un margen de libertad que no es tolerable para todos. Menos para los políticos, con su encallecido afán por controlarles la vida a las personas. Ese flujo y reflujo de la libertad artística, en sociedades para las cuales es un bien apreciado casi tanto o más que un artículo exótico, nos da indicios sobre la fragilidad de la libertad en general. En las sociedades estatistas, burguesas o socialistas, da lo mismo, los funcionarios a sueldo siempre aspirarán a controlar, a dosificar, los grados de libertad disponibles con que los individuos pueden desenvolverse. El artista creador está más expuesto a esta clase de controles. En las sociedades totalitarias esa clase de control es más brutal. Lo que no quiere decir que en las supuestas sociedades democráticas no se dé. El control podría ser más solapado, pero existe. El alcance entonces de los gestos libertarios del artista será siempre modesto, pues estará bajo la batuta de los retortijones digestivos del funcionario de turno. Es realmente excepcional el artista que no halague al poder. $Y$ viceversa: es muy rara la organización estatal que no busque atontar al artista, con ofertas de viajes, premios, fama y luces incandescentes. En esa paradoja indescifrable, a veces siniestra, y en otras tan parecida al síndrome de Estocolmo, cuando el secuestrado se revuelca en el fango con su secuestrador, la que termina rodando por los suelos, estragada y humillada es la libertad. Entre los tibios defensores del estado, y los recoletos defensores de la libertad, la más sentida diferencia es la institucionalidad. El artista no necesita ninguna clase de institución para crear. Para ejercerse plenamente, la libertad tampoco. En consecuencia, el que sale sobrando es el estado. Con este artículo se ha visto que, tanto en el capitalismo como en el socialismo, la libertad es la virgen, tentación inmaculada de los largos y filosos dientes y uñas del monstruo del estado, que todo lo engulle y lo mancha. A pesar de sus ambigüedades, de su tornadizo aliento, y de su volátil sentido de la 
libertad, son los artistas los únicos que pueden salvarnos de la barbarie. O nos hunden en ella poniéndole fuego a Roma. Arenas y Wilde, así ha podido verse en este ensayo, nos enseñan cómo evitar un destino tan triste.

\section{Bibliografía}

Anónimo. (1996). Los procesos contra Oscar Wilde. Madrid: Valdemar.

Arenas, R. (1996) Antes que anochezca. Barcelona: Tusquets.

Arenas, R. (1997). El mundo alucinante. Una novela de aventuras. Barcelona: Tusquets.

Arenas, R. (1999).El color del verano. O nuevo "Jardín de las delicias". Barcelona: Tusquets.

Arenas, R. (2000). Celestino antes del alba. Barcelona: Tusquets.

Arenas, R. (2001a). Necesidad de libertad. Grito luego existo. Miami, Florida: Ediciones Universal.

Arenas, R. (2001b). La represión (intelectual) en Cuba. Conferencia pronunciada el 30 de agosto de 1980 en la Universidad de Columbia en Nueva York, con motivo del Segundo Congreso de Intelectuales Disidentes. En De La Paz Luis (Ed.). Reinaldo Arenas, aunque anochezca. Textos y documentos. Miami: Ediciones Universal.

Arenas, R. (2001c). El palacio de las blanquísimas mofetas. Barcelona: Tusquets.

Arenas, R. (2002). Otra vez el mar. Barcelona: Tusquets.

Cabrera, G. (1998). Reinaldo Arenas o la destrucción del sexo. Madrid: Alfaguara.

Cacheiro, A. (2000). Reinaldo Arenas. Una aproximación política Maryland: International Scholars Publications.

Cernuda, L. (2002). Prosa II. Volumen III de Las obras completas. Madrid: Siruela.

Charvátová, A. (s.f.). Los escritores cubanos en los Estados Unidos (Cien años después). En Luis de la Paz (Editor). Reinaldo Arenas, aunque anochezca. Textos y documentos. Miami: Ediciones Universal. 
De La Paz, Luis (2001). Reinaldo Arenas, aunque anochezca. Textos y documentos. Miami, Florida: Ediciones Universal.

De Villena, L. (2002) La rebeldía del dandy en Luis Cernuda. En Rebeldía, clasicismo y crisis. Luis Cernuda, asedios plurales a un poeta príncipe. Valencia: Pre-Textos.

Eagleton, T. (1989) Saint Oscar. Suffolk, England: Field Day.

Goldman, E. (1996). Viviendo mi vida. Madrid: Fundación de Estudios Libertarios Anselmo Lorenzo.

Holland, M. y Hart-Davis, R. (2000). The Complete Letters of Oscar Wilde. New York: Henry Holt and Co.

Judt, T. (2008). Reappraisals. Reflections on the Forgotten Twentieth Century. New York: The Penguin Press.

Kauffman, M. (1989). Gross Indecency. The Three Trials of Oscar Wilde. New York: Vintage Books.

Kropotkin, P. A. (2005). Memorias de un revolucionario. España: KRK Editores.

Ocasio, R. (2001). A Gay Cuban Activist in Exile: Reinaldo Arenas. Florida: University Press of Florida.

Newsome, D. (1997). El mundo según los victorianos. Percepciones e introspecciones en una era de cambio. Santiago de Chile: Editorial Andrés Bello.

Paz, O. (1990). El ogro filantrópico. Barcelona: Seix-Barral.

Prewitt, J. (1997). Cosmopolitan Criticism. Oscar Wilde's Philosphy of Art. Virginia: University Press of Virginia.

Quesada, R. (2001). La fantasía del poder. Mujeres, imperios y civilización. San José, Costa Rica: EUNED.

Quesada, R. (2004). La oruga blanca. Un retrato de Óscar Wilde. Heredia, Costa Rica: EUNA.

Rodríguez, E. (2003). Obra selecta. Caracas, Venezuela: Ayacucho.

Rojas, R. (2006). Tumbas sin sosiego. Revolución, disidencia y exilio del intelectual cubano. Barcelona: Anagrama.

Ruskin, J. (1997). Unto This Last and Other Writings. London: Penguin Classics. 
Shentalinski, V. (2006). Esclavos de la libertad. Los archivos literarios de la KGB. Tomo I_Barcelona: Galaxia Gutenberg-Circulo de lectores.

Todorov, T. (2007). Los aventureros del absoluto. Barcelona: Galaxia Gutenberg-Circulo de lectores.

Valero, R. (1991). El desamparado humor de Reinaldo Arenas. University of Miami: North-South Center.

Wilde, O. (1998). The Soul of Man Under Socialism. En Plays, Prose Writings, and Poems. London: Everyman.

Wilde, O. (1999). De Profundis. Barcelona: Edicomunicación.

Wilde, O. (2000). Obras selectas. Madrid: Austral.

Witte, Bernd. (2002). Walter Benjamin. Una biografía. Barcelona: Gedisa. 